\title{
WestVirginiaUniversity
}

THE RESEARCH REPOSITORY @ WVU

Graduate Theses, Dissertations, and Problem Reports

2018

\section{Experimental Analysis of Unsteady Aerodynamic Covert Feather Behavior}

Laura J. Ordaz

Follow this and additional works at: https://researchrepository.wvu.edu/etd

\section{Recommended Citation}

Ordaz, Laura J., "Experimental Analysis of Unsteady Aerodynamic Covert Feather Behavior" (2018). Graduate Theses, Dissertations, and Problem Reports. 6357.

https://researchrepository.wvu.edu/etd/6357

This Thesis is protected by copyright and/or related rights. It has been brought to you by the The Research Repository @ WVU with permission from the rights-holder(s). You are free to use this Thesis in any way that is permitted by the copyright and related rights legislation that applies to your use. For other uses you must obtain permission from the rights-holder(s) directly, unless additional rights are indicated by a Creative Commons license in the record and/ or on the work itself. This Thesis has been accepted for inclusion in WVU Graduate Theses, Dissertations, and Problem Reports collection by an authorized administrator of The Research Repository @ WVU. For more information, please contact researchrepository@mail.wvu.edu. 
Experimental Analysis of Unsteady Aerodynamic Covert Feather Behavior

\author{
Laura J. Ordaz \\ Thesis submitted to the \\ College of Engineering and Mineral Resources \\ at West Virginia University \\ in partial fulfillment of the requirements \\ for the degree of \\ Master of Science \\ in \\ Mechanical Engineering
}

Wade Huebsch, Ph.D., Chair

Christopher Griffin, Ph.D.

Patrick Browning, Ph.D.

Department of Mechanical and Aerospace Engineering

Morgantown, West Virginia

2018

Keywords: Covert Feather, Unsteady Aerodynamics, Avian Flight

Copyright 2018 Laura J. Ordaz 


\section{ABSTRACT \\ Experimental Analysis of Unsteady Aerodynamic Covert Feather Behavior}

\section{Laura J. Ordaz}

The interest in man-made flying vehicles has existed for over 100 years. Bird flight has been the major inspiration for the creation of such vehicles. More recently, UAVs (unmanned aerial vehicles) have become more popular and their use in more applications has developed the need for improved maneuverability. UAVs are also decreasing in size which has allowed them to operate within similar flight conditions as birds. Studying bird feather behavior may open doors and shed some light as to how the bird achieves such agility and control, which may then be adapted to UAV flight. In this research, the motion of the freely moving covert feathers on a live trained American kestrel and a preserved pre-existing Red-tailed hawk wing were studied. Highspeed and GoPro video footage was taken of an American kestrel while landing on a perch inside of the WVU Emissions and Free Flight Wind Tunnel. The distance between the perches varied. The GoPro and high-speed cameras were setup in different locations capturing movement from a variety of perspectives. Video analysis was performed on this footage to obtain flight data, including velocity and covert feather frequency as the bird approached the landing perch. The preexisting Red-tailed hawk wing was tested in the WVU Closed Loop Wind Tunnel. A high-speed camera was used to capture feather movements. The test regime included static and dynamic angles of attack. The dynamic motion was achieved using a motor and link system. Frequencies recorded during static angle testing were compared to frequencies found during dynamic motion. Both sets of frequencies were found to be within the same range. These recorded feather frequencies were then compared to the frequencies obtained in the free flight experiment. Frequencies observed during the free flight experiment were slightly higher than those found while testing the preserved wing. 


\section{Acknowledgements}

To my mom and dad who always picked me up when I felt discouraged. You both have been an amazing support system. To my family who motivated me and encouraged me to follow my dreams.

To my committee, for being involved in this journey and for willing to make the time to offer support and encouragement.

To Shawn Smearcheck for contributing to the wind tunnel experimental setup and his additional knowledge. Thank you for all the help over the past two years!

Sincerely,

Laura Ordaz 
Table of Contents

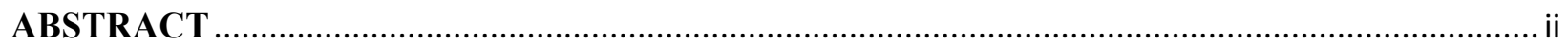

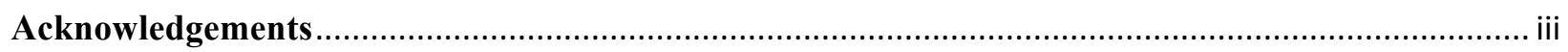

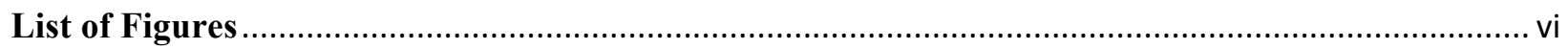

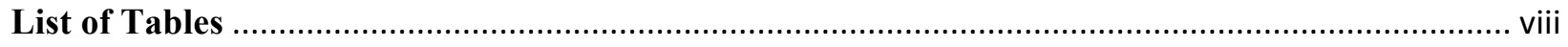

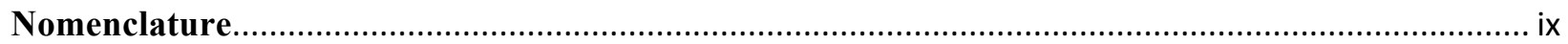

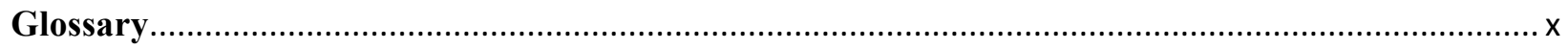

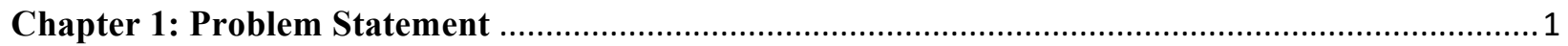

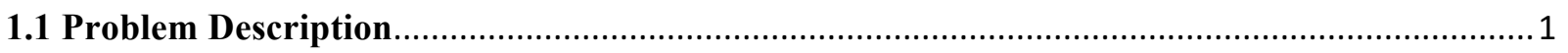

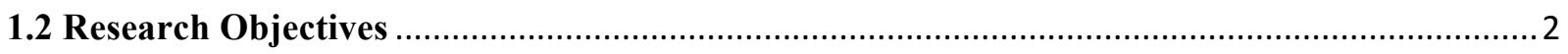

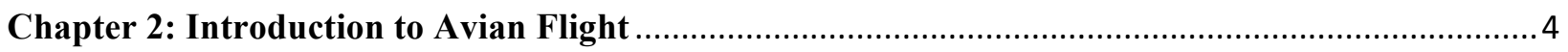

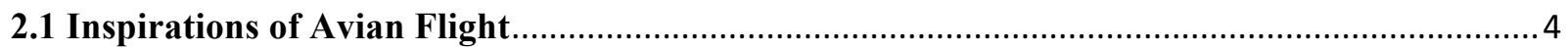

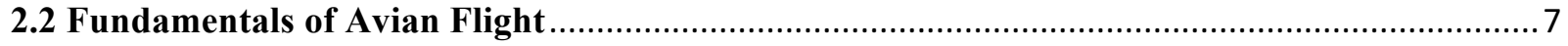

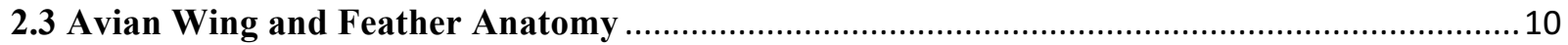

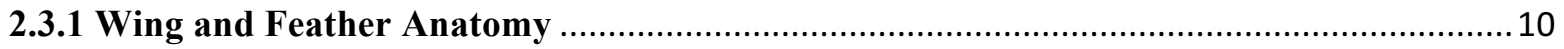

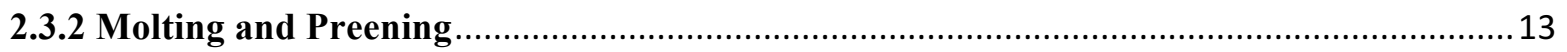

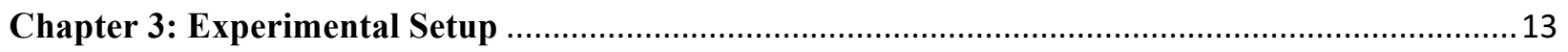

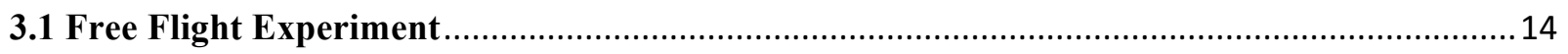

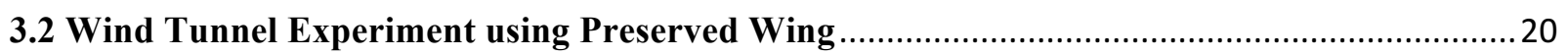

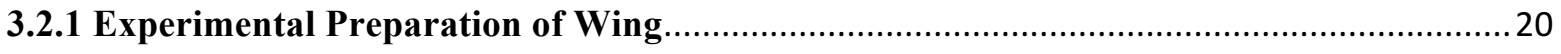

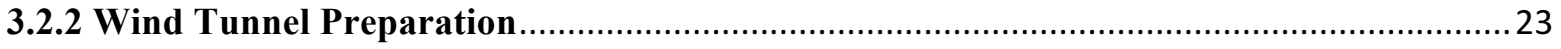

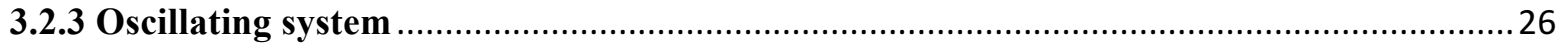

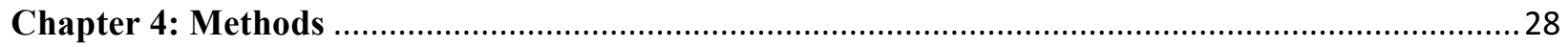

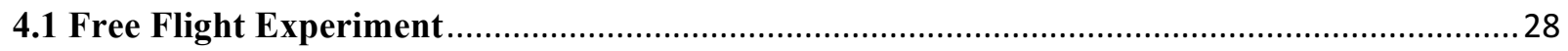

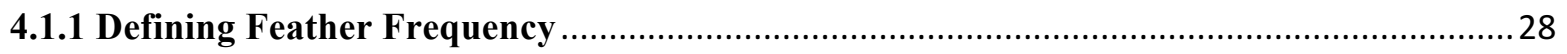

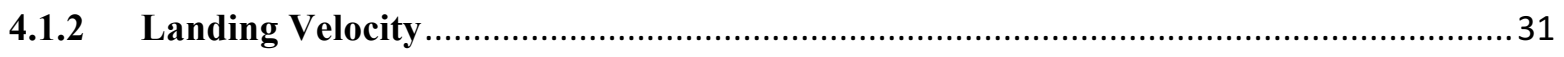

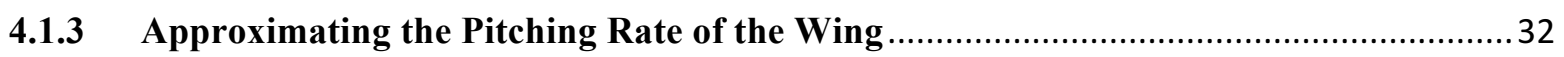

4.2 Wind Tunnel Experiment using Preserved Wing ….................................................. 33

4.2.1 Calculating Mean Aerodynamic Chord (MAC) ……...................................................... 33

4.2.2 Defining Test Section Velocity Range …................................................................... 34

4.2.3 Alignment of Cadaver Wing in Tunnel .......................................................................... 36

4.2.4 Coordinating Dynamic Angle with Static Angle .......................................................... 37 
4.2.5 Defining Feather Frequency.

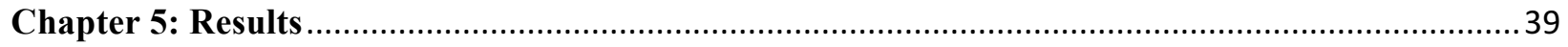

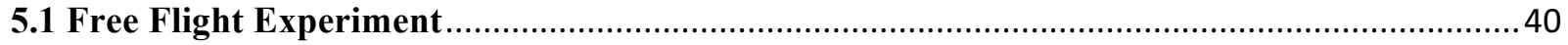

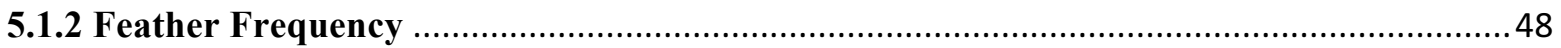

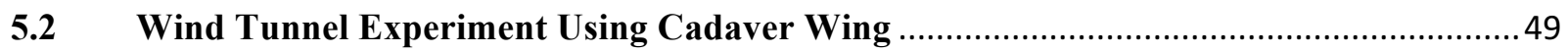

5.2.1 Feather Frequency for Static Angles of Attack............................................................ 50

5.2.2 Feather Frequency for Dynamic Angles................................................................ 54

$5.3 \quad$ Static, Dynamic, and Free Flight Data Comparison .................................................5 56

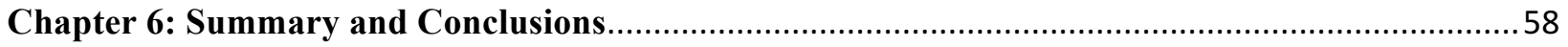

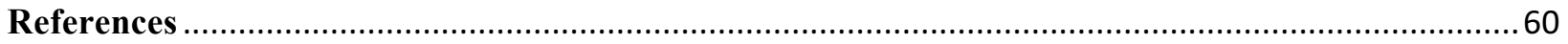

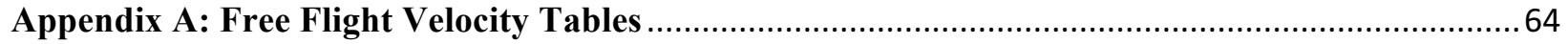

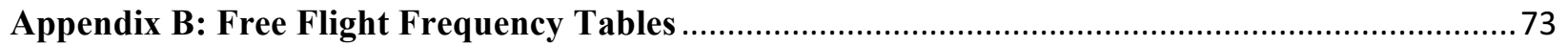

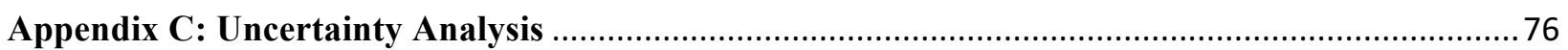




\section{List of Figures}

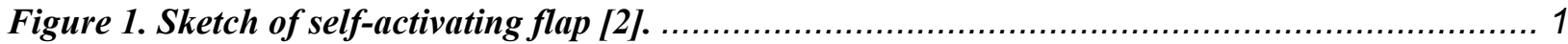

Figure 2. American kestrel used in the free flight experiment (WVU Photo by M.G. Ellis) [5]........... 2

Figure 3. Original patent for a flying machine from 1906 by the Wright brothers [7].................. 5

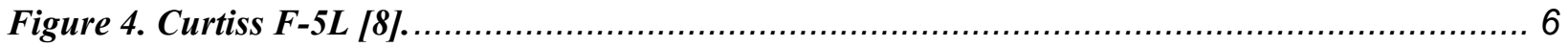

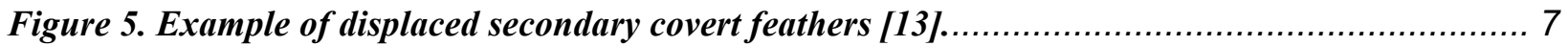

Figure 6. Landing progression of eagle. It can be observed that the bird tips its body up changing the

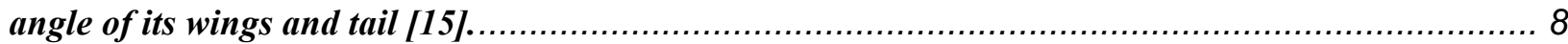

Figure 7. Example of airfoil shape resembling wing cross-section [16].................................... 8

Figure 8. Evolution of vorticity field: 1.) leading edge vortex 2.) shear layer vortex 3.) trailing edge

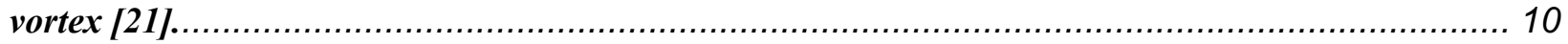

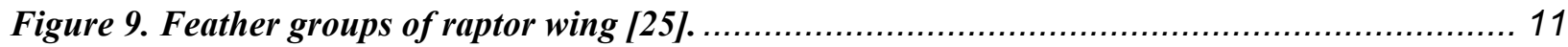

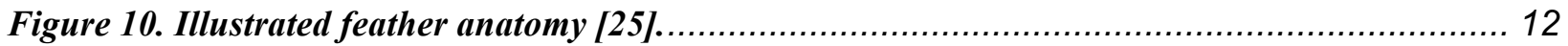

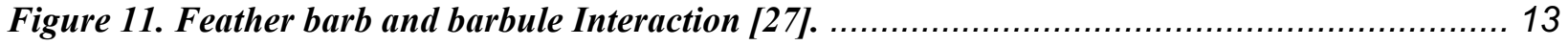

Figure 12. Kestrel approaching landing perch to receive positive reinforcement. ......................... 15

Figure 13. Location of the GoPro cameras in relation to the landing perch at that instance [20]....... 16

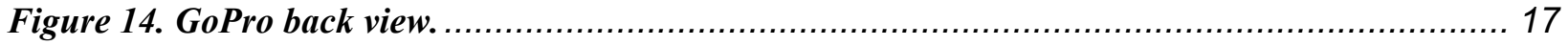

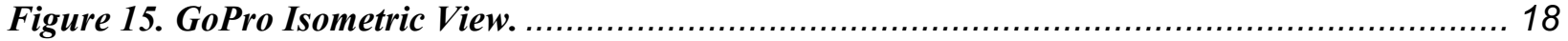

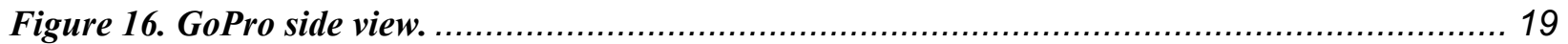

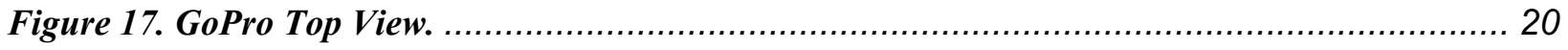

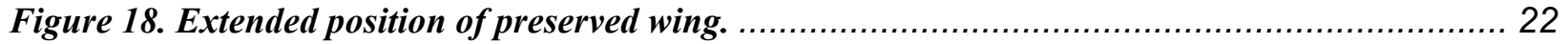

Figure 19. Connection between mounting piece and wing in the scapular feather region................ 23

Figure 20. West Virginia University Wind Tunnel. ........................................................ 24

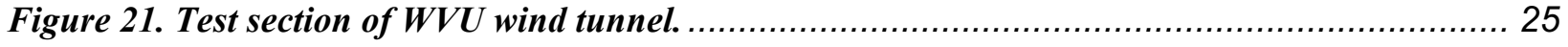

Figure 22. System used to oscillate the wing in the wind tunnel......................................... 26

Figure 23. The location of the oscillating system in reference with the test section and wing........... 27

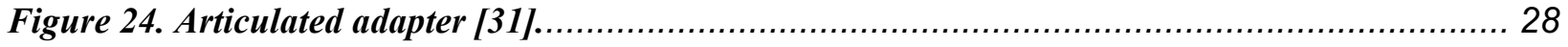

Figure 25. Regions 1, 2, 3, and 4 make up the marginal covert feathers and region 5 makes up the alula feathers. Diagram was produced using a sketch of an avian wing previously created [34]. ....... 29 
Figure 26. Progression of feather motion on live bird wing. Frame: 0 represents the frame right before any feather motion occurs and Frame: 33 represents the frame right after feather motions concludes.

Figure 27. Snapshot of Tracker tracking the birds head while landing. ................................... 32

Figure 28. Traced approximated angle of the wing which can be compared to find the pitching rate. 33

Figure 29. Outline of bird wing used to find the average chord length.

Figure 30. Cadaver wing model aligned and prepared for testing in wind tunnel section at 0 degrees angle of attack. 36

Figure 31. Diagram of left wing showing regions where frequency was recorded. Diagram was produced using a sketch of an avian wing previously created [33]. These defined regions were

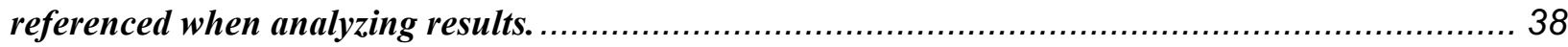

Figure 32. Progression of feather motion occurring while testing the preserved wing .................... 39

Figure 33. Progression of Wing Flaps Leading up to touchdown on the perch.......................... 40

Figure 34. Direction of covert feather movement. Diagram was produced using a sketch of an avian

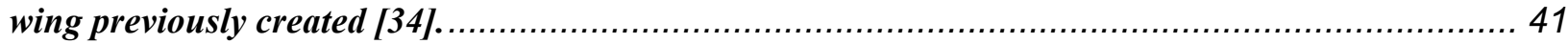

Figure 35. Series of frames taken from high-speed footage showing how the feather movement travels

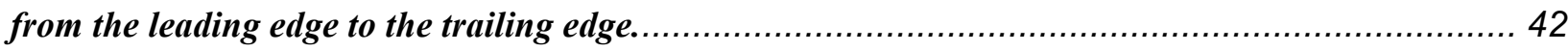

Figure 36. Example of dome created by the wings and tail of the bird when landing on a perch lower than its takeoff perch.

Figure 37. The magnitude of the velocity of the bird approaching and landing on perch: session 1... 45

Figure 38. The magnitude of the velocity of bird approaching and landing on perch: session 2. ....... 46

Figure 39. Overlay of landing profiles occurring during session 1......................................... 47

Figure 40. Overlay of landing profiles occurring during session 2 .................................... 47

Figure 41. Frequency vs. Av. Velocity based off of Table 8. ................................................ 49

Figure 42. Static Testing: Measured Strouhal number as a function of Reynolds number for wing... 51

Figure 43. Static angle of attack vs. wing region showing region activity as angle of attack increases. 52

Figure 44. Frequency vs. static angle data including feather location................................... 53

Figure 45. Dynamic Testing: Measured Strouhal number as a function of Reynolds number for wing.

Figure 46. Dynamic angle of attack vs. wing region showing region activity as angle of attack

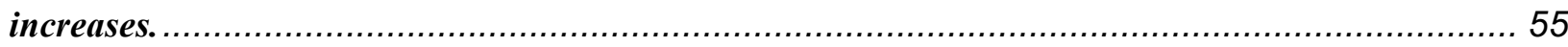

Figure 47. Distribution of 180 frequencies recorded during static angle testing......................... 57

Figure 48. Distribution of 299 frequencies recorded during dynamic pitch testing........................ 57

Figure 49. Distribution of 48 frequencies recorded during free flight testing............................. 58 


\section{List of Tables}

Table 1. Pitching rate data collected during two different sessions........................................ 33

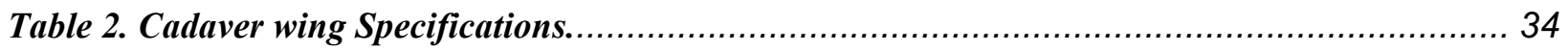

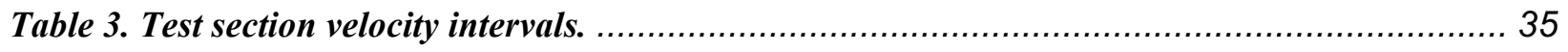

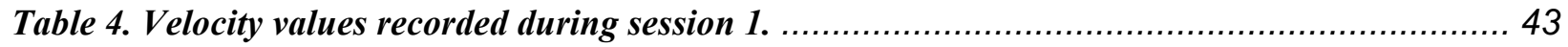

Table 5. Velocity values recorded during session 2. ................................................... 44

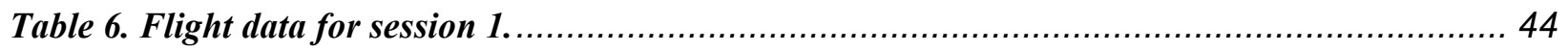

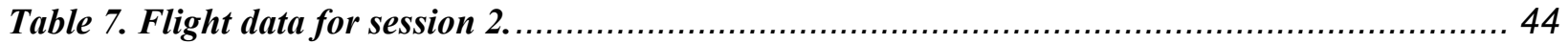

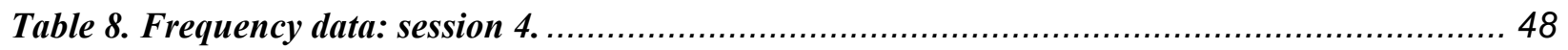

Table 9. Static Testing: $A N O V A$ results for feather frequency correlation to angle of attack and

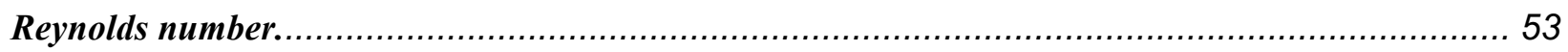

Table 10. Static Testing: ANOVA results for feather activity location correlation to the angle of attack

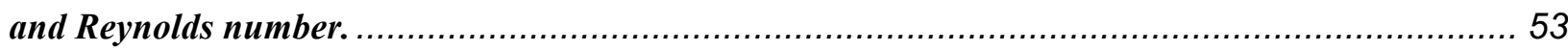

Table 11. Dynamic Testing: ANOVA results for feather frequency correlation to $10-\mathrm{Hz}$ binned pitching

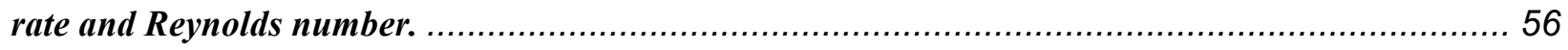

Table 12. Dynamic Testing: ANOVA results for feather frequency correlation to 25-Hz binned pitching

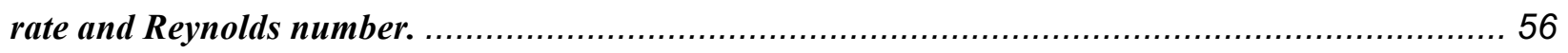

Table 13. Dynamic Testing: ANOVA results for feather location to 10-Hz binned pitching rate and

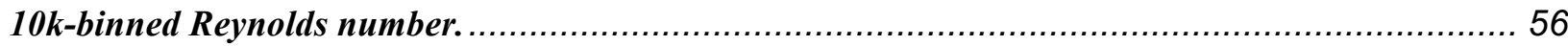

Table 14. Dynamic Testing: ANOVA results for active feather frequency to $10-\mathrm{Hz}$ binned pitching rate

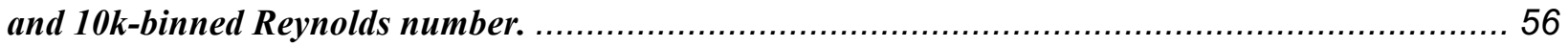




$\begin{array}{ll}\text { Nomenclature } & \\ \mathrm{C}_{\mathrm{L}} & \text { Lift Coefficient } \\ \mathrm{L} & \text { Lift } \\ \mathrm{A} & \text { Wing Area } \\ \mathrm{D} & \text { Drag } \\ \rho & \text { Density } \\ \mathrm{v} & \text { Velocity } \\ \mathrm{k} & \text { Reduced Frequency } \\ \omega & \text { Circular Frequency } \\ \mathrm{c} & \text { MAC (mean aerodynamic chord) } \\ \mathrm{U}_{\infty} & \text { Velocity of Flow } \\ \mathrm{Re} & \text { Reynolds Number } \\ \mu & \text { Dynamic Viscosity } \\ \Delta \mathrm{P} & \text { Pressure Difference } \\ \mathrm{S}_{\mathrm{w}} & \text { Wing Area } \\ \mathrm{b} & \text { Span of Wing }\end{array}$




\section{Glossary}

Bottom Out Occurs when the bird glides and reaches the lowest elevation point above the ground before it starts to rise towards the perch and the landing regime begins i.e., decelerating flaps begins.

Feather Frequency Occurs when the feather begins from rest, reaches highest point in the upward stroke and then returns to the lowest point again in a downward stroke.

Full Extension When wing appears to be stretched out as far as possible. The length of the wing belonging to the live bird is unknown but the length of the

Glide Bird travels forward with no wing movement and little to no movement of the body

Landing Flap Last flap occurring before the birds feet make contact with the perch

Touch Down $\quad$ Occurs when the feet make full contact occurs and the last stabilization flap has occurred.

Wing Flap Occurs when the bird's wings reach the lowest point in its downward stroke, reaches highest point in the upward stroke and then returns to the lowest point again in another downward stroke. This entire motion is referred to as a single flap.

Wing Rotation Occurs at the bird's shoulder of bird

Fluttering Occurs when feather rises off of the wing at any angle and oscillates quickly. 


\section{Chapter 1: Problem Statement}

\subsection{Problem Description}

Studying bird flight and covert feather effects can be useful for furthering aerodynamic understanding and optimization. For many years, numerous individuals interested in ornithology, physics, and engineering have become captivated by the ease and effortless flight patterns of birds. Aircraft design is constantly improving with the continued understanding of bird flight and unsteady aerodynamics. Mimicking bird feathers may improve agility, precision control, and performance. Recently, covert feathers have become more prominent in the research to further develop small aircrafts such as UAVs. Freely moving feathers like these may be the elements that allow the bird to maneuver easily in any conditions. Past research has analyzed drone maneuverability. Specifically, it focused on how the speed of the drone would affect its turning agility. As expected, it was found that as speed increased, the time it took for the drone to turn would also increase [1]. For example, in 2004, a research team from Berlin, Germany created a covert feather inspired flap, attached it to the trailing edge of an airfoil, and tested it in a wind tunnel. The objective was to study the separation control by this passive flap [2].
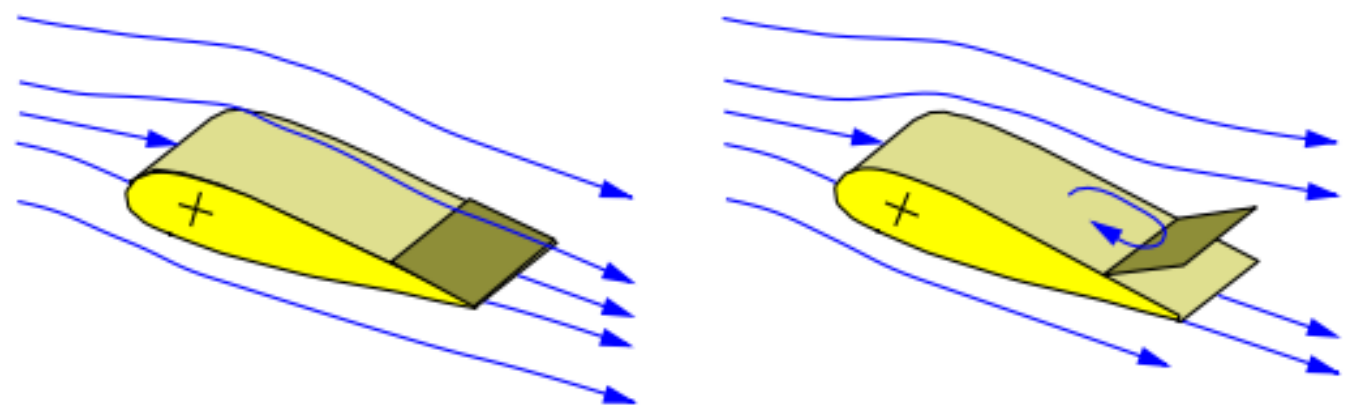

Figure 1. Sketch of self-activating flap [2].

A bird's ability to control its feathers comes from the fact that at the base of each feather is a tiny hole, called a follicle, in the bird's skin. Each follicle clutches the base of a feather with muscles to stop the feather from falling out. It has not been proven that these follicles control covert feather motion, though. Covert feathers are referred to as freely moving or "passive" [3]. 
This research will investigate unsteady aerodynamic covert feather behavior by analyzing videos taken of a live American kestrel during landing on a perch in the WVU Reedsville Free Flight and Environmental Wind Tunnel and testing a preserved Red-tailed hawk wing in the WVU Closed Loop Wind Tunnel. Figure 2 shows the American kestrel used in the free flight experiment. In the wild, kestrels are known to have a wide variety of flight behaviors such as "kiting" or hovering in flight making it desirable for observation [4].

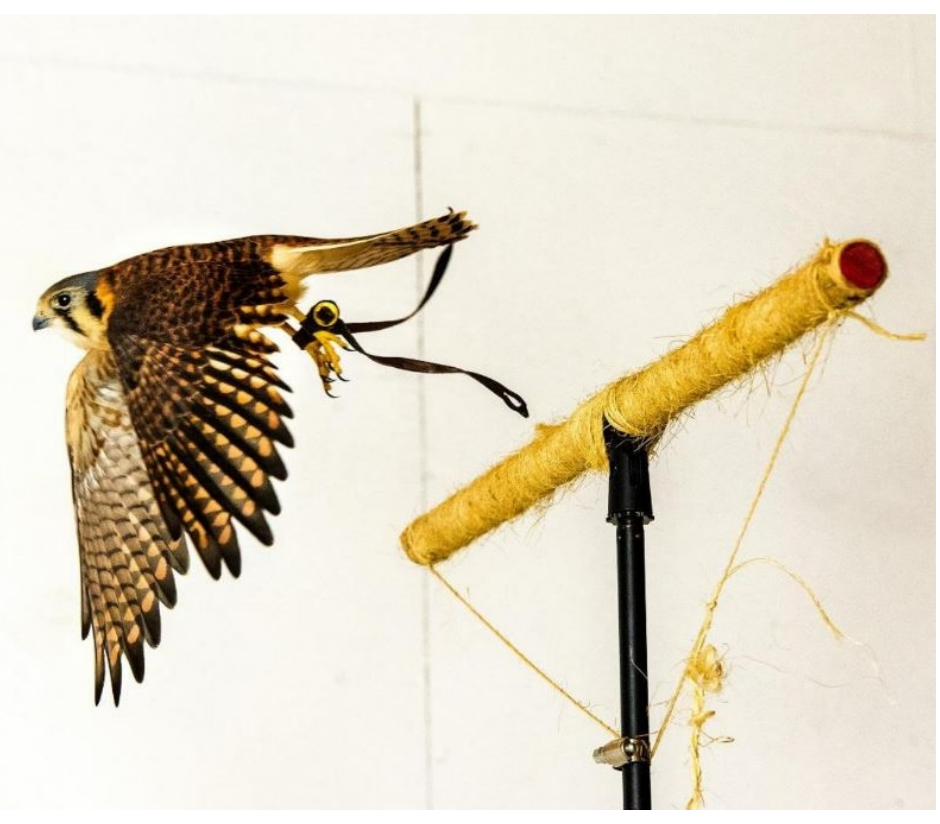

Figure 2. American kestrel used in the free flight experiment (WVU Photo by M.G. Ellis) [5].

Overall, this research will give some insight into a better understanding high angle of attack unsteady aerodynamics and its correlation to feather motion. It was hypothesized that feather frequencies recorded during static angles of attack would be lower and less frequent than those recorded while pitching the wing due to unsteady aerodynamic phenomena.

\subsection{Research Objectives}

In 2014, a research group from WVU recorded videos of a live American kestrel in the WVU Reedsville Free Flight and Environmental Wind Tunnel. The kestrel would fly between two perches, a take-off perch and a landing perch. Both perches were moved to varying locations which would change the distance between them allowing for different portions of the bird's flight to be captured. Four GoPro cameras were used to obtain a side view, top view, isometric view, and rear 
view of the landing bird. A high-speed camera was used to capture feather movement occurring at high frequency as the bird landed.

In the first part of this study, video analysis was conducted on this footage taken in 2014. The bird's landing velocity was obtained using a program called Tracker [6]. Landing patterns were also able to be traced and compared using this program. The high-speed footage was used to record covert feather frequency and other feather phenomena. The pitch rate of the bird's wing while landing was approximated. This data along with the landing velocity of the bird was used to derive the test conditions for the preserved wing experiment.

In the second part of this study, a preserved Red-tailed hawk wing was set up in the WVU Closed Loop Wind Tunnel. The wing was attached to a shaft linked to a four-bar mechanism driven by a motor. This mechanism allowed for the wing to pitch from 0 to 55 degrees. The wing was tested at static angles of attack using a protractor to align the wing in the test section at 5-degree intervals starting at 0 degrees and ending at 55 degrees. This procedure was repeated at ten test section head pressures between 0.06 and 0.20 in. of $\mathrm{H}_{2} \mathrm{O}(4.99 \mathrm{~m} / \mathrm{s}$ and $9.12 \mathrm{~m} / \mathrm{s})$. No feather motion occurred at air velocities lower than $4.99 \mathrm{~m} / \mathrm{s}$. At velocities higher than $9.12 \mathrm{~m} / \mathrm{s}$, the wing itself would begin to warp which may cause the data to be inaccurate. The motor was then used to pitch the wing at set rates ranging between $360 \mathrm{deg} / \mathrm{s}$ and $684 \mathrm{deg} / \mathrm{s}$. This procedure was repeated at the same ten test section head pressures previously stated. A high-speed camera was used during both static and dynamic tests to record feather movement.

Frequencies found during the video analysis of the static and dynamic tests were compared. These results were then compared with the frequencies found during the free flight experiment. The results obtained from this research will give some insight as to the behavior of the freely moving covert feathers on the wing during the three scenarios tested. Experiments like this will help reveal the importance of these feathers and their benefits. 


\section{Chapter 2: Introduction to Avian Flight}

\subsection{Inspirations of Avian Flight}

For thousands of years humans have been developing ideas allowing humans to fly. In the 1480's, Leonardo da Vinci developed a design for a flying mechanism called the Ornithopter. Though it was never built, modern flying machines like the helicopter designs are based on the concept. In the 1780's, the Montgolfier brothers invented the first hot air balloon. Smoke from a fire was used to fill a silk bag attached to a basket. 1783 marked the first manned flight whose passengers were Jean - Francois Pilatre de Rozier and Francis Laurent. In the 1890's, Otto Lilienthal designed and built the first glider to fly a human long distances. His book on aerodynamics published in 1889 was used by the Wright brothers as an inspiration for their designs. In 1906, the Wright brothers created the first powered aircraft propelling humans through the sky. Many designs failed, but the final design, Figure 3 below, shows a lot of similarities to the profile of a gliding bird. 


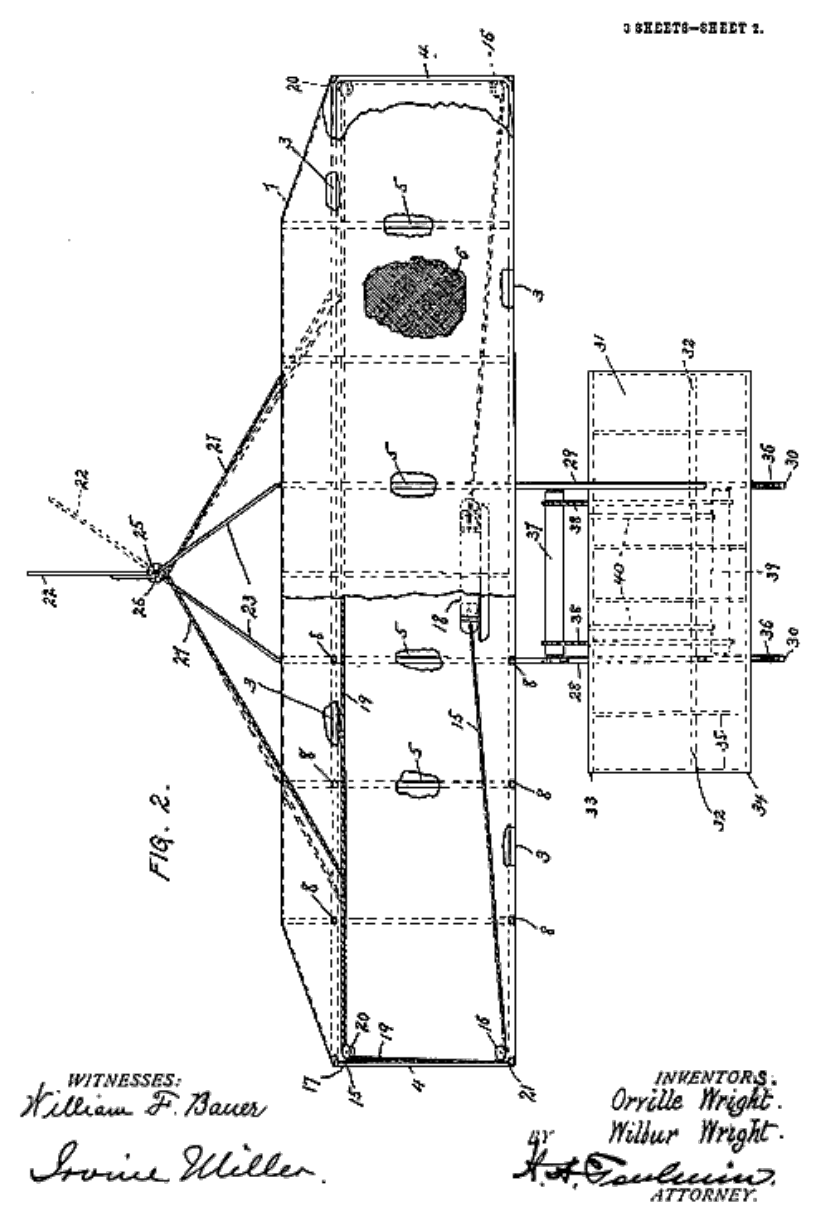

Figure 3. Original patent for a flying machine from 1906 by the Wright brothers [7].

Since the Wright brothers, many engineers and designers have spent countless hours working to improve aircraft design. Recently, the use of the UAS (unmanned aerial system) has taken off in a variety of missions and applications. More modern UAVs began to make their appearance about 100 years ago and were used primarily for military purposes. In September of 1924, the Curtiss F-5L took flight and made history as being the first radio-controlled vehicle flown remotely through all phases of flight (takeoff, maneuver, and landing) at a range of 10 miles. Curtiss F-5L pictured in Figure 4 was tested for over 14 months until interest in furthering the project was lost [8]. 


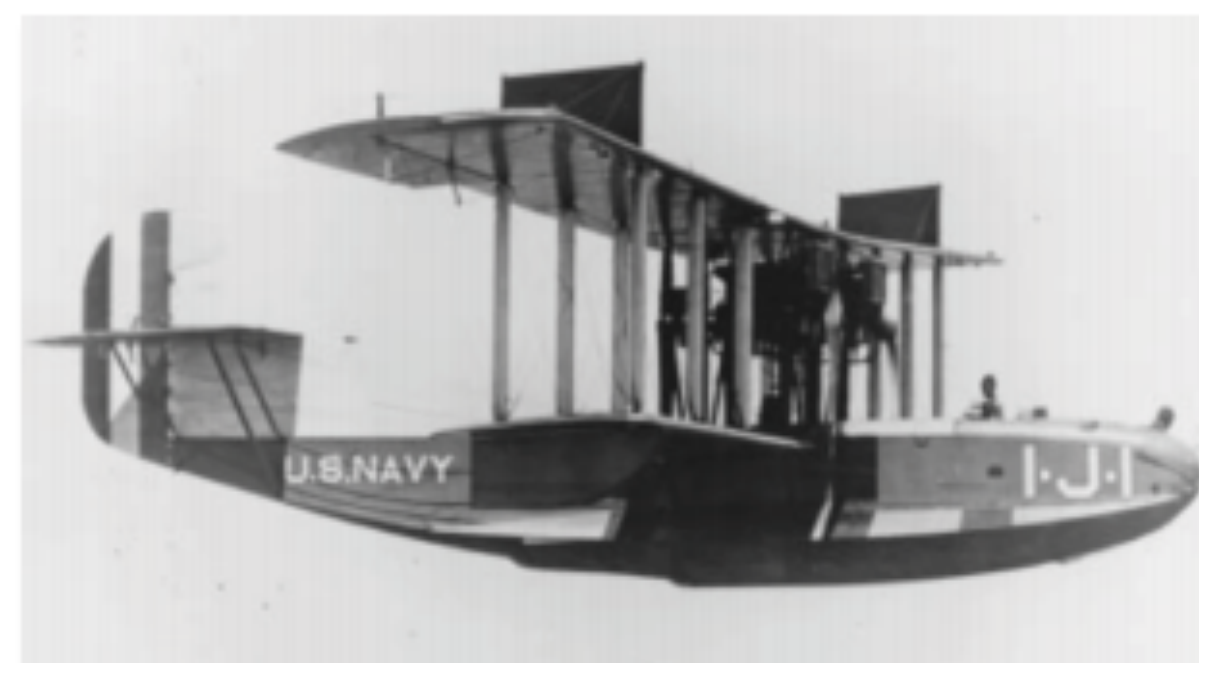

Figure 4. Curtiss F-5L [8].

Curtis F-5L was only the beginning. Over time engineers have developed UAVs that operate remotely while being thousands of miles from the operator. These vehicles use GPS and live video stream to transmit footage [8]. Now that UAVs are operating successfully, the goal is to improve flight for optimal use in a variety of flight regimes.

The consolidation of nature and technology is not an unfamiliar practice. In 2004, a study on molluscan glue proteins was conducted by the U.S. Department of Biology [9]. This study intended to develop new technologies for glue and adhesives. A more recent study in 2016 by the China University of Petroleum tested how micro-flowers and secondary nano-sheets affect the wettability of a metal surface [10]. The idea for this research came from observing that the Lotus leaf contains many small barbs to retard water droplets from sticking.

Nature has had billions of years to evolve and progress, while humans with access to suitable equipment have only been designing for hundreds of years. It is logical to look towards the creatures and structure around us for ideas to advance technology. 'Biomimicry' is a term popularized by Janine Benyus in 1997. Biomimicry is the imitation of the models, systems, and elements of nature for the purpose of creating more sustainable designs [11].

"Biomimicry ushers in an era based not on what we can extract from nature, but on what we can learn from her. This shift from learning about nature to learning from nature requires a new method of inquiry."

- Janine Benyus, Biomimicry 3.8 Co-Founder 
As previously discussed, in 2004 a research team from Germany tested a covert feather inspired flap. This type of design was again tested in 2011 by a research team in Singapore with the intention of observing an enhancement in lift. This type of flap is called a "passive flap device" and was inspired by the observation of landing birds. It was observed that as the bird prepared for landing, it would reposition its wings causing flow separation to occur. Secondary covert feathers would rise up from the wing and create recirculation pockets as shown in Figure 5 [12] [13].

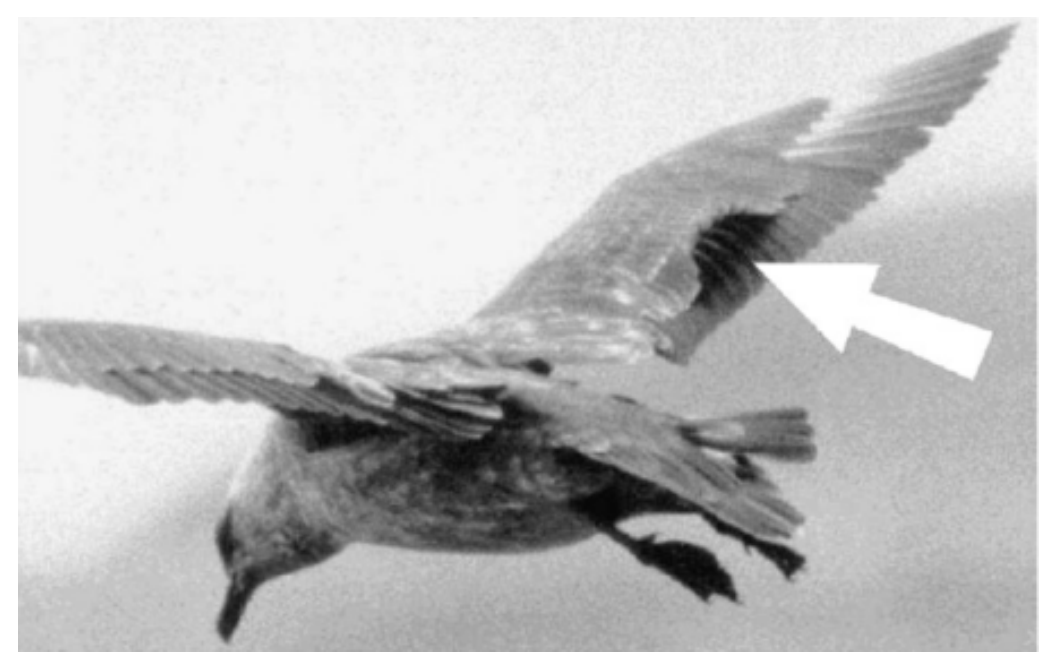

Figure 5. Example of displaced secondary covert feathers [13].

Birds are masters of the air and of maneuverability. Studying avian flight allows researchers to take a closer look at not only the effects of the wing motion but will also give some insight into how the feathers contribute to air manipulation [11].

\subsection{Fundamentals of Avian Flight}

This section includes a brief explanation of unsteady aerodynamics because one of the objectives of this study was to compare frequency data obtained during static and dynamic angles.

\subsubsection{Lift and Drag Effects}

This study focused on flight patterns and feather movement occurring at high frequencies while the bird is landing. Figure 6 shows the landing progression of an eagle. It can be observed that the bird tips its body up changing the angle of its wings and tail. This phenomenon was also 
observed during the free flight experiment part of this study. During landing, wing flaps occur while the bird changes the overall angle of its body, slowing it down [14].

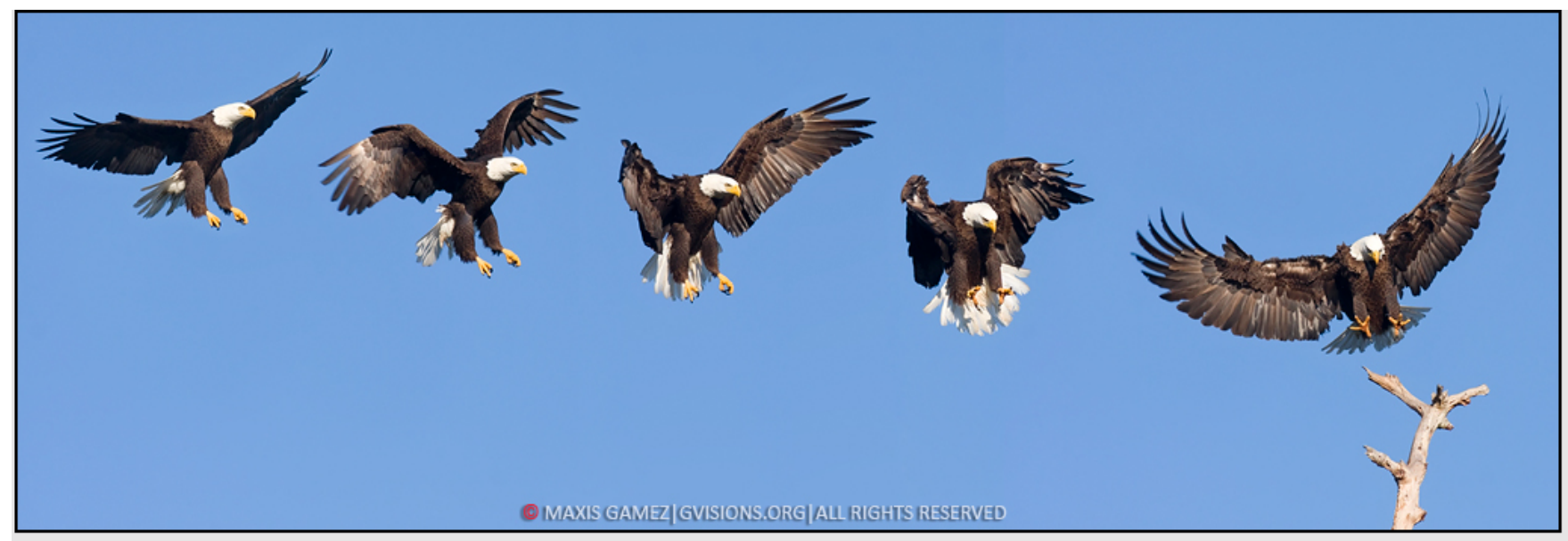

Figure 6. Landing progression of eagle. It can be observed that the bird tips its body up changing the angle of its wings and tail [15].

Wing flapping is a complex process made up of a down stroke and upstroke that produces net lift and thrust propelling the bird through the air. The aerodynamic forces allowing flight to occur are lift and drag. The wing of a bird acts like an airfoil as shown in Figure 7.

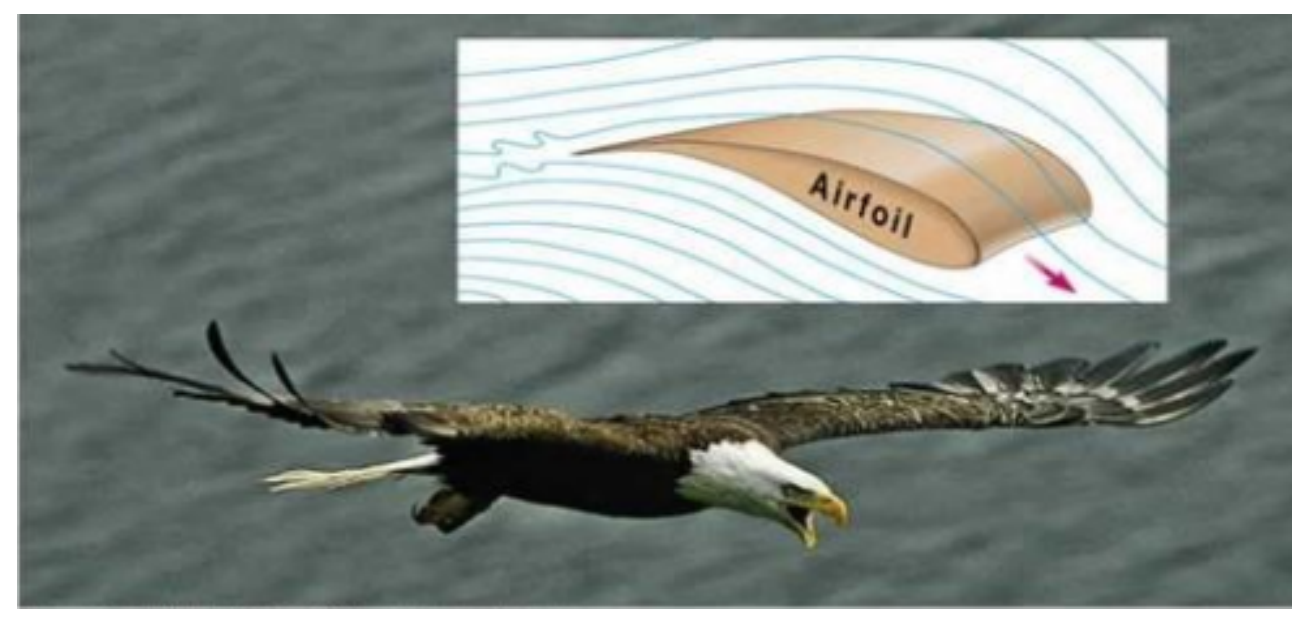

Figure 7. Example of airfoil shape resembling wing cross-section [16].

The shape of the wing causes faster air flow over the top of the wing than the bottom. From fluid dynamics, the increase in velocity of air travelling over the top of the wing is accompanied by a lower pressure and the air travelling under the wing is slower accompanied by 
a higher pressure [17] [18]. These simultaneously occurring events cause lift. As the wing is extended and retracted, the amount of area over which the air flows is changed. Simply, this is how the bird controls the amount of lift it produces. The shape of the wing is constantly changing or morphing to accommodate for things like natural convection, wind variations, obstacles, and executing quick maneuvers to catch prey [19]. Drag is a force that acts opposite of the direction the bird is travelling. A greater surface area created when the bird is landing, shown in Figure 6, increases drag.

\subsubsection{Unsteady Aerodynamics}

Unsteady aerodynamics can produce much different results than steady aerodynamics. Unsteady aerodynamics occur when the wing in a free stream changes with respect to time. In this study, the flapping wings of the live bird and the motion of the preserved wing while pitching are subject to the effects of unsteady aerodynamics. Phenomena occurring during pitching motion includes dynamic stall. At the critical angle of attack, the maximum lift coefficient is achieved. A stall occurs when the angle of attack surpasses the critical angle of attack. This causes a loss of lift. As the wing pitches, a leading-edge vortex is created that travels across the wing from the leading edge to trailing edge. This vortex adds suction to the upper surface of the wing increasing lift and delaying stall. As the vortex reaches the trailing edge of the wing it detaches from the wing surfaces causing a loss of lift, i.e. dynamic stall. In summary, dynamic stall occurs when the

leading-edge vortex creates a brief increase in lift before it separates and causes a loss of lift [20]. Figure 8 gives a visual example of leading-edge vortex travelling down the airfoil. 

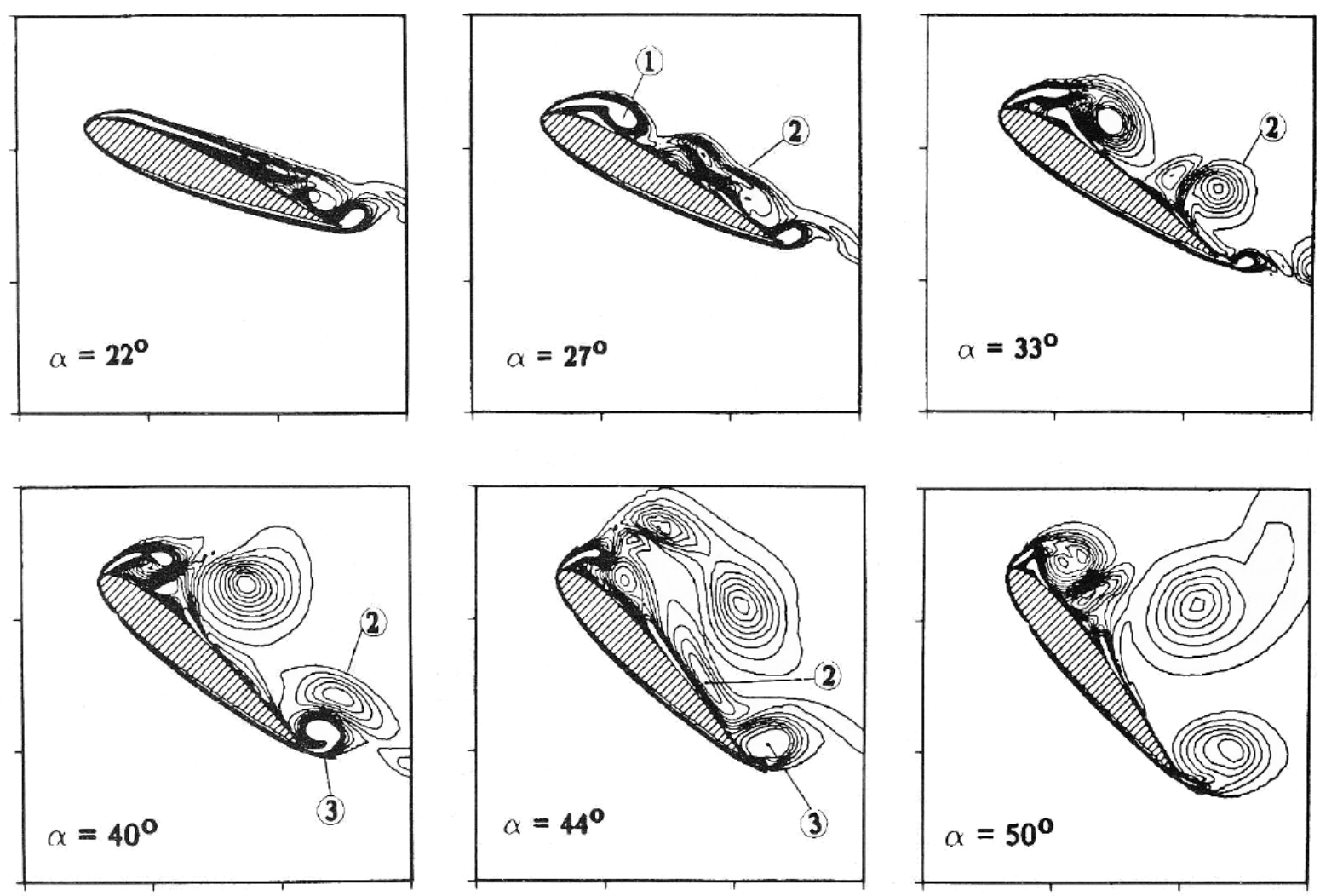

Figure 8. Evolution of vorticity field: 1.) leading edge vortex 2.) shear layer vortex 3.) trailing edge vortex [21].

\subsection{Avian Wing and Feather Anatomy}

In addition to introducing the avian wing anatomy, this section will also discuss how a bird maintains healthy feathers through molting and preening. This is important because a preserved wing is used for part of this study and the lack of molting and preening may affect the performance of this wing and feathers.

\subsubsection{Wing and Feather Anatomy}

The American kestrel wing span is approximately 20-25 inches. The wings are long, narrow, and taper to a point [22]. During flight, they tend to flap rapidly then glide or hover while rapidly beating their wings [23]. The wing span of an adult Red-tailed hawk is approximately 4658 inches. The wings are long, wide, and broad built for soaring. During flight, they tend to give several strong flaps followed by long periods of soaring [24]. Though the wing size and shape differ, there are similarities in the feathers themselves. 
Birds of prey such as the osprey, kestrel, Northern Goshawk, Red-tailed hawk, Great Gray Owl, etc. all share a similar wing feather pattern. Each raptor wing includes a large set of primaries, an inner set of feathers known as secondaries, tertials, and an overlaying layer of coverts. Figure 9 shows the location of each group of feathers.

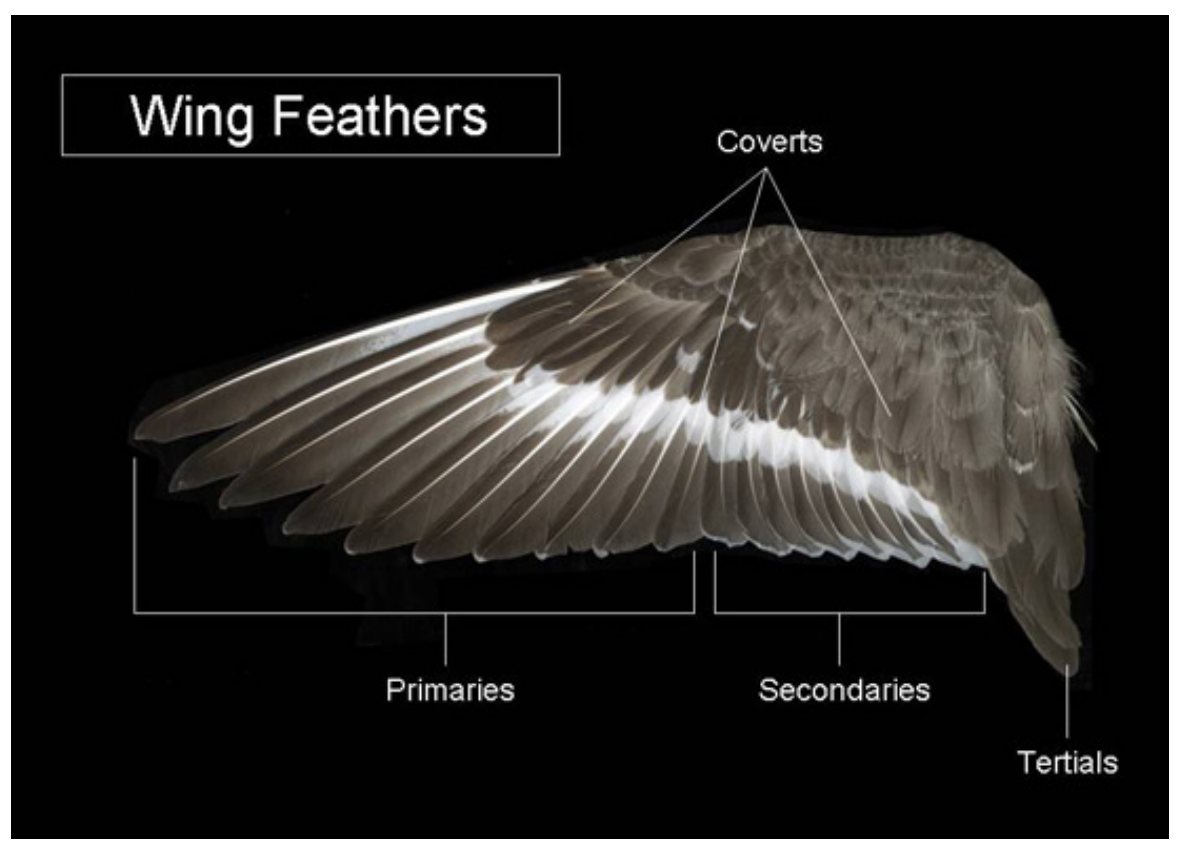

Figure 9. Feather groups of raptor wing [25].

Feathers have many functions. There is usually a thick underlying layer of feathers used to insulate the body. Primary and secondary feathers form the surface needed to create lift. In addition, feathers provide waterproofing and color for attracting a mate or for camouflage [17].

On average, the primaries consist of approximately ten feathers. These sharply pointed, asymmetric feathers directly influence flight of the bird. They do so by expanding to create a large surface area as the bird beats its wings to achieve lift. The primaries need to be firmly attached to the underlying skin and muscle to withstand large amounts of force during takeoff and quick stops. The number of secondary feathers depends on the length of the wing [26]. Covert feather across the top of the wing provide an airfoil shape to achieve lift during flight. The covert feathers are a dense group made up of hundreds of small feathers that protect other feathers from damage as well as insulate the wing [26]. Even a single feather has its own anatomy. Figure 10 shows the basic terms for each section of a feather. 


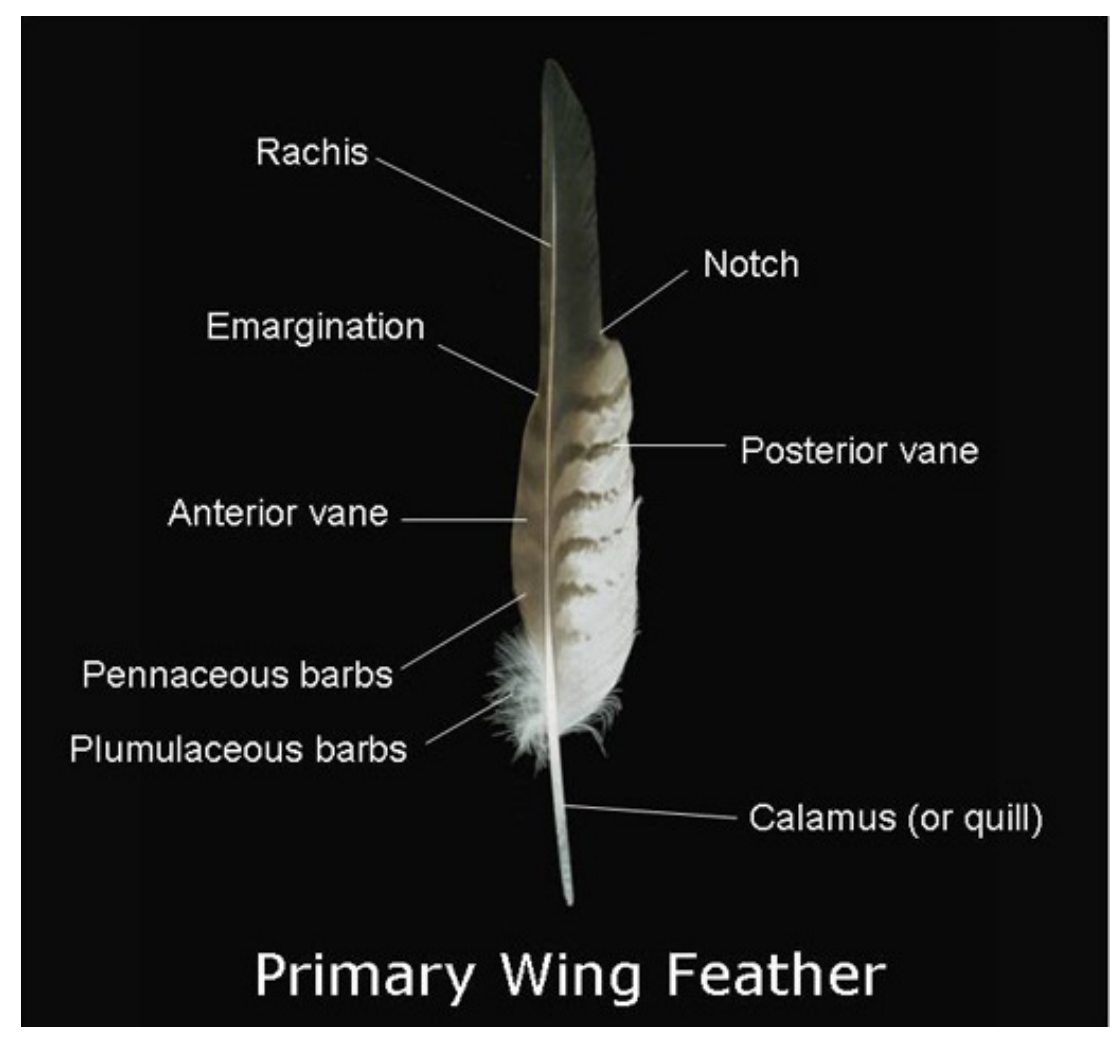

Figure 10. Illustrated feather anatomy [25].

On a smaller scale, all feathers are equipped with barbs and barbules. This characteristic allows the feathers to stick together due to the small hooks. Figure 11 shows how the barbs and barbules interlock to form a zipper effect; sealing out moisture and strengthening the feathers [17]. 


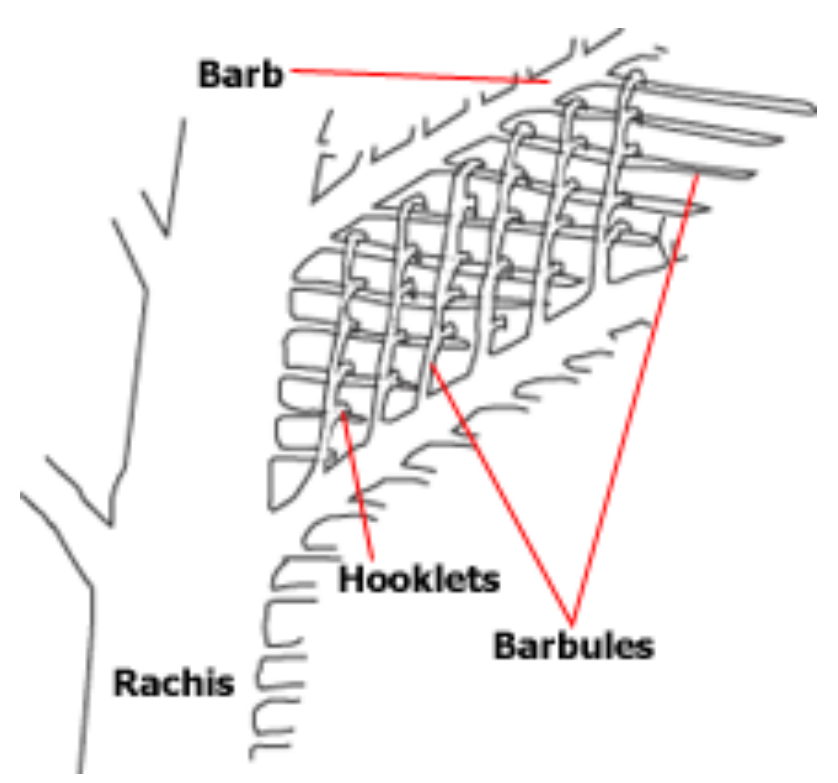

Figure 11. Feather barb and barbule Interaction [27].

\subsubsection{Molting and Preening}

Just as dead skin cells are replaced with new ones on humans, a bird must also replace old, damaged feathers with new ones. Damage can be caused by ultra violet light or just decomposition from use. However, instead of continually losing feathers throughout the year, birds often have a molting period where a large portion of feathers are replaced. This molting period could occur annually or every two years. The loss of many feathers takes a toll on the flight efficiency, so birds usually do not molt during breeding season. If this overlap does occur then only few essential feathers will be lost at one time. It has been found that the time required to replace the primary feathers, whether that be one by one or all simultaneously, increases disproportionately with body size [26] [28].

Preening is the way a bird keeps itself free from parasites, bugs, and heavy debris. For proper cleaning, the bird rubs its preen glands to dispense oil over the feathers. This oil then dries, creating a protective layer over the delicate feathers. Some birds are able to speed up the preening process by bathing in water. However, each group of feathers are carefully groomed with either the beak or the feet in order to protect the barbules. As mentioned before, most birds only molt once a year. Therefore, the feathers must get proper attention and care often; especially the flight feathers [17]. In addition, preening allows the bird to align the feathers in the most optimal position and will 'zip' the feathers that have come apart. This improves flight efficiency, waterproofing, and insulation. 


\section{Chapter 3: Experimental Setup}

An American kestrel was used in the free flight experiment. A preserved Red-tailed hawk wing was used in the wind tunnel section experiment. Both types of birds belong to the raptor family. Raptors, or birds of prey, make up the family Accipitridae. Appropriate documentation was filed to keep the wings for testing. The live American Kestrel and the cadaver wing were both attained by the Avian Conservation Center of Appalachia (ACCA). ACCA is a local rehabilitation center for wounded wild birds. They are also able to possess non-releasable raptors to use in their educational program [29]. The bird trainer involved in this study was Erin Katzner. She is the director of Global Engagement for the Peregrine Fund Idaho location. She is a Certified Professional Bird Trainer and had experience working with kestrels prior to her involvement in the experiment.

\subsection{Free Flight Experiment}

Video footage of the American kestrel was taken at the WVU Reedsville Free Flight and Environmental Wind Tunnel in March of 2014 by a team from West Virginia University. This team included Wade Huebsch, Ph.D., Christopher Griffin, Ph.D., and Patrick Browning, Ph.D. This wind tunnel is a subsonic open loop tunnel with a square cross-section of dimensions 16'x16' and is $115^{\prime}$ in length. It is able to achieve wind speeds of up to 16 meters/second. Honeycomb screens limit the turbulence intensity within the test section to less than 1\% [5]. For this experiment, the air flow in the test section was kept as stagnant as possible to maintain a controlled and closed environment for testing. The same trained captive female American kestrel at approximately one year of age was used in all video footage taken over seven consecutive days. The bird was given food rewards as positive reinforcement for desired behavior during training and continued during the free flight experiment in the form of pieces of mouse or day-old chicks. The intake of food was recorded for each test flight which averaged 55 grams per test session. Her weight varied between 125 and 145 grams [5].

The objective of this experiment was to observe flight patterns and obtain flight data such as velocity and angular velocity of the wings as the bird flew between two perches, a take-off perch and landing perch. Throughout testing, both perches were moved to increase or decrease the distance between them. The height of the perches was also adjusted. These conditions were altered 
for different tests to see how the flight was affected. Figure 12 shows the bird used in testing as it approached the landing perch.

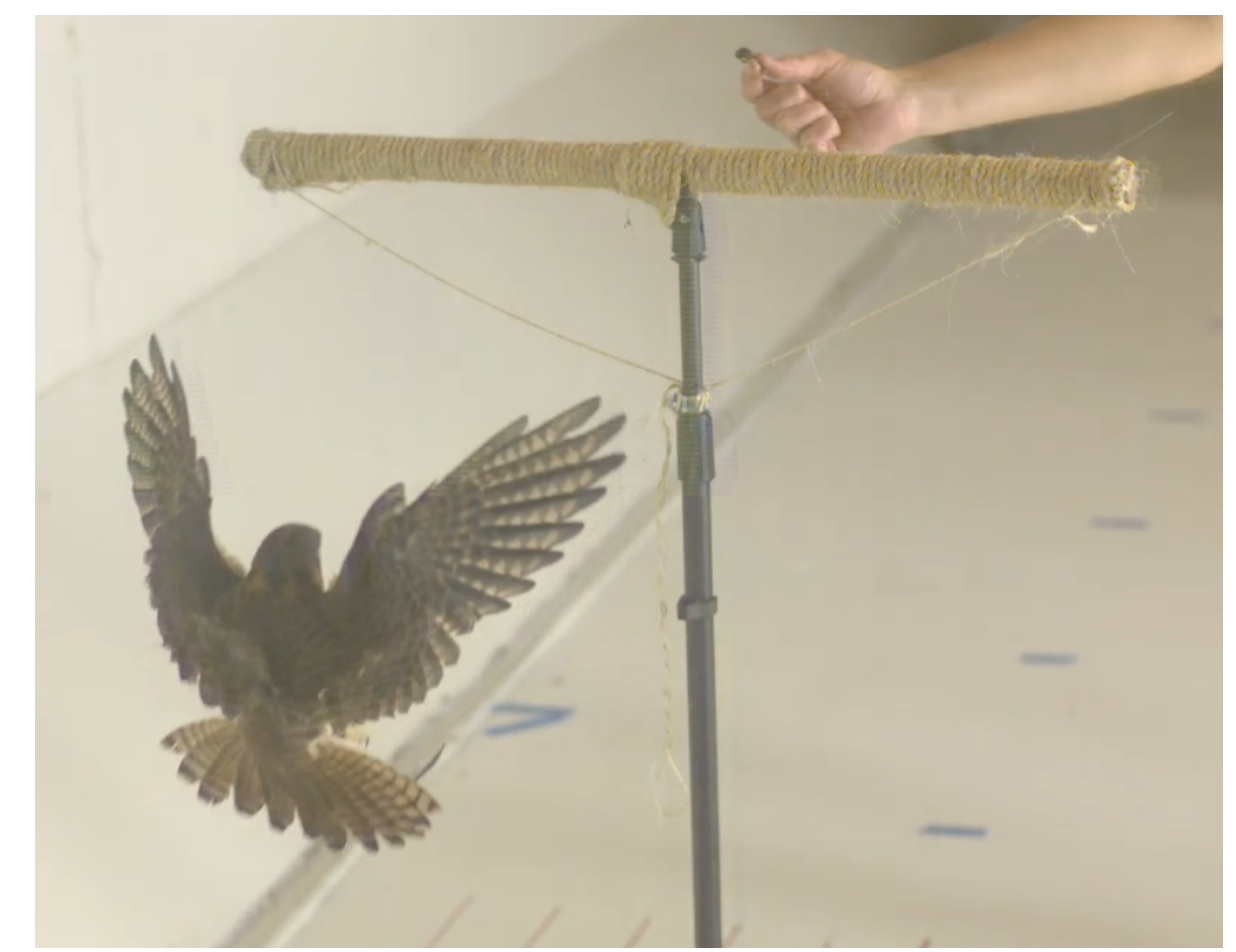

Figure 12. Kestrel approaching landing perch to receive positive reinforcement.

In the Reedsville wind tunnel, there were five cameras used to capture all footage. Four were HERO3+ GoPro's and the other was a Photron Fastcam SA5 high-speed camera. The GoPro cameras were set to record at 720p resolution at 100 FPS and 1080p resolution at 60FPS during testing. All GroPro footage was captured simultaneously. The approximate camera locations in relation to the landing perch at that instance can be referenced in Figure 13. Not included in this figure is the location of the high-speed camera which changed position quite often. The main purpose of the high-speed camera was to capture any feather movement. Though it is capable of capturing full color video up to 1,000,000 FPS at a resolution of 64px x 64px, only 1,000 FPS and 2,000 FPS were used. Rates this high require additional sources of light. Six 4' long light panels were used to increase the brightness of the test section. Each light used six T5HO 54 watt bulbs that individually provided 4850 lumens at a color temperature of 5000K. 


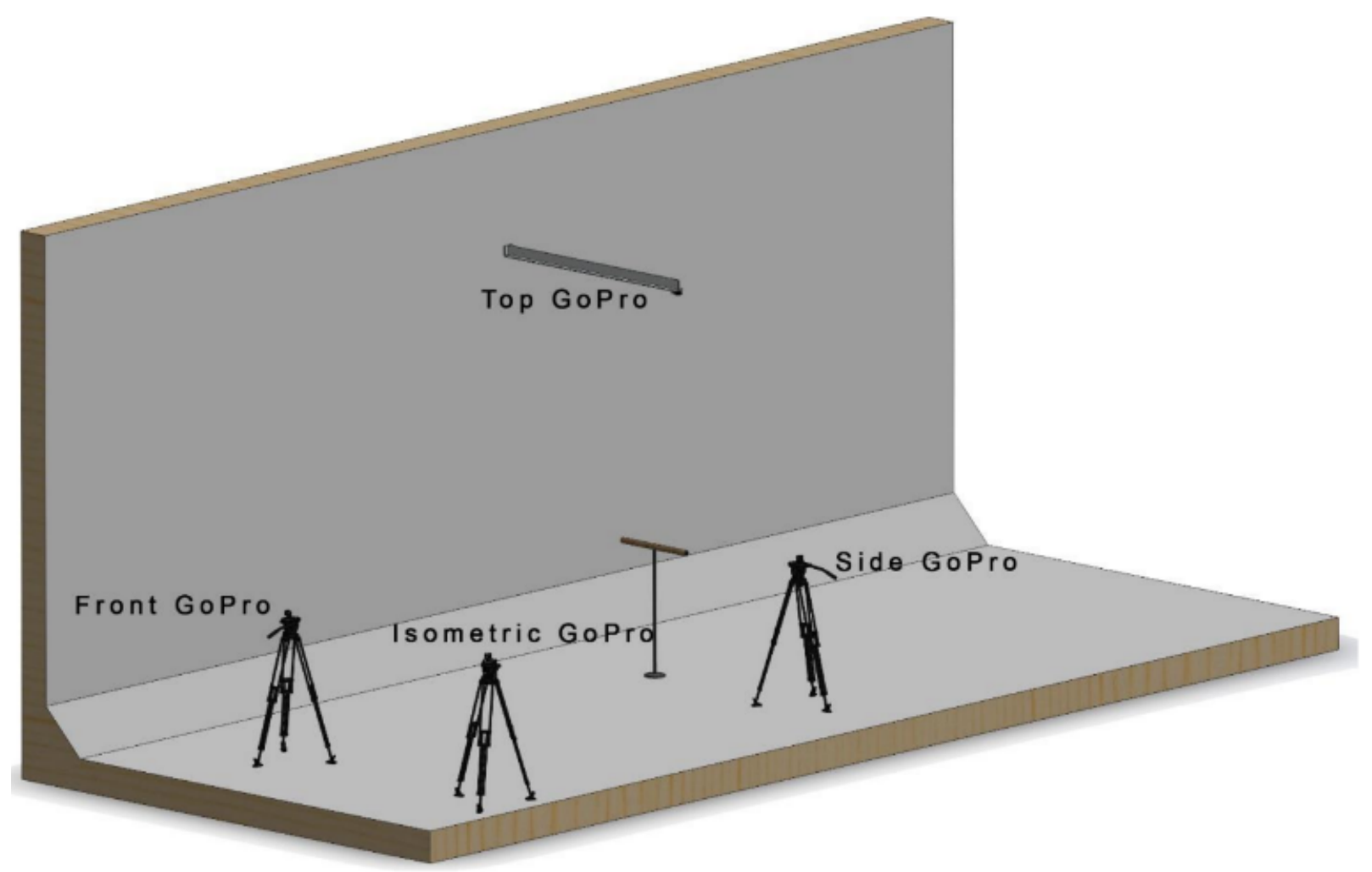

Figure 13. Location of the GoPro cameras in relation to the landing perch at that instance [20].

Located on the floor and wall were two grid sheets used for measurements. Each box of the checkered grid has a width of four inches making the checkered sheets both on the floor and on the wall 3'x 4'. To the left and right of the checkered sheet on the floor were pieces of black tape. The distance between the black tape measures a three-foot span.

The following figures show a snapshot of what the video footage looks like at the different camera locations. Figure 14 captures the bird activity from behind. The entire perch is pictured as well as the grid on the floor and only part of the grid on the wall. The camera is as centered in the front of the perch as possible without disrupting the bird flight. For this experiment, this angle was used to observe larger scale flight patterns such as the number of flaps taken during landing. 


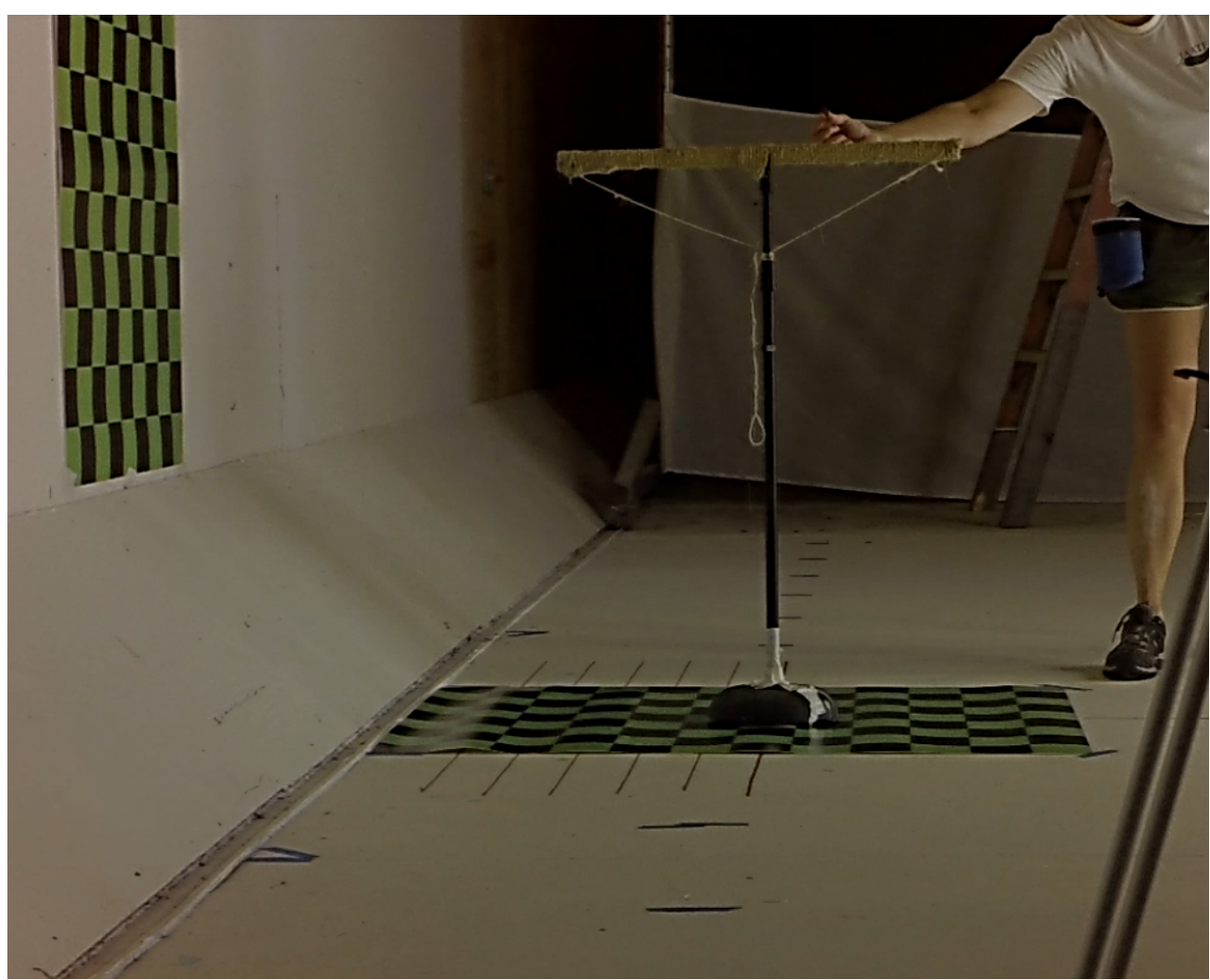

Figure 14. GoPro back view.

Figure 15 captures the location of the high-speed camera at that instance, the entire landing perch, and the grid on the wall and floor. For this experiment, the angle was only used to capture larger scale flight patterns such as the number of flaps taken during landing. 


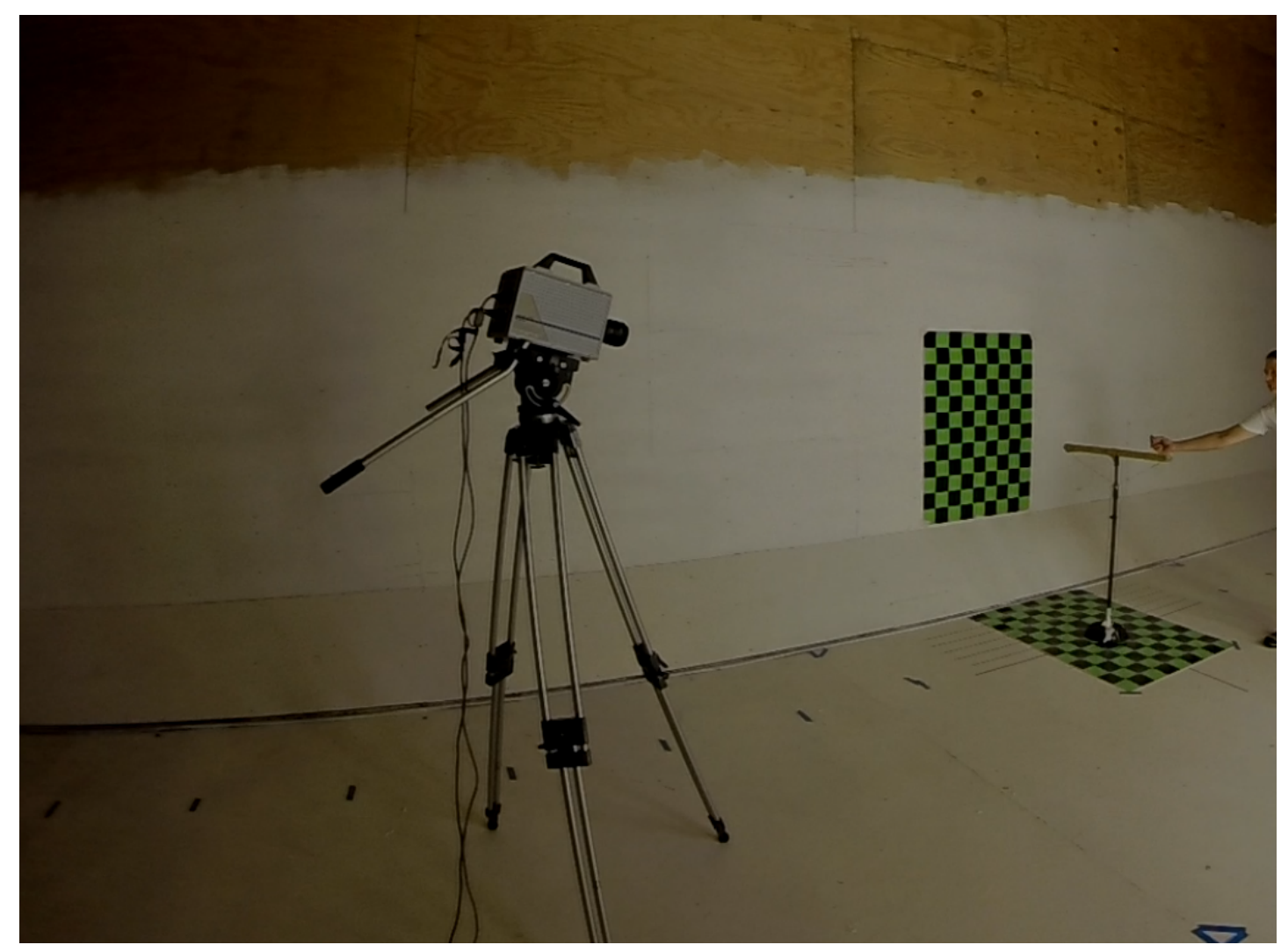

Figure 15. GoPro Isometric View.

In reference to this certain experiment, the 'Side View' seen in Figure 16 was one of the most important perspectives captured. This snapshot features the entire perch from the side and the grids on the floor and wall. The velocity of the bird as it landed could be tracked and landing profiles could be observed. Other observations were made such as when the bird bottomed out and at what point from the perch did the bird begin its landing regime. 


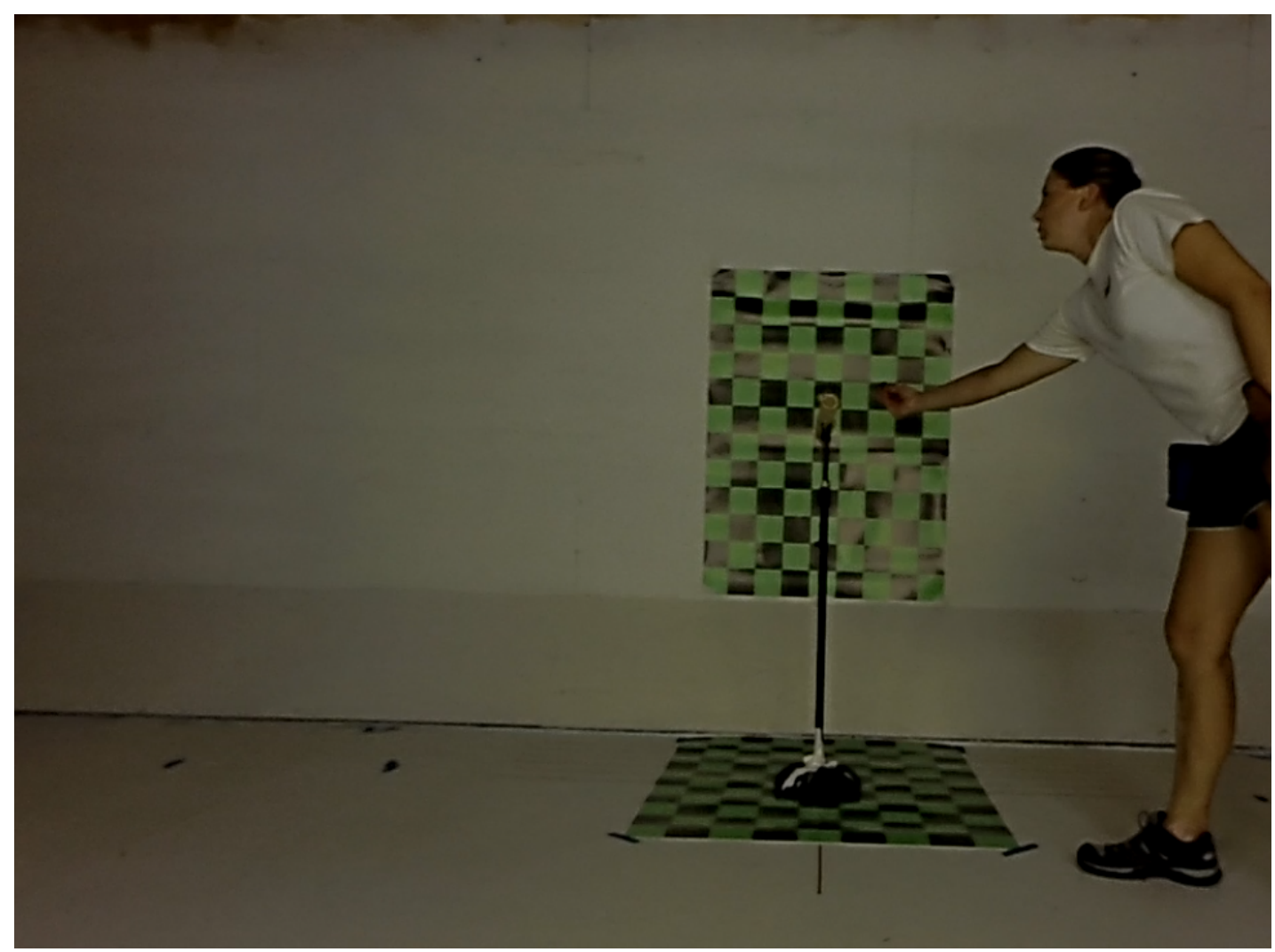

Figure 16. GoPro side view.

The 'Top View' shown in Figure 17 features the grid on the wall and the floor and the perch. The view only allowed for very limited observations such as the flight profile and wing planform. 


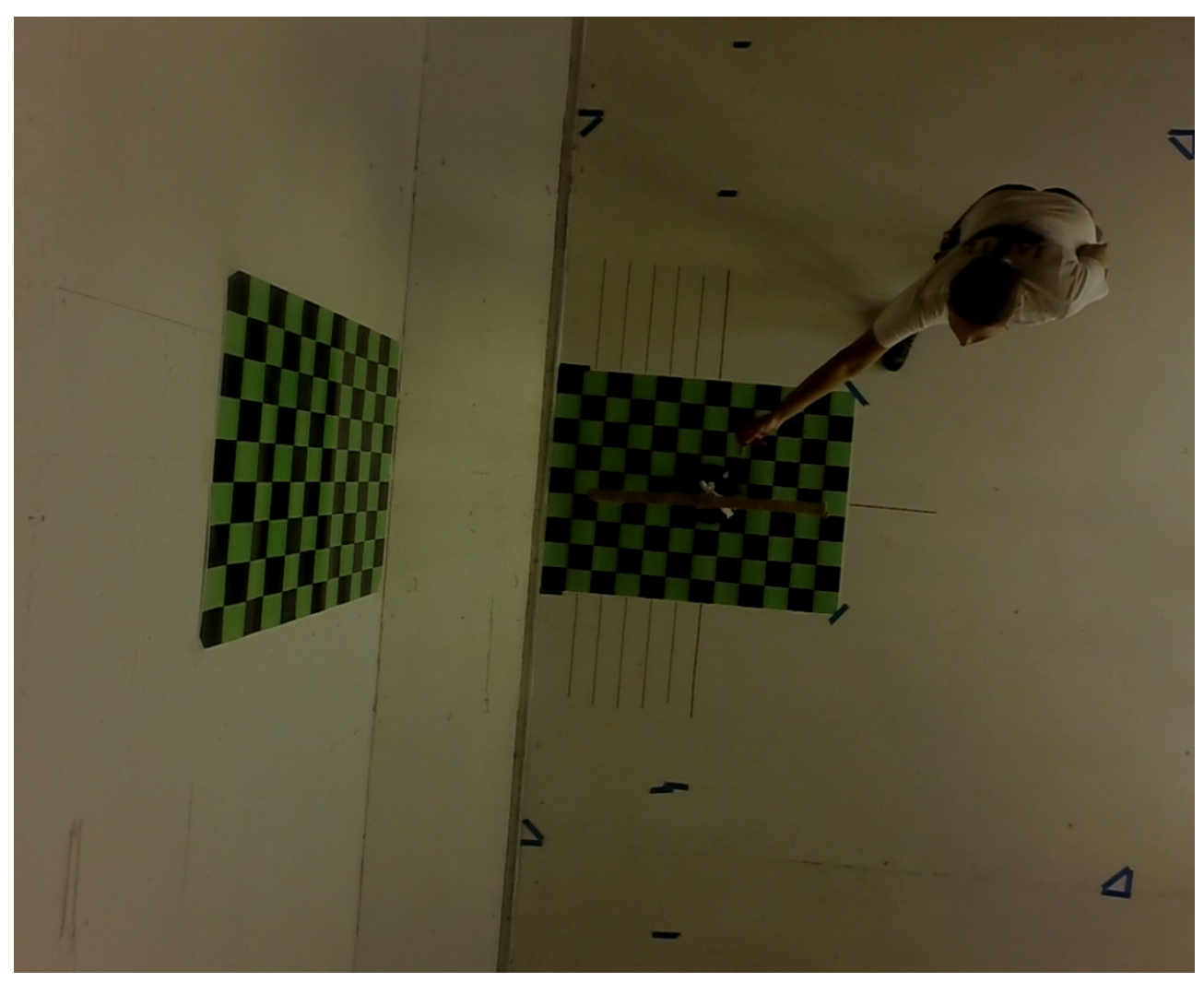

Figure 17. GoPro Top View.

\subsection{Wind Tunnel Experiment using Preserved Wing}

The pitch rate of the bird's wing while landing was approximated during video analysis of the free flight experiment. This data along with the landing velocity of the bird was used to derive the test conditions for the preserved wing experiment. This experiment attempts to recreate these test conditions by using a four-bar mechanism and motor to pitch the wing and use the wind tunnel to set a velocity inside the test section that matches the live bird landing velocity.

\subsubsection{Experimental Preparation of Wing}

For the wind tunnel experiment, the port wing from a young (less than two years of age) male Red-tailed hawk was used. Both harvest and preservation of this particular wing was completed for use in a previous experiment conducted by Jordan Cox, M.S. from West Virginia University. Mounting pieces were also affixed to the wing during this procedure. No birds were harmed in the process of obtaining the cadaver wing. The wing was detached at the end of the humorous bone close to the shoulder and coracoid in the body. All feathers associated with the wing were maintained at the detachment point. To recreate true flight conditions, the harvested 
wing should maintain its pliable fleshy tissue below the feathers. Though this is the ideal model, it would be difficult to achieve. To reduce the number of issues that may occur, a preservation method was used to dry the wing using corn meal, dry rice, and disodium tetraborate [30]. The combination of the three ingredients dehydrated the wing but the disodium tetraborate also was used to kill parasites. Drying out the wing in this way causes a reduction in the amount of flesh under the wing and feathers [30] [31]. No literature was found to support how this may impact the wing under test conditions.

The complete preservation process includes harvesting, freezing, and drying the wing. Until the wing can be preserved, it is kept frozen at a storage temperature of $\leq-10^{\circ} \mathrm{F}$ which also kills any parasites. After the wing is removed from the freezer and thawed, it is ready to be mounted to a supportive wire mesh using multiple mounting points. The availability of multiple mounting points on the wire mesh allows the wing to be preserved in different shapes. The wing is to be engrossed in the corn meal, dry rice, and disodium tetraborate mixture for at least thirty days to ensure effectiveness. This preservation process slows down biological degeneration so the wing can remain unrefrigerated [31].

Preservation was done with the intention of preserving the rigidity but fluidity of a natural wing. To mock a wing outstretched during gliding flight behavior, the wing had to be fixed in a way so that it stayed erect while in the wind tunnel. It was dried in an extended position as shown in Figure 18. Over time, the bone joints become stiff and tissues such as skin and ligaments under the feathers become rigid. 


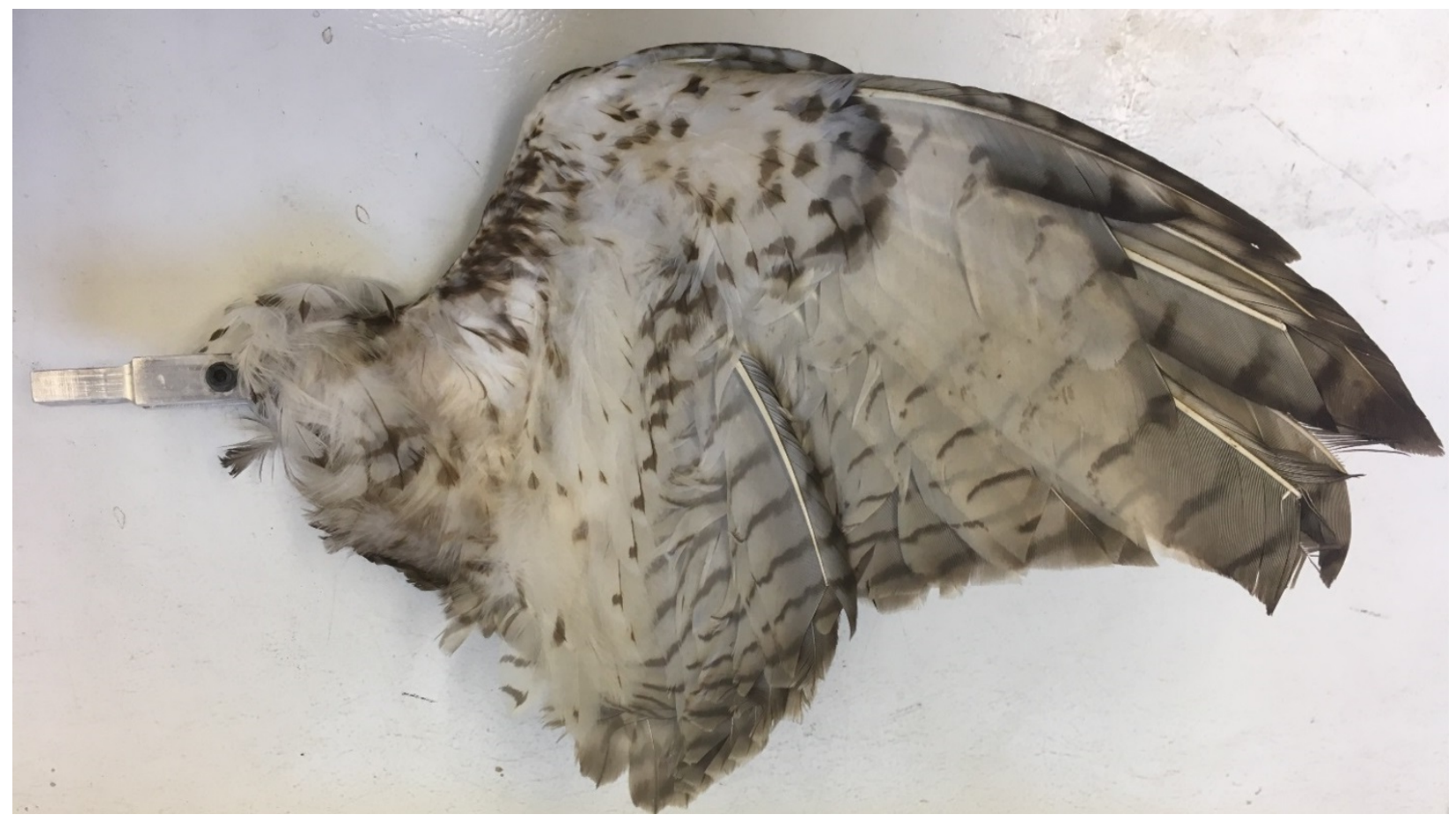

Figure 18. Extended position of preserved wing.

An aluminum piece was mounted to this point of detachment. This aluminum piece was used to affix the wing inside the wind tunnel securely [31]. Figure 19 shows the wing at the point of detachment connected to the aluminum mounting piece. 


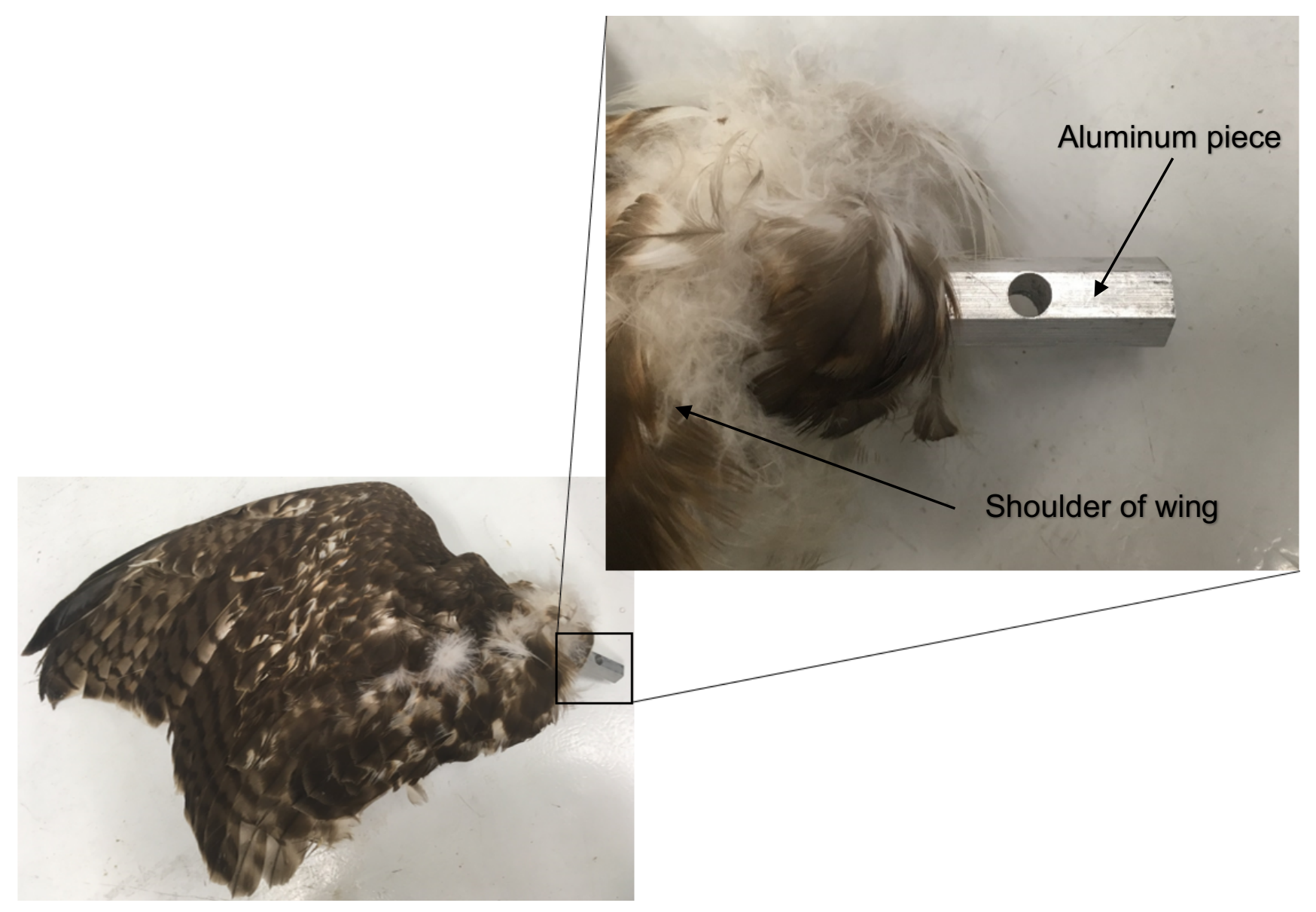

Figure 19. Connection between mounting piece and wing in the scapular feather region.

\subsubsection{Wind Tunnel Preparation}

The cadaver wing tests were conducted in the WVU Low Speed Closed Loop wind tunnel. It can achieve speeds up to 50 meters/sec with a turbulence intensity of $0.2 \%$ in the 3 ' $\times 4$ ' test section, shown in Figure 20 [5]. 


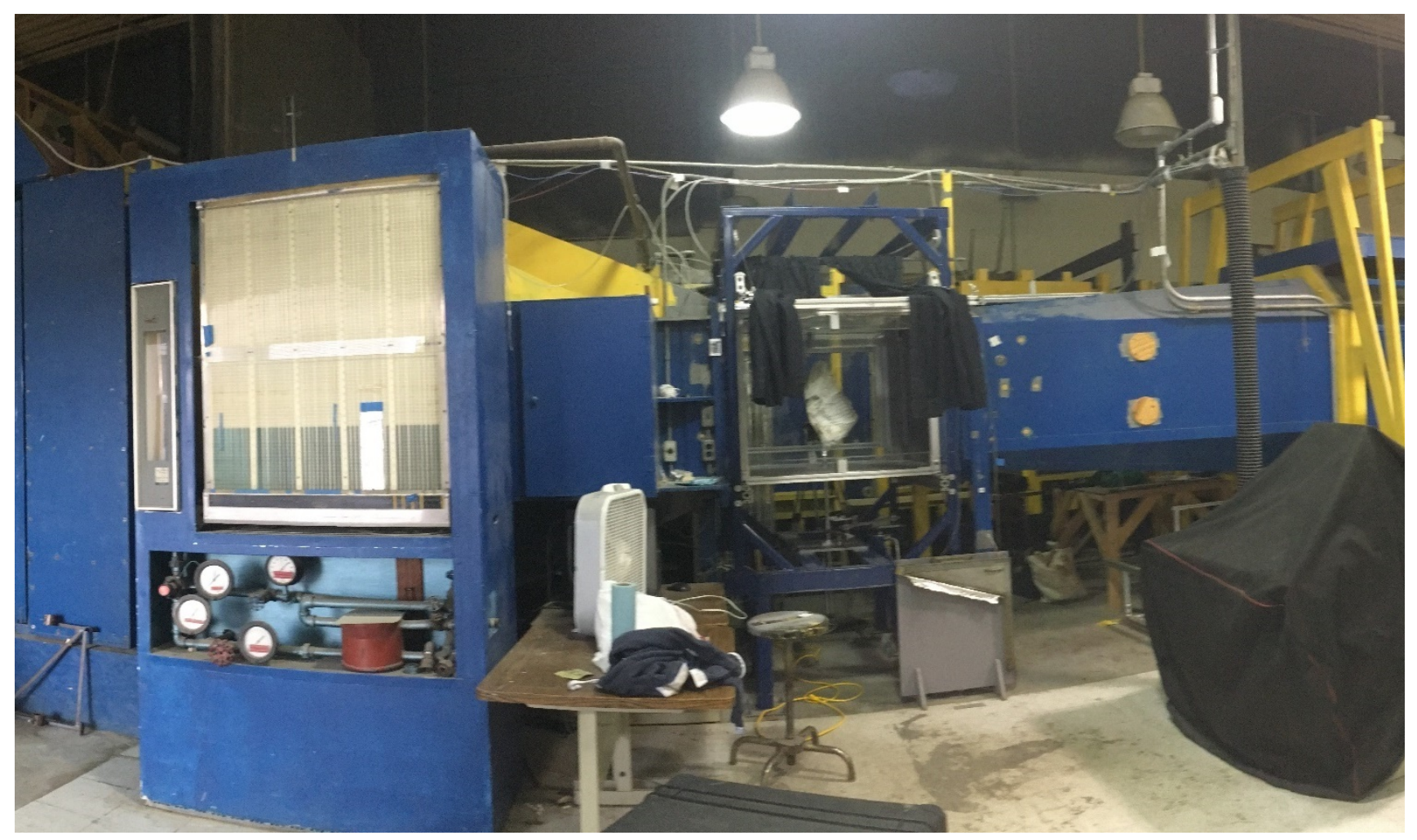

Figure 20. West Virginia University Wind Tunnel.

Referring to Figure 20, the air flow travels from left to right through the test section. There is approximately a three-foot-wide section of thin plastic where objects tested can be viewed. This section has plastic panes on the front, top, and back of the tunnel. The high-speed camera was set to capture footage at 1,000 FPS, so additional lighting was required. Three long four-foot white lights were used to illuminate the wing in the wind tunnel. Two black curtains were hung on the rear side of the test section to omit any objects or glare in the background shown in Figure 21. 


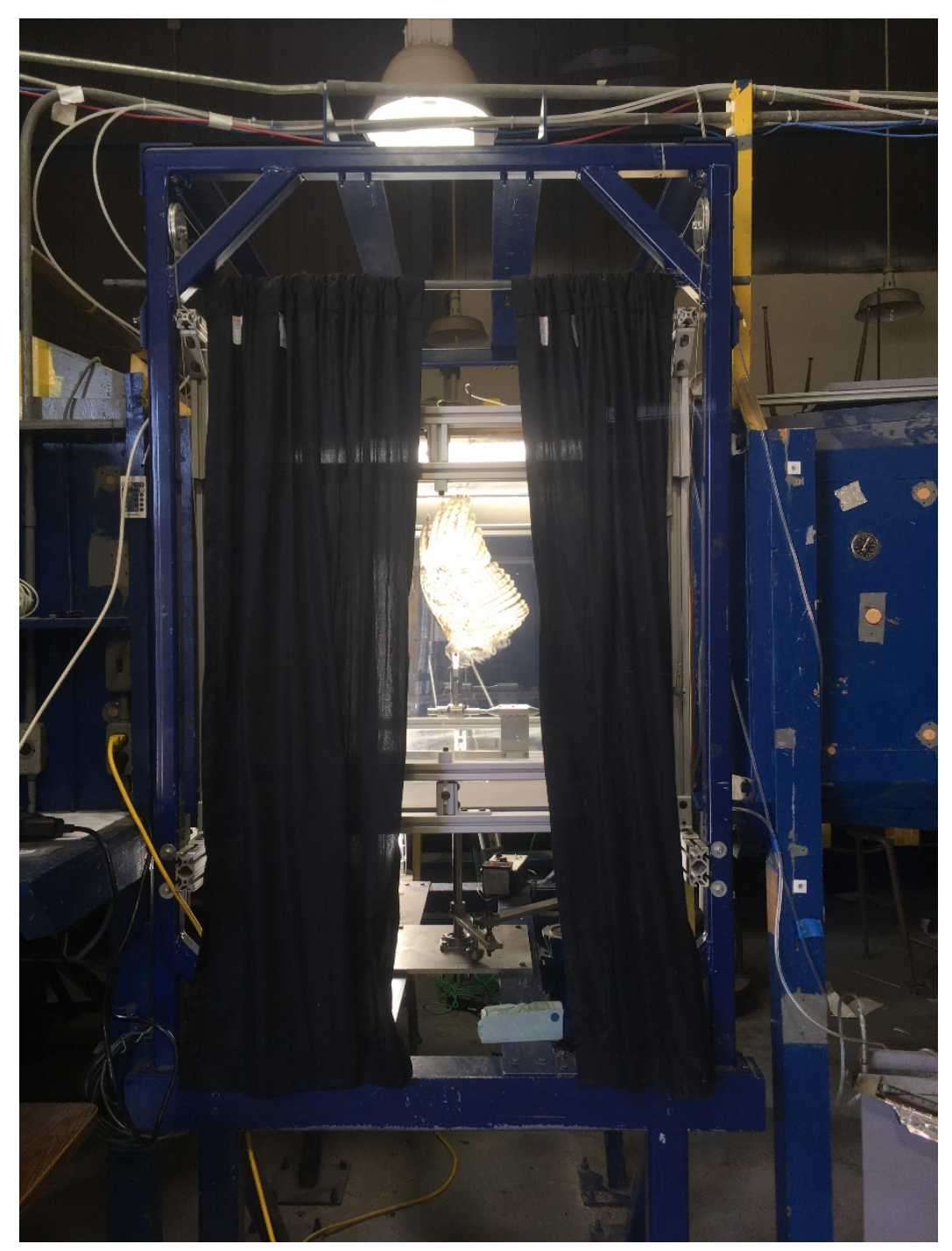

Figure 21. Test section of WVU wind tunnel.

The high-speed camera was setup level with the wing. A network cable connected the camera and the laptop via a gigabit Ethernet adapter. The Ethernet adapter allows the user to connect to a high-performance network and supports a 10/100/1000BASE-T network. The laptop was used for the imaging software and for converting videos from VID to MP4.

Photron FASTCAM viewer (PFV) was used in collaboration with the high-speed camera. It is a unified imaging software used as an interface for the control of the high-speed camera. Some features include FPS options, data saving, image enhancing and analysis of the simple motion [32]. Handbrake is an open source video transcoder. It was used as an interface to convert the videos captured from the high-speed camera from VID to MP4. 


\subsubsection{Oscillating system}

To simulate a pitching wing during flight, a four-bar mechanism [20] was used to oscillate the wing and obtain dynamic angles of attack of the wing as shown in Figure 22. This mechanism was built by Christopher Griffin, Ph.D. and modified by Shawn Smearcheck, M.S. of West Virginia University. The mechanism rotated the wing from a 0 to 55-degree angle of attack then returned back to 0 . This system was setup below the test section. It consists of three links, a 0.5 HP variable speed motor, and a mounted shaft. The shaft is reinforced at the two ends. This oscillating mechanism was also used to manually align the wing during static angle testing. Figure 22 shows the link directly attached to the same shaft the wing is fixed to. This link will be oscillating at the same rate as the wing and can be used to accurately measure the static angles of attack of the wing. A protractor was used to align this link at 5-degree intervals. The angle was checked multiple times for consistency before each test occurred.

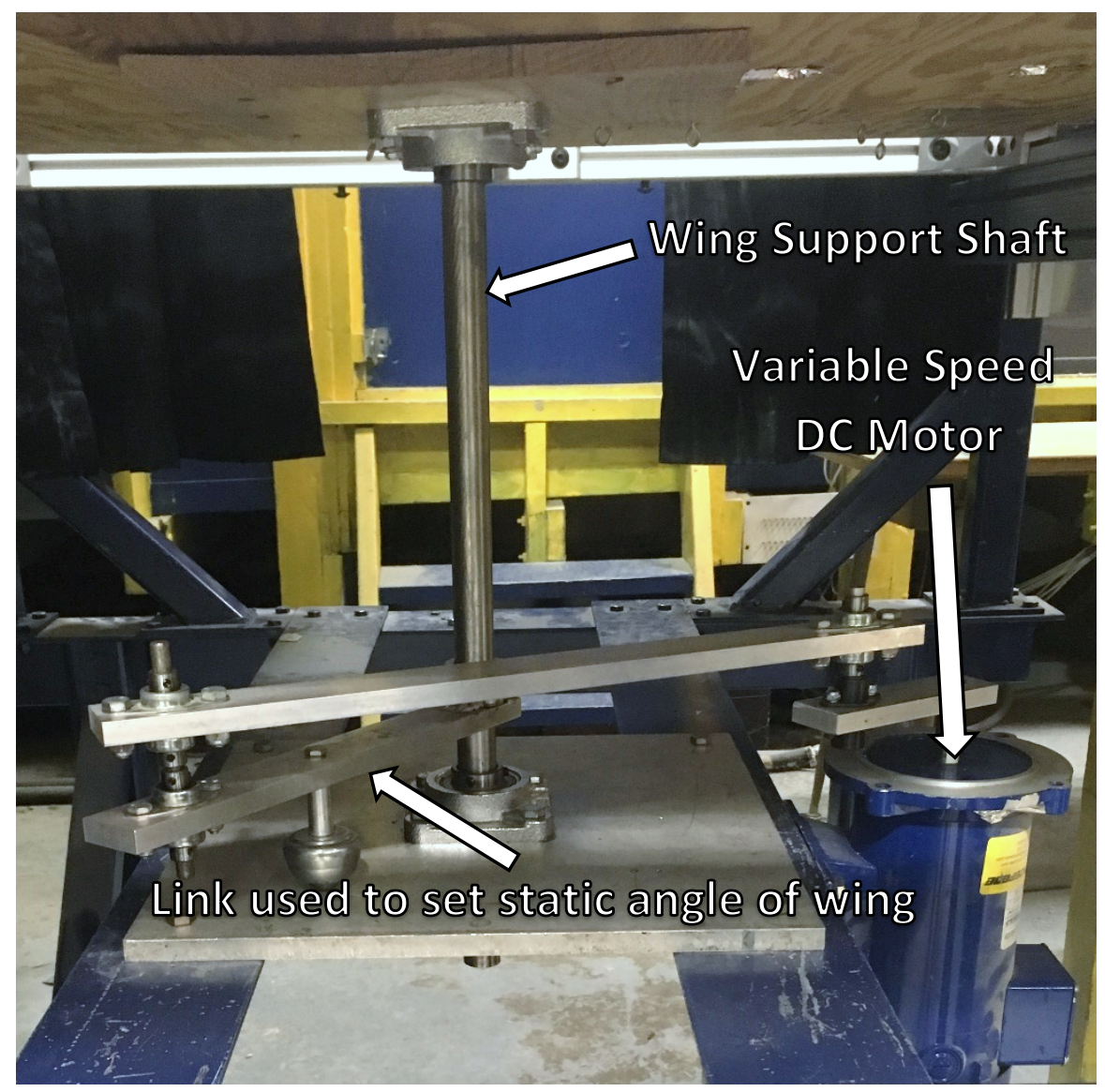

Figure 22. System used to oscillate the wing in the wind tunnel. 
Figure 23 shows the location of the oscillating system in reference with the test section and wing. The shaft inserted up into the bottom of the wind tunnel test section.

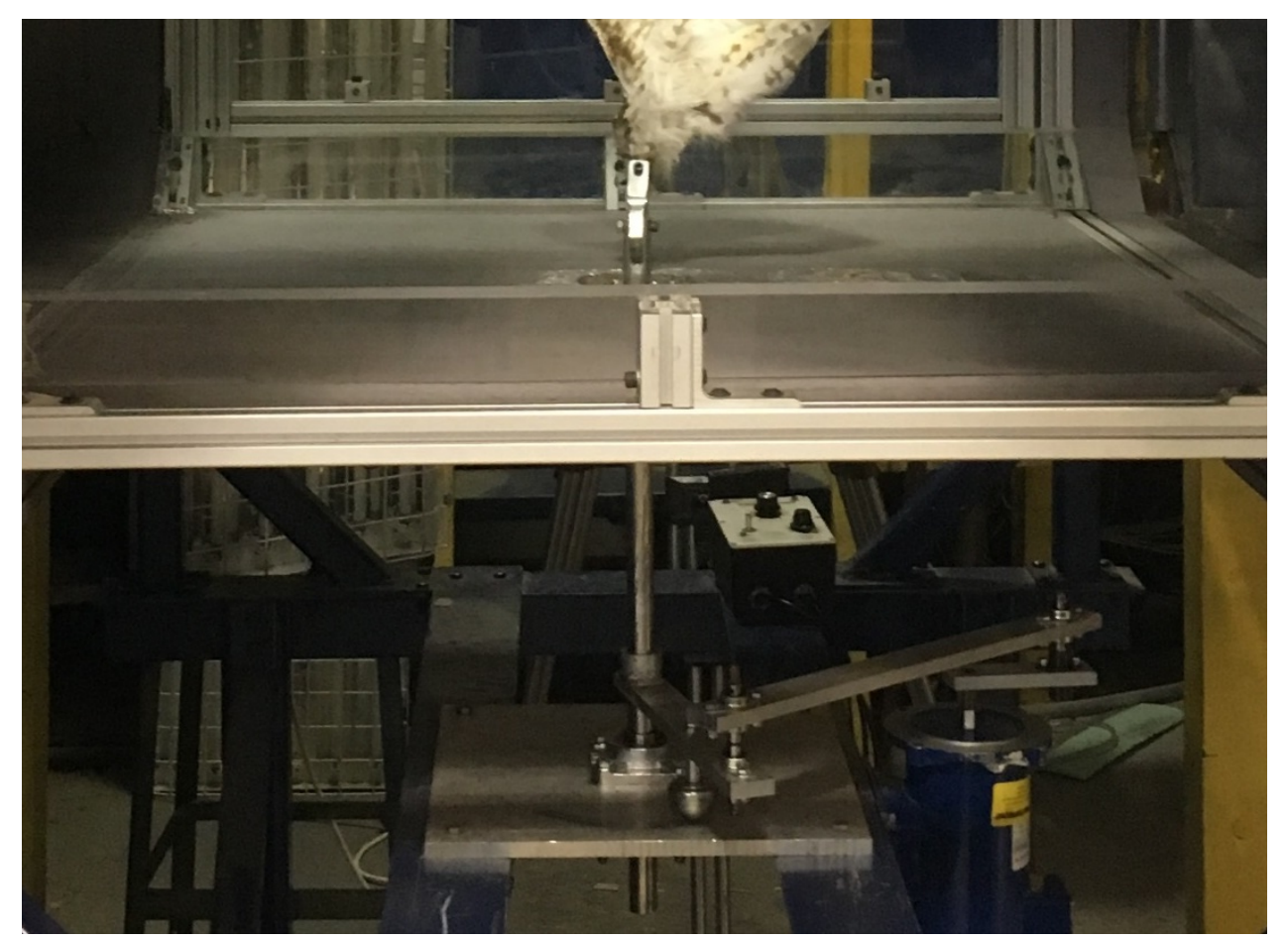

Figure 23. The location of the oscillating system in reference with the test section and wing.

The articulated adapter, shown in Figure 24, connected right on to the shaft via two set screws. The articulated adapter controlled the angle of incidents, dihedral, and sweep of the wing. The cadaver wing then attached to the articulated adapter. 


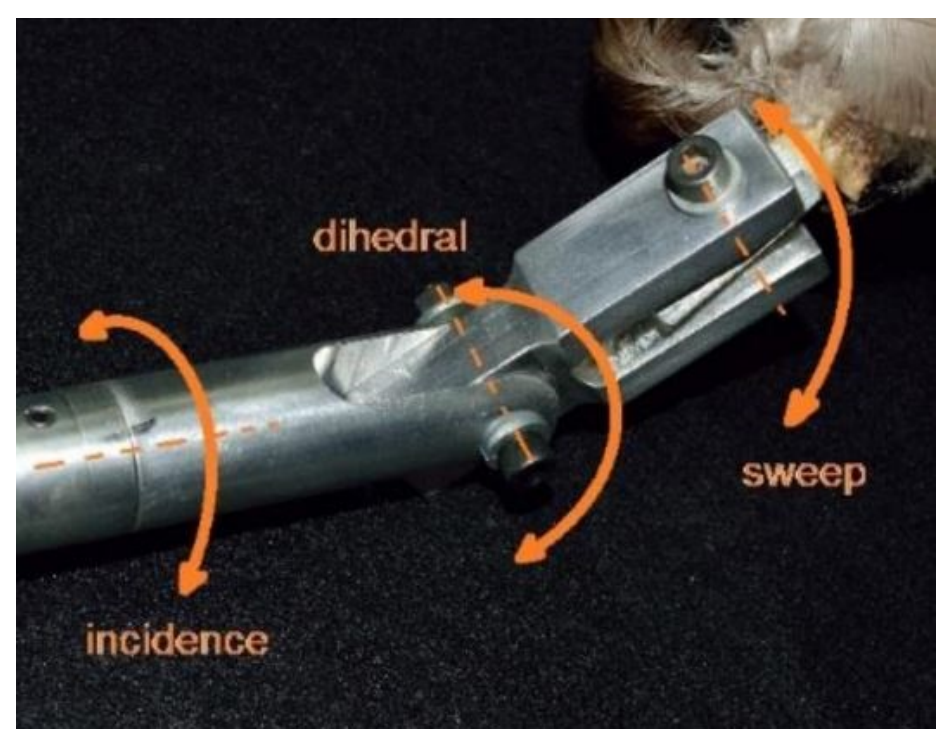

Figure 24. Articulated adapter [31].

\section{Chapter 4: Methods}

Video analysis was completed using VLC media player because it allowed the footage to be observed frame by frame. This single frame progression ensured that even the slightest movements were able to be recognized and recorded.

\subsection{Free Flight Experiment}

\subsubsection{Defining Feather Frequency}

For the free flight video analysis, frequency measurements were taken primarily on the right wing due its angle and close proximity to the high-speed camera. The wing was split into regions to make it possible to locate frequency measurements. Region 1, 2, 3 and 4 include the marginal coverts. Region 5 includes the alula feathers. Figure 25 displays the diagram used in the free flight experiment. The feather regions were driven only by the groups of feathers that moved. 


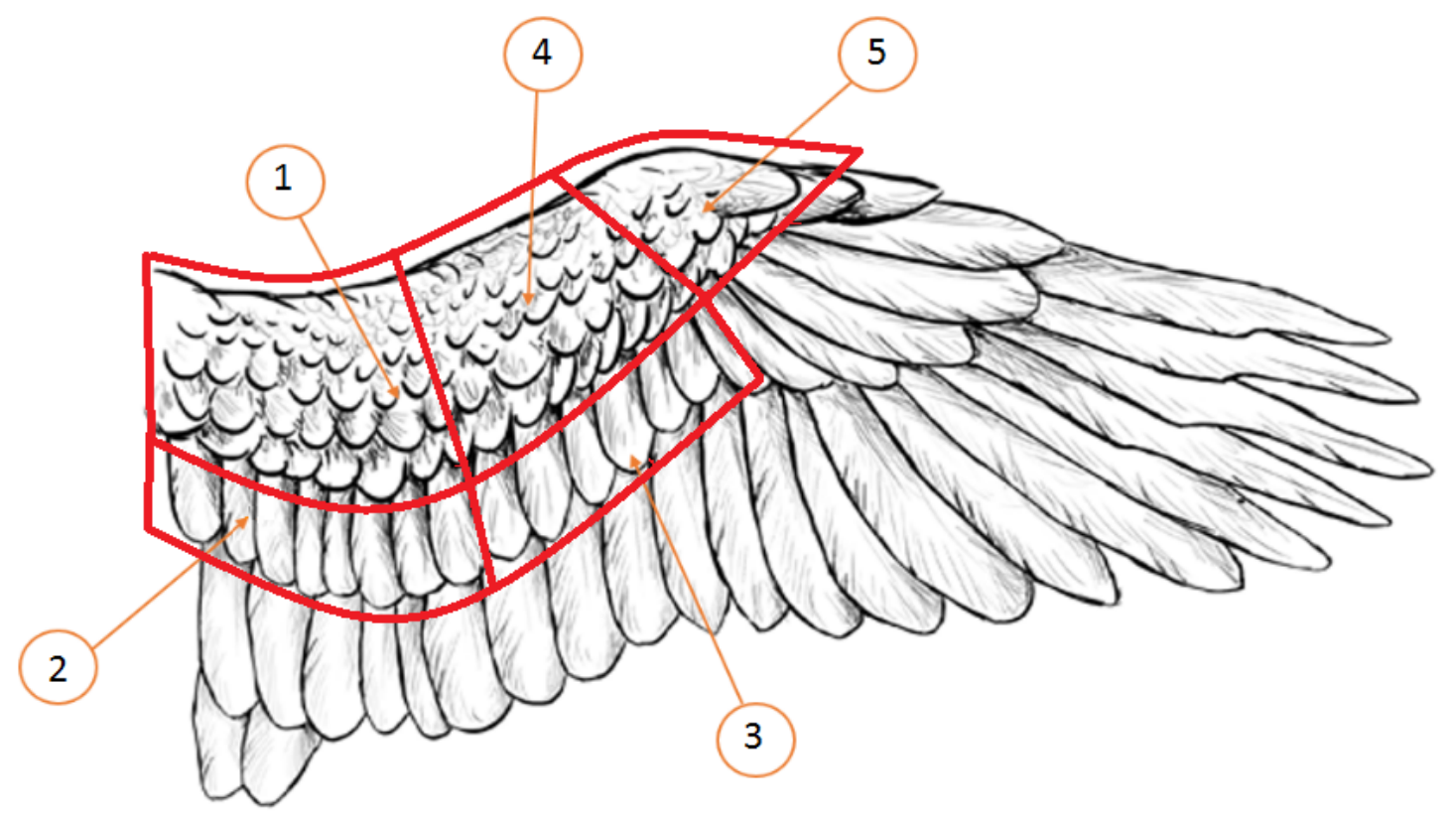

Figure 25. Regions 1, 2, 3, and 4 make up the marginal covert feathers and region 5 makes up the alula feathers. Diagram was produced using a sketch of an avian wing previously created [34].

Before frequencies were recorded, all high-speed videos were analyzed to determine conditions that would conclude if feather motion would be considered a frequency. To be considered a frequency, the feathers would rise up, reach a minimum angle of approximately 75 degrees, and then settle back down against the other feathers. While analyzing footage, some feathers would reach a higher angle and some would reach a lower angle. This approximated 75degree angle was chosen because it occurred most often. Figure 26 shows an example of feather motion on the live right bird wing. In all images of live bird, a strap can be seen attached to the leg. This strap is called a jess and is used in falconry to better control the bird while they are on a glove or during training [33]. At Frame: 0 the feather is at a low angle before any motion beings. At Frame: 14 the feather reaches its highest angle in this instance. At Frame: 33 the feather has returned to a low angle and no further motion is observed. 


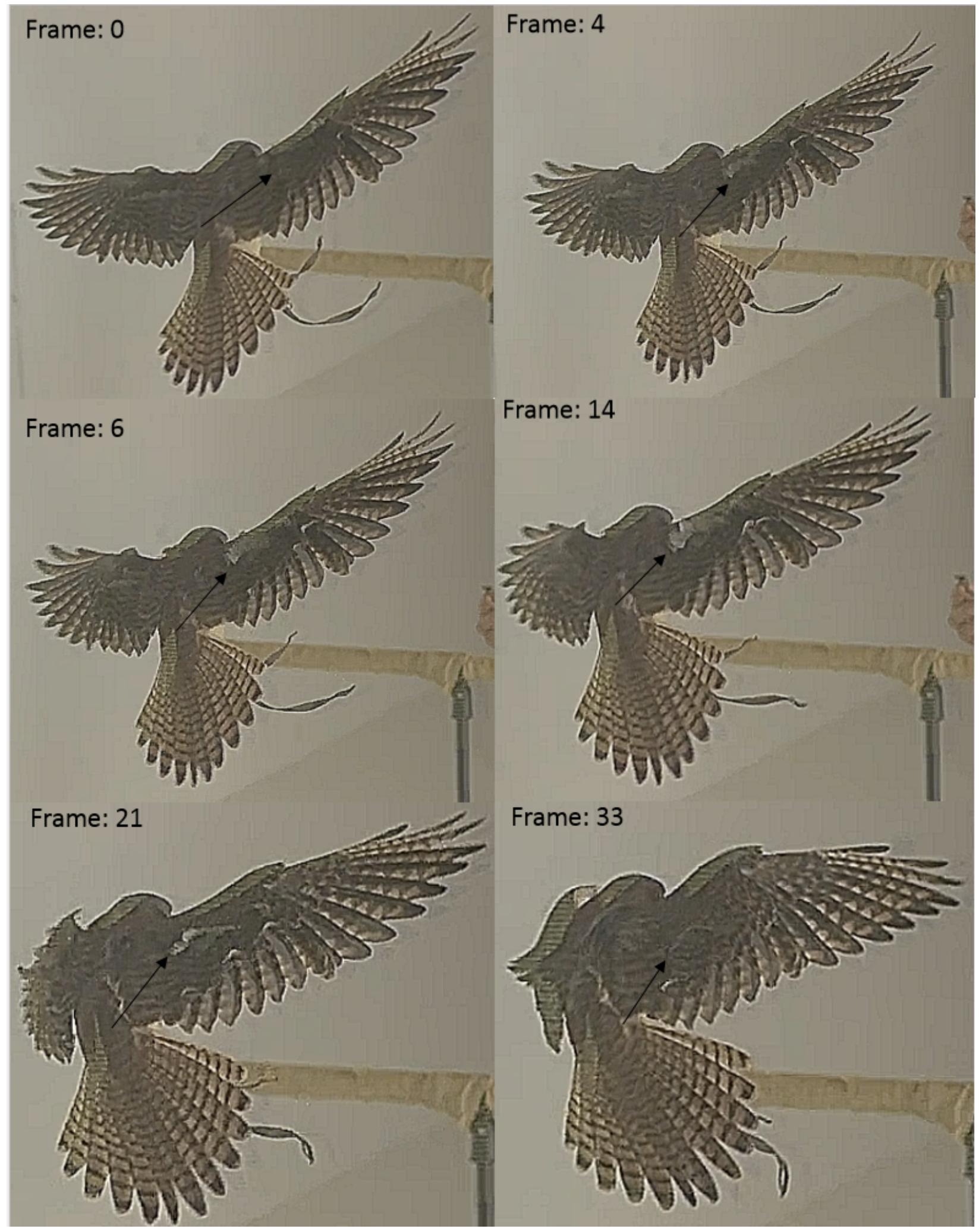

Figure 26. Progression of feather motion on live bird wing. Frame: 0 represents the frame right before any feather motion occurs and Frame: 33 represents the frame right after feather motions concludes. 
The 'start frame' records the frame count when the feather began movement and the 'end frame' records the frame count when the feather settled back down to its original position. For the videos used to observe frequencies, the high-speed camera was set to record at 1000 FPS so the total frame count was divided by 1000 to get the time in seconds. The following equations were used to find the frequency.

$$
\begin{gathered}
\text { Total Frames }(\text { Period })=\frac{\text { Start Frame-End Frame }}{1000} \\
\text { Frequency }(\mathrm{Hz})=\frac{1}{\text { Period }}
\end{gathered}
$$

For example, Figure 26 shows the progression of a frequency occurring over 33 frames. This frame count divided by 1000 gives a time of 0.033 s. One divided by this calculated time gives the frequency of the feather to be $30.30 \mathrm{~Hz}$.

\subsubsection{Landing Velocity}

Velocity was recorded using Tracker, which is a video analysis and modeling tool. The user is able to manually track an object's position, velocity, and acceleration and overlay this data for comparison [6]. The point used to track the bird was manually set as close to the center of the head as possible. The center of the head was the easiest point to locate on each frame. Figure 27 shows an example of the path taken by the bird while landing which was traced using Tracker. Videos used in Tracker contained all of the following in sequence: bottom out, wing flaps, touching down. 


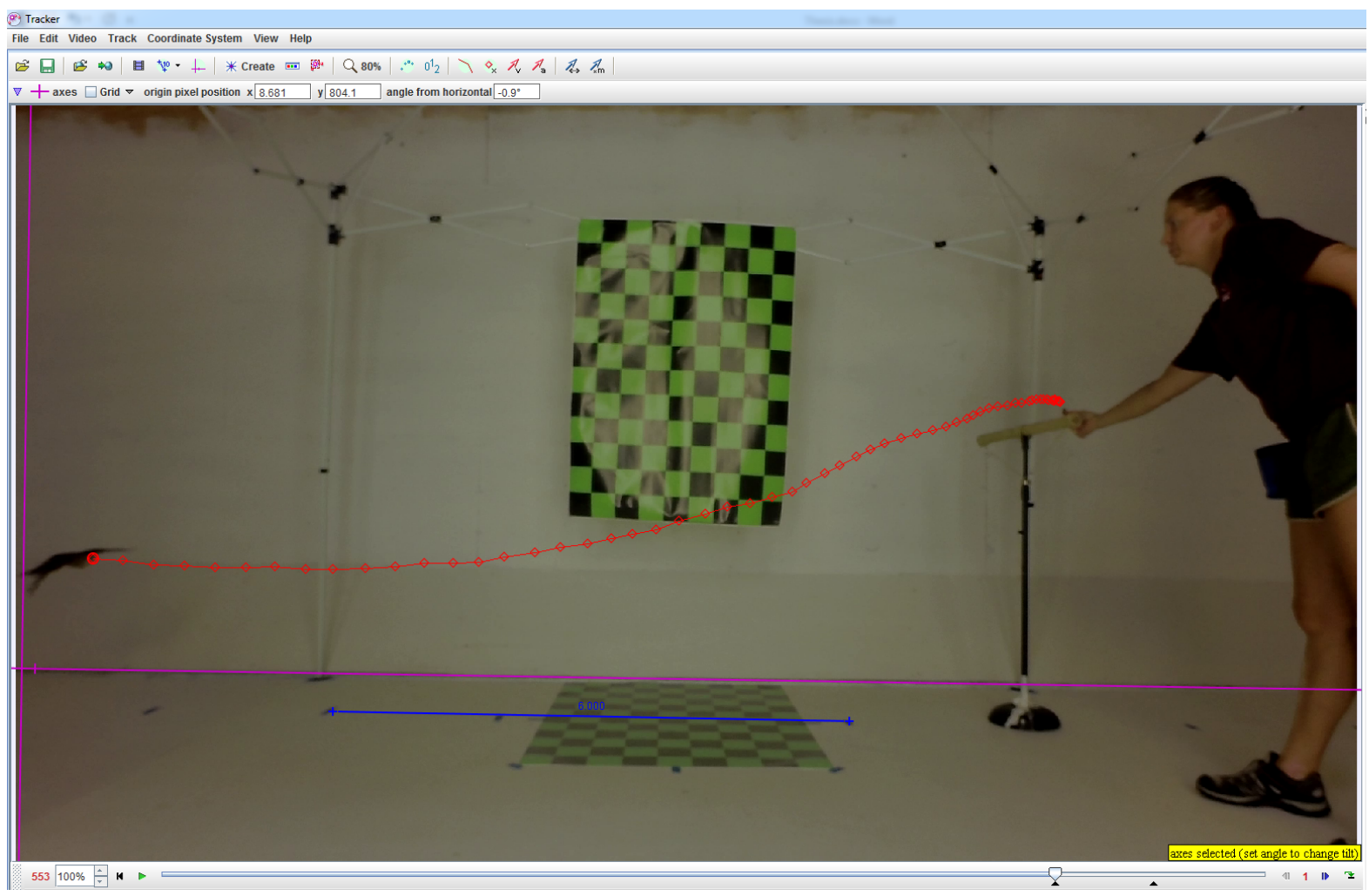

Figure 27. Snapshot of Tracker tracking the birds head while landing.

\subsubsection{Approximating the Pitching Rate of the Wing}

The pitching rate of the wing during the landing sequence had to be approximated. Videos used were taken during two different sessions and were recorded at 59 FPS. A snapshot of the bird was taken when the bird wing was closest to a zero angle of attack. A second snapshot was taken when it appeared like the wing had reached a maximum angle of attack. The angle of the wing in both snapshots was approximated and traced with a black line as shown in Figure 28 then compared. From Table 1, the pitching rate ranges from $354 \mathrm{deg} / \mathrm{s}$ (59 RPM) to $688.3 \mathrm{deg} / \mathrm{s}$ (131 RPM). 


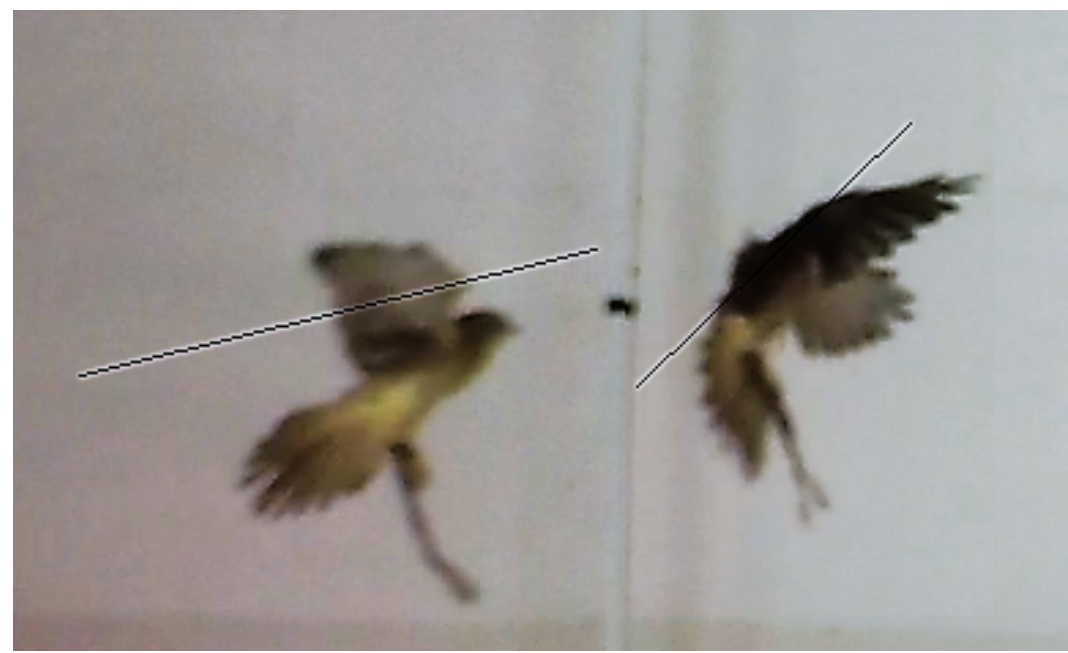

Figure 28. Traced approximated angle of the wing which can be compared to find the pitching rate.

Table 1. Pitching rate data collected during two different sessions.

\begin{tabular}{|c|c|c|c|c|c|c|}
\cline { 2 - 7 } \multicolumn{1}{c|}{} & Wing Flap & Duration (frames) & Time & Approx. $\Delta$ Angle & Rate (deg/s) & Rate (RPM) \\
\hline \multirow{4}{*}{ Session 1 } & A & 4 & 0.068 & 40 & 590.00 & 98.3 \\
\cline { 2 - 7 } & B & 4 & 0.068 & 40 & 590.00 & 98.3 \\
\cline { 2 - 7 } & B & 3 & 0.051 & 35 & 688.33 & 114.7 \\
\cline { 2 - 7 } & B & 5 & 0.085 & 30 & 354.00 & 59.0 \\
\hline Session 3 & C & 3 & 0.051 & 40 & 786.67 & 131.1 \\
\hline
\end{tabular}

\subsection{Wind Tunnel Experiment using Preserved Wing}

\subsubsection{Calculating Mean Aerodynamic Chord (MAC)}

Since the bird wing is an undefined shape, a different approach had to be taken to measure the MAC. The outline of the wing was traced onto a large piece of paper. The chord length was measured every half of an inch of the trace starting with the tip of the primary feather region. From this collected data, the average was taken giving the mean chord length. Figure 29 shows the traced wing used for measurements. Measurements were not taken of the live bird wing so the average wing chord length of 9 inches was used [35]. 


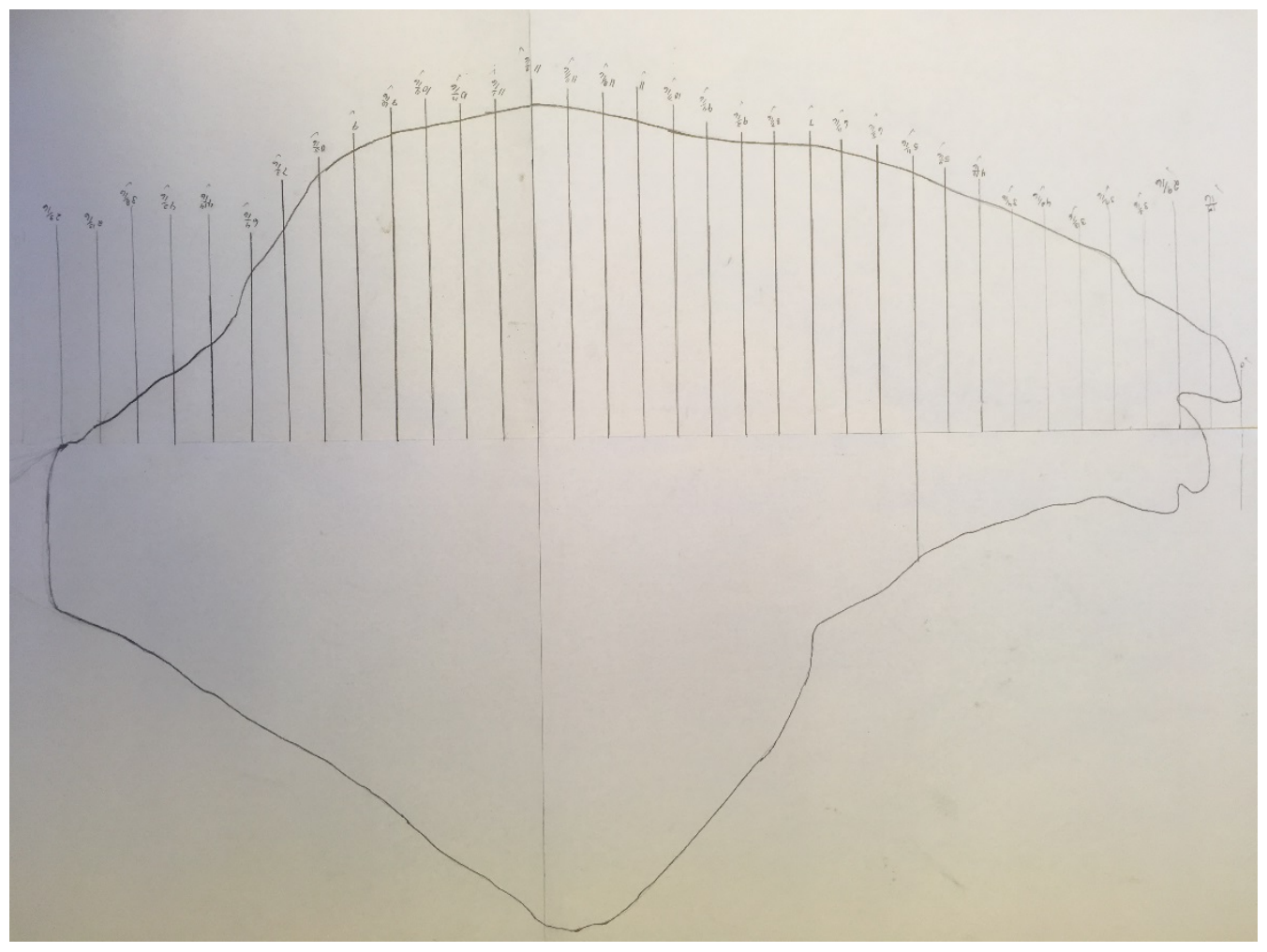

Figure 29. Outline of bird wing used to find the average chord length.

To calculate the MAC the following equation was used.

$$
M A C=\frac{1}{S_{w}} * \int_{0}^{b / 2} c^{2} d y
$$

where $S_{w}$ represents the wing area, $b$ represents the wing span, and $\mathrm{c}$ is the chord at the y coordinate (vertical lines at 0.5 -inch intervals). Measured data in Table 2 was obtained from the harvested wing.

Table 2. Cadaver wing Specifications.

\begin{tabular}{|c|c|c|}
\hline Specification & Value & Unit \\
\hline Span (b) & 43.18 & $\mathrm{~cm}$ \\
\hline Mean Aerodynamic Chord (MAC) & 21.10 & $\mathrm{~cm}$ \\
\hline
\end{tabular}

\subsubsection{Defining Test Section Velocity Range}

During the live bird experiment, the velocity was tracked from when the bird came into the camera view in a gliding regime until it completed its last wing flap before touchdown on the landing perch. After reviewing all velocity data, the average velocity occurring right before the bird bottomed out was $6.70 \mathrm{~m} / \mathrm{s}$. The average velocity occurring right after the last flap concluded 
before touchdown was $3.40 \mathrm{~m} / \mathrm{s}$. Stated in previous literature, the Red-tailed hawk commonly flies between $8.94 \mathrm{~m} / \mathrm{s}$ and $17.88 \mathrm{~m} / \mathrm{s}$ [36]. In preliminary testing, testing at lower velocities $(0 \mathrm{~m} / \mathrm{s}$ to $3 \mathrm{~m} / \mathrm{s}$ ) yielded very little feather motion which included only fluttering. The velocity of the air inside of the test section was measured using a pitot static tube. The tests were run at approximate test section tunnel heads of 0.06 to 0.20 inches of water column. This range allowed for an ample amount of feather motion to occur. 0.06 to 0.20 in. $\mathrm{H}_{2} \mathrm{O}$ equates to 4.99 to $9.12 \mathrm{~m} / \mathrm{s}(\mathrm{Re}=56,801$ to 103,768). These values were obtained using the following equations.

$$
v=\left(\frac{2\left(P_{T}-P\right)}{\rho}\right)^{1 / 2}
$$

where $v$ is the velocity of the air inside the wind tunnel, $\left(P_{T}-P\right)$ is the pressure difference (in. $\mathrm{H}_{2} \mathrm{O}$ ), and $\rho$ is the density of the fluid air during the experiment.

$$
R e=\frac{\rho \mathrm{vc}}{\mu}
$$

where Re is the Reynolds number, $c$ is the MAC of the wing, and $\mu$ is the dynamic viscosity of the air at the time of the experiment.

The following table contains the list of wind tunnel velocity intervals.

Table 3. Test section velocity intervals.

\begin{tabular}{|c|c|c|}
\hline Test Section Head Pressure (in. H2O) & Reynolds Number & Velocity $(\mathrm{m} / \mathrm{s})$ \\
\hline 0.06 & 56801 & 5.0 \\
\hline 0.07 & 61354 & 5.4 \\
\hline 0.09 & 69610 & 6.1 \\
\hline 0.10 & 73307 & 6.4 \\
\hline 0.12 & 80365 & 7.0 \\
\hline 0.14 & 86749 & 7.6 \\
\hline 0.16 & 92813 & 8.2 \\
\hline 0.18 & 98441 & 8.7 \\
\hline 0.19 & 101139 & 8.9 \\
\hline 0.20 & 103768 & 9.1 \\
\hline
\end{tabular}




\subsubsection{Alignment of Cadaver Wing in Tunnel}

For this experiment, the sweep of the wing and the dihedral was set to resemble the wing in the landing phase using the articulated adapter. The zero-degree angle of attack was determined by aligning the lower curvature of the leading edge and the trailing edge of the cadaver wing with the direction of the free stream flow in the test section. The oscillating system limited the angle of attack to 55 degrees. Figure 30 shows the wing mounted in the test section.

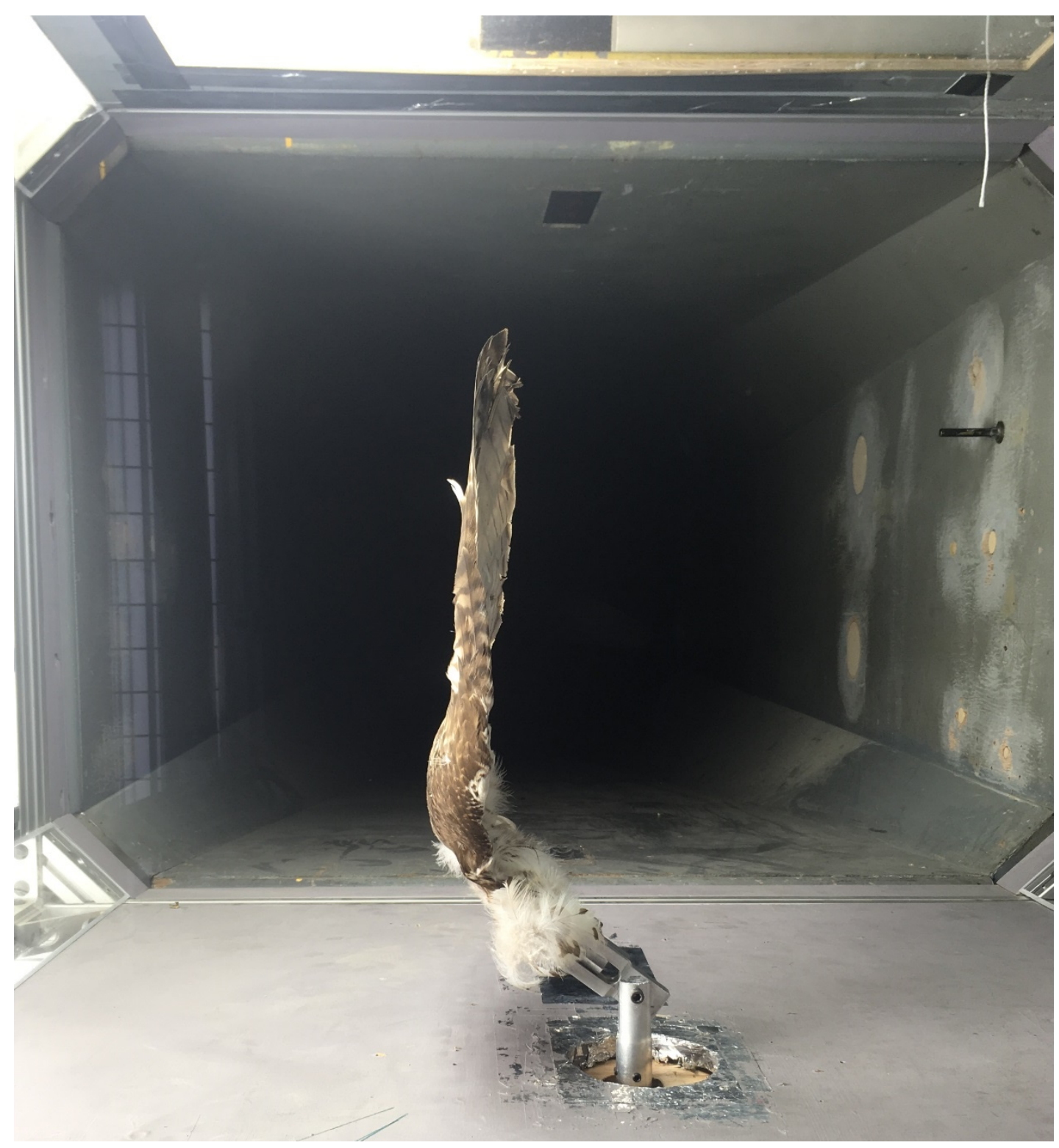

Figure 30. Cadaver wing model aligned and prepared for testing in wind tunnel section at 0 degrees angle of attack. 


\subsubsection{Coordinating Dynamic Angle with Static Angle}

The four-bar mechanism previously discussed was used to pitch the wing. This type of mechanism has been used in many experiments while testing airfoils. To obtain an instantaneous angle of attack, $\alpha(\mathrm{t})$, while using this mechanism, the following equation was used.

$$
\alpha(t)=\alpha_{0}+\alpha_{1} \sin (\omega t)
$$

In (6), $\alpha(t)$ is the instantaneous angle of attack at desired time $t . \alpha_{0}$ is the mean angle of attack which is equal to $27.5^{\circ}$ for this particular experiment. $\alpha_{1}$ is the oscillation magnitude which is equal to the maximum angle of attack, $55^{\circ}$, minus the mean angle of attack, $27.5^{\circ} . \omega$ is circular frequency which is the RPMs of the motor in $\mathrm{rad} / \mathrm{s}$. After calculating the instantaneous angles of attack at which the feather frequencies began, the videos were reviewed again to see if these calculated angles seemed reasonable.

Though, the live bird is capable of a wing pitching rate of 131 RPMs, the motor was only set to a maximum of 114 RPMs. Beyond this point, the swift rotation would cause the wing to jerk. Reduced frequency was used to compare the pitching rate range to the live bird pitch up rates recorded. The reduced frequency can be found using the following equation.

$$
k=\frac{\omega c}{2 U_{\infty}}
$$

In (7), $\mathrm{k}$ is the reduced frequency, $\mathrm{c}$ is the MAC of the wing, $\mathrm{U}_{\infty}$ is the velocity in the test section. Each time the wing was pitched, the degree of freedom, 55 degrees, was divided by total time it took for the wing to travel from 0-degree angle of attack to 55-degree angle of attack. This gave an accurate pitch rate in $\mathrm{deg} / \mathrm{s}$. For the live bird experiment, the maximum reduced frequency calculated was 0.13 and the minimum was 0.05 . For the wind dynamic pitch wing tunnel experiment, the maximum reduced frequency was 0.23 and the minimum was 0.08 .

For static angles, the oscillating system was used. The main shaft connects the cadaver wing and the links below the wind tunnel. The link connected directly to the shaft moved at the same rate of the wing. The wing was manually set using the oscillation system operating at 0 RPM.

\subsubsection{Defining Feather Frequency}

The same wing region diagram was used for the preserved wing but was mirrored to reflect the regions of the left wing. Figure 31 shows the diagram of the regions where frequencies were 
recorded on the left wing. The method of recording and calculating frequency, using (1) and (2), on the live bird wing was applied to the preserved wing.

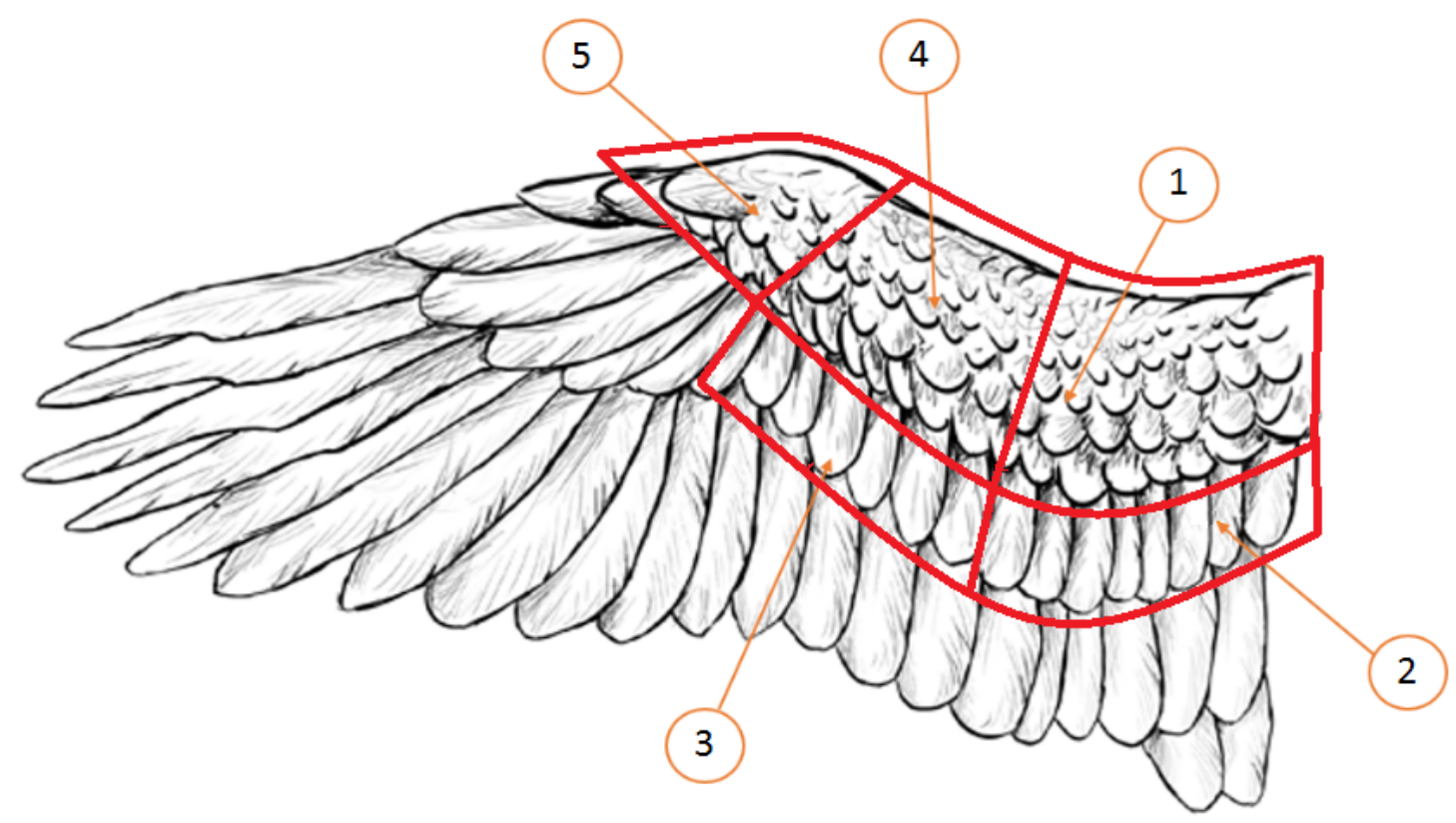

Figure 31. Diagram of left wing showing regions where frequency was recorded. Diagram was produced using a sketch of an avian wing previously created [33]. These defined regions were referenced when analyzing results.

To be considered a frequency, the feathers would rise up, appear to reach an angle of approximately 70 degrees, and then settle back down against the other feathers. While analyzing footage, some feathers would reach a higher angle and some would reach a lower angle. This approximated 70-degree angle was chosen because it looked to be the median angle and occurred most often. Figure 32 shows the progression of feather motion occurring while testing the preserved wing. At Frame: 0 the feather is at a low angle before any motion beings. At Frame: 25 the feather reaches its highest angle in this instance. At Frame: 62 the feather has returned to a low angle and no further motion is observed. Frequency calculations were not based on a single feather during the specified data session. During one wing flap multiple feathers would oscillate but only the feathers whose oscillations fit the criteria for a frequency were recorded as well as in what region that feather resided in. The same feathers may be active in all wing flaps but were only recorded if their motion fit the criteria. 


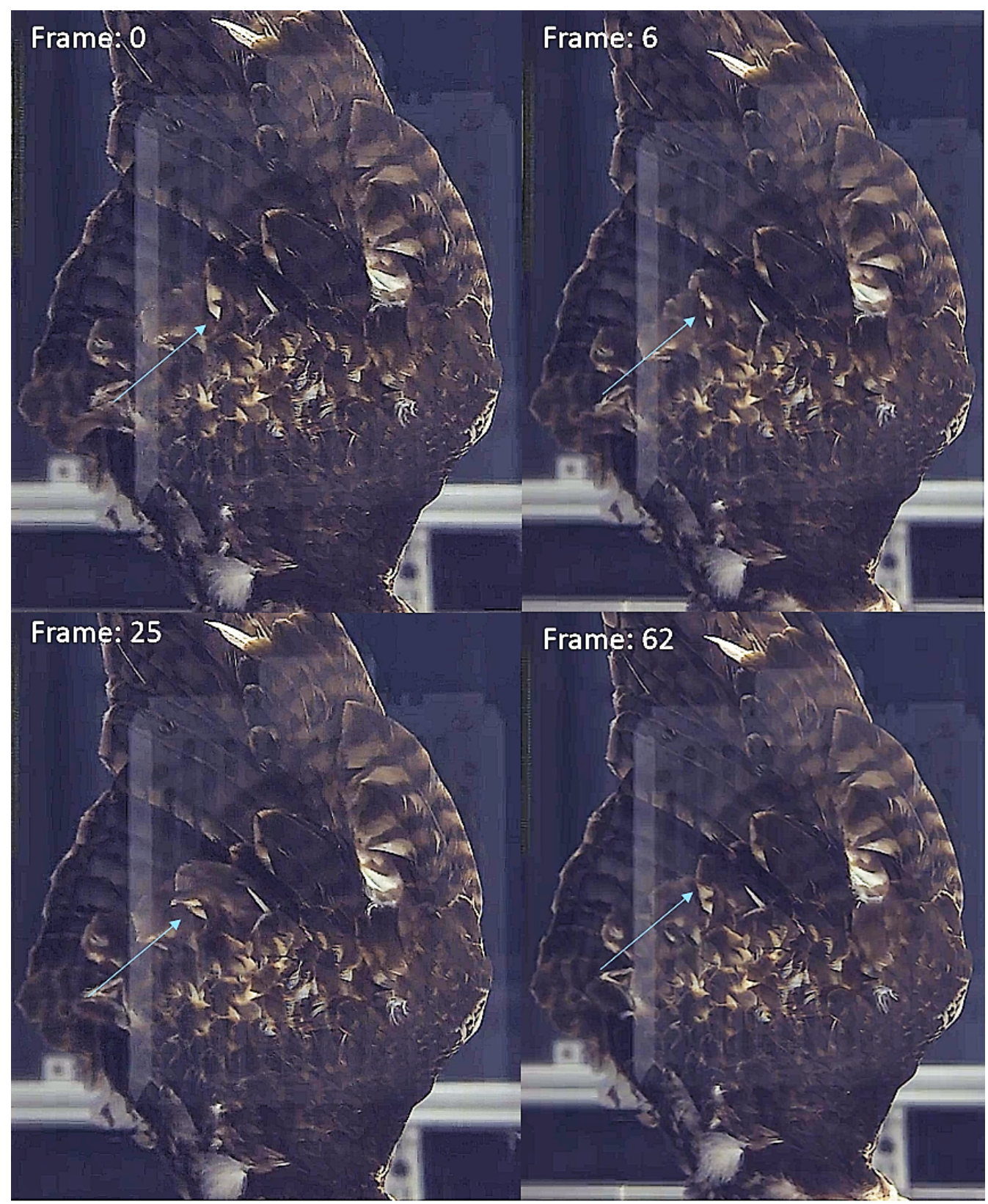

Figure 32. Progression of feather motion occurring while testing the preserved wing.

\section{Chapter 5: Results}

The overall goal of the free flight experiment was to observe and record bird velocity, feather behavior, and any other noticeable flight patterns at different flight conditions during the birds landing regime. The overall goal of the cadaver wing experiment was to observe changes in feather activity and record feather frequencies at different Reynolds number for dynamic angles and static angles and compare these two scenarios. The final goal was to then compare the data collected using the cadaver wing with the data recorded during the live bird experiment. 


\subsection{Free Flight Experiment}

Footage used for analysis was taken during four different sessions each occurring on separate days. There is no difference between the sessions except that they occurred on different days. In all GoPro videos, the locations of the perches varied appearing both on and off camera. Only certain GoPro videos allowed for the desired data to be recorded. For example, of the 18 total GoPro videos recorded during session 1, three videos showed a clear landing path that could be traced and compared while only two videos captured the entire landing process allowing for the landing velocity to be recorded. For the free flight experiment, the GoPro camera captured the last three wing flaps taken by the bird leading up to touchdown on the perch. High-speed footage was captured during session 2, 3, and 4. Only certain high-speed videos allowed for the desired data to be recorded. Of all the footage, only one video captured three wing flaps leading up to the touchdown. For reference purposes, the flaps have been labeled Wing Flap A, Wing Flap B, Wing Flap C. This progression can be visualized in Figure 33.

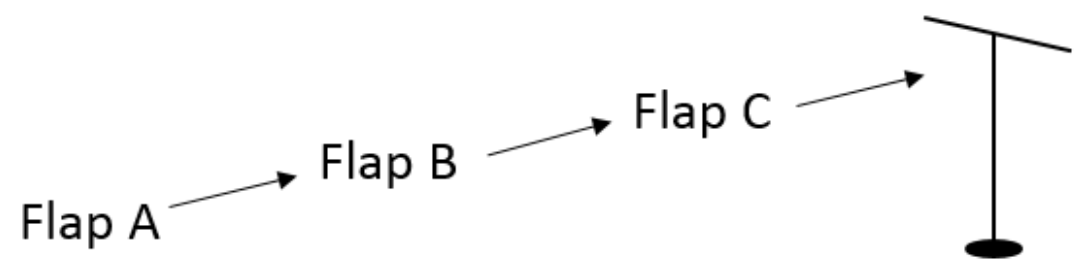

Figure 33. Progression of Wing Flaps Leading up to touchdown on the perch.

During the free flight experiment a few general observations were made. The covert feathers on the birds back become more active as wings rotated up increasing the angle of attack while approaching the perch. Feather frequency decreases as the bird begins to slow down when landing. The high-speed cameras allowed for particular feather trends to be observed. Covert feather motion begins at the leading edge of the wing and travels to the trailing edge as shown in the Figure 34 with the green arrows. Figure 35 displays a series of frames taken from high-speed footage that shows the progression of the feather motion as it travels down the wing from the leading edge to the trailing edge denoted $\mathrm{a}, \mathrm{b}, \mathrm{c}$, and $\mathrm{d}$. The locations of the feather motion are also referenced in Figure 34 using red letters a, b, c, and d which correlate with the progression in Figure 35. 


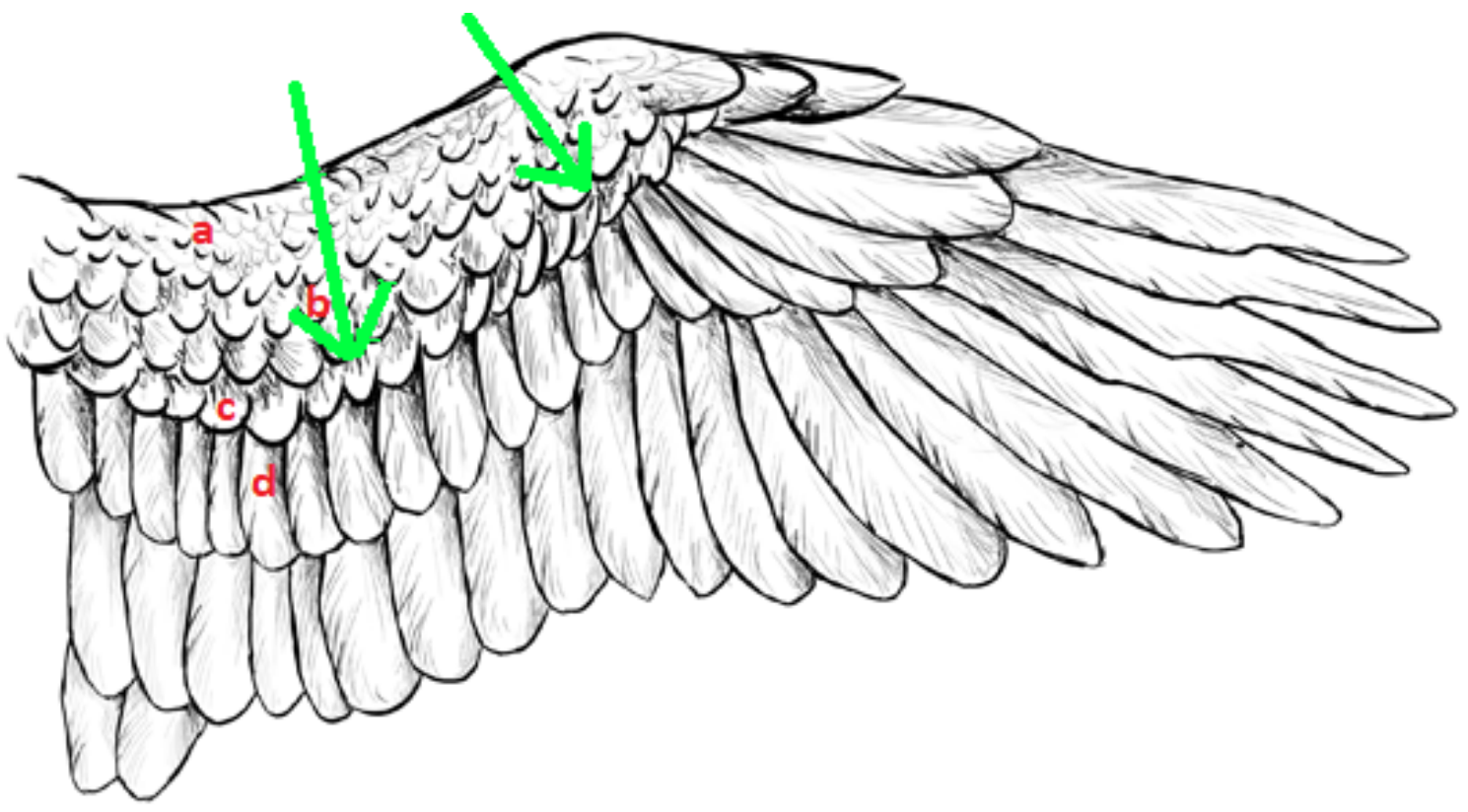

Figure 34. Direction of covert feather movement. Diagram was produced using a sketch of an avian wing previously created [34]. 


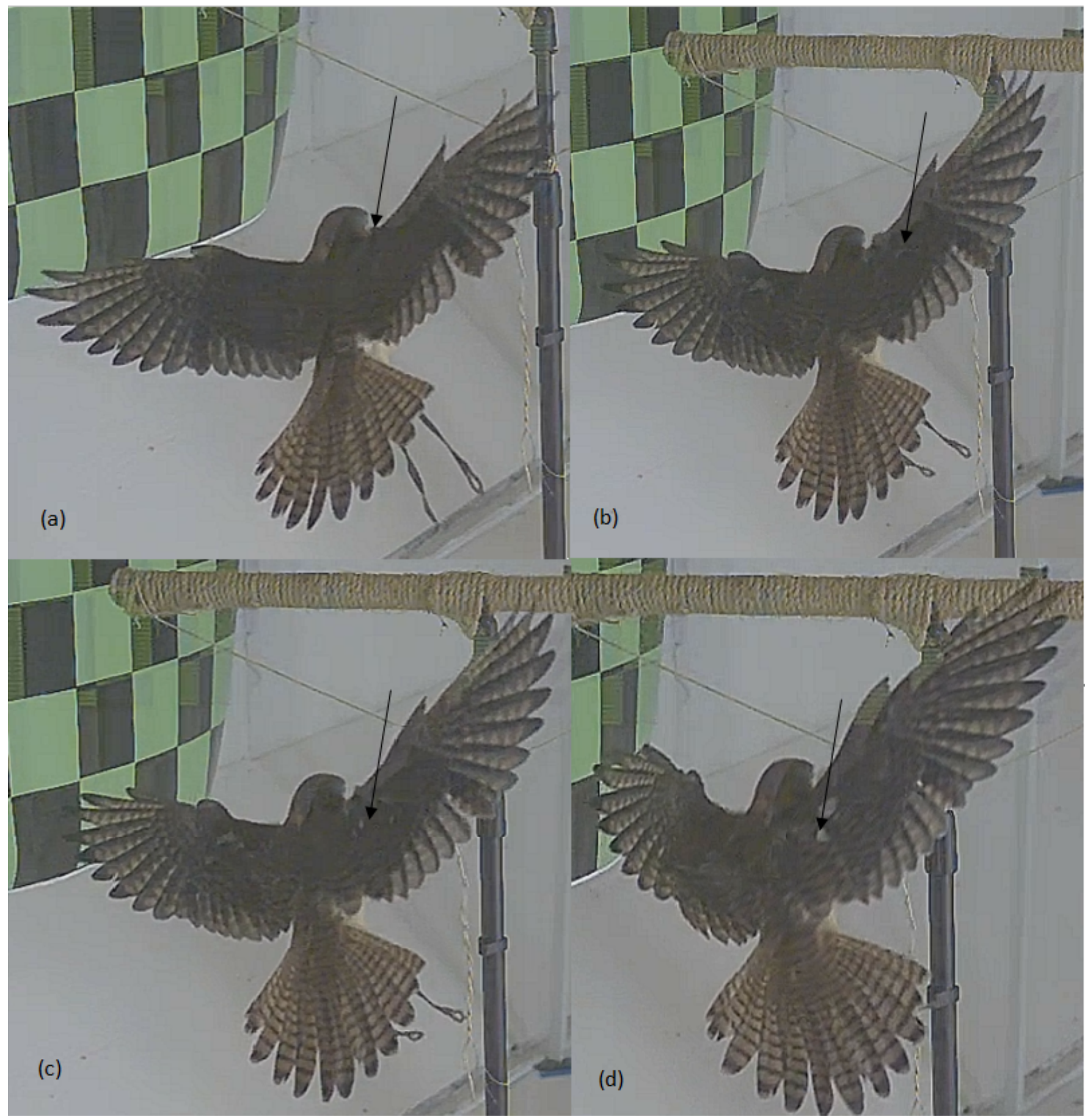

Figure 35. Series of frames taken from high-speed footage showing how the feather movement travels from the leading edge to the trailing edge.

As the bird approaches the landing perch, the angle of attack of the wings are increasing as shown in Figure 35. After some investigation, it was also observed that when the American kestrel lands, it swoops to one side (predominantly right). Figure 36 shows an example of the bird creating 
a dome with its wings as it approaches the landing perch. This was observed in multiple flights where the bird landed on a lower perch than it had taken off from.

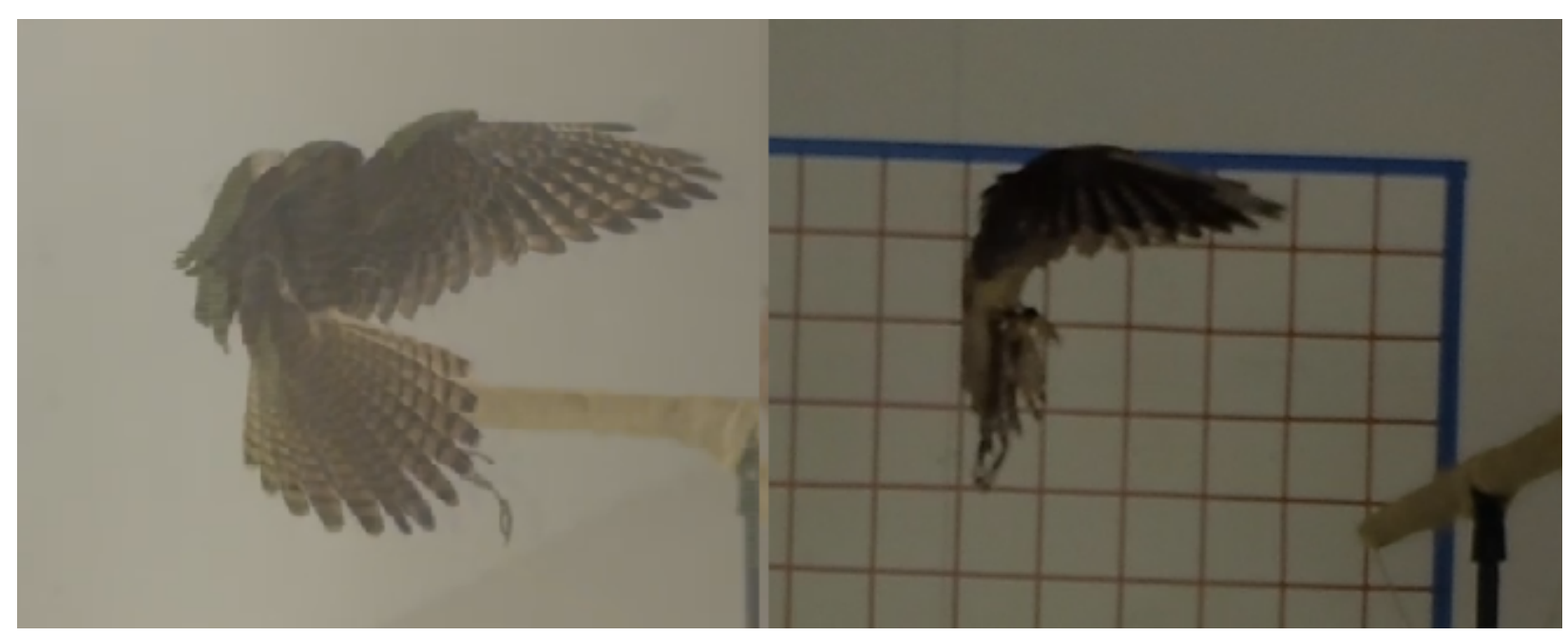

Figure 36. Example of dome created by the wings and tail of the bird when landing on a perch lower than its takeoff perch.

\subsubsection{Landing Velocity}

The landing velocity was recorded for six different flights during two sessions. All GoPro videos used for analysis included the bird's landing regime when it reached its lowest vertical distance from the floor (bottoming out) and then touchdown onto the perch. Average velocities are as follows: Wing Flap A $=6.05 \mathrm{~m} / \mathrm{s}$, Wing Flap B $=4.85 \mathrm{~m} / \mathrm{s}$, and Wing Flap C=3.72 m/s. Data included in Table 4 and Table 5 can be referenced in Appendix A.

Table 4. Velocity values recorded during session 1.

\begin{tabular}{|c|c|c|c|c|c|}
\hline \multicolumn{5}{|c|}{ Session 1 } \\
\hline Flight & Wing Flap A (m/s) & Vel. Change & Wing Flap B (m/s) & Vel. Change & Wing Flap C (m/s) \\
\hline 1 & 5.66 & $-15.37 \%$ & 4.79 & $-44.8 \%$ & 2.64 \\
\hline 2 & 5.55 & $-20.36 \%$ & 4.42 & $-36.96 \%$ & 2.78 \\
\hline 3 & 6.10 & $-10.48 \%$ & 5.46 & $-25.33 \%$ & 4.08 \\
\hline
\end{tabular}


Table 5. Velocity values recorded during session 2.

\begin{tabular}{|c|c|c|c|c|c|}
\hline \multicolumn{7}{|c|}{ Session 2 } \\
\hline Flight & Wing Flap A (m/s) & Vel. Change & Wing Flap B (m/s) & Vel. Change & Wing Flap C (m/s) \\
\hline 1 & 7.08 & $-28.15 \%$ & 5.09 & $-16.34 \%$ & 4.26 \\
\hline 2 & 6.29 & $-40.27 \%$ & 3.76 & $+11.5 \%$ & 4.19 \\
\hline 3 & 5.55 & $+0.757 \%$ & 5.59 & $-21.65 \%$ & 4.38 \\
\hline
\end{tabular}

Perch distances and landing times are listed in Table 6 and Table 7. It is important to remember that the landing time was recorded from the point of bottoming out to when the birds' feet touch the perch. Frequencies were not affected by the change in perch distance. Based off of Table 6 and Table 7, there is no significant change in the landing time when perch distance changes. When the bird took off from the perch that was higher than the landing perch, the bird was unable to bottom out. This made it difficult to determine the landing time which is why no data is listed for these flights.

Table 6. Flight data for session 1.

\begin{tabular}{|c|c|c|}
\cline { 2 - 3 } \multicolumn{1}{c|}{} & Perch Distance $(\mathrm{ft})$ & Landing Time $(\mathrm{s})$ \\
\hline Flight 1 & 24 & 0.50 \\
\hline Flight 2 & 24 & 0.52 \\
\hline Flight 3 & 28 & 0.62 \\
\hline
\end{tabular}

Table 7. Flight data for session 2.

\begin{tabular}{|c|c|c|}
\cline { 2 - 3 } \multicolumn{1}{c|}{} & Perch Distance (ft) & Landing Time (s) \\
\hline Flight 1 & 42 & 0.56 \\
\hline Flight 2 & 44 & 0.68 \\
\hline Flight 3 & 46 & 0.72 \\
\hline
\end{tabular}

Figure 37 shows the magnitude of the velocity of the bird during the landing regime for session 1. Figure 38 shows the total velocities of the bird during the landing regime for session 2. For both sessions, the velocity profiles are very similar to each other. 


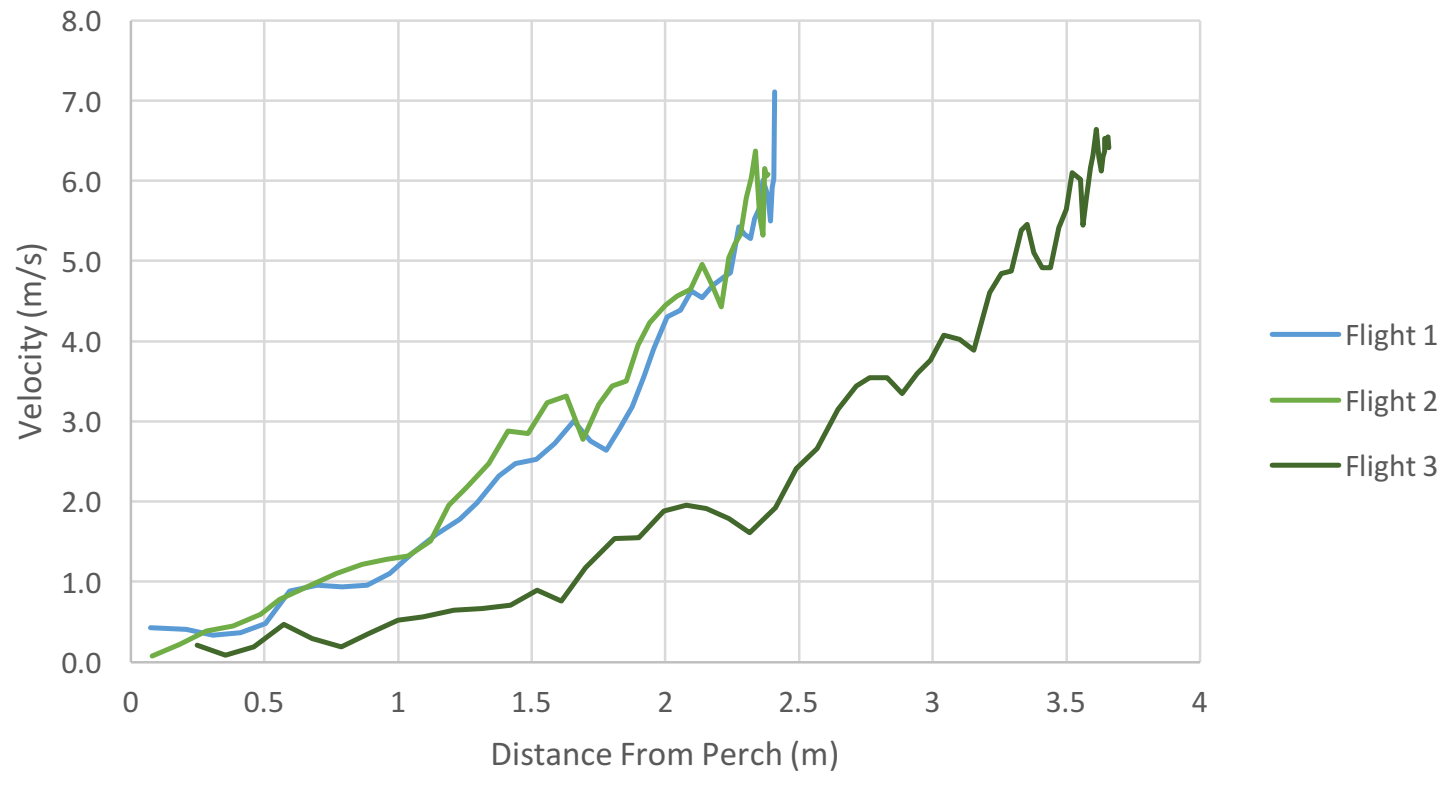

Figure 37. The magnitude of the velocity of the bird approaching and landing on perch: session 1. 


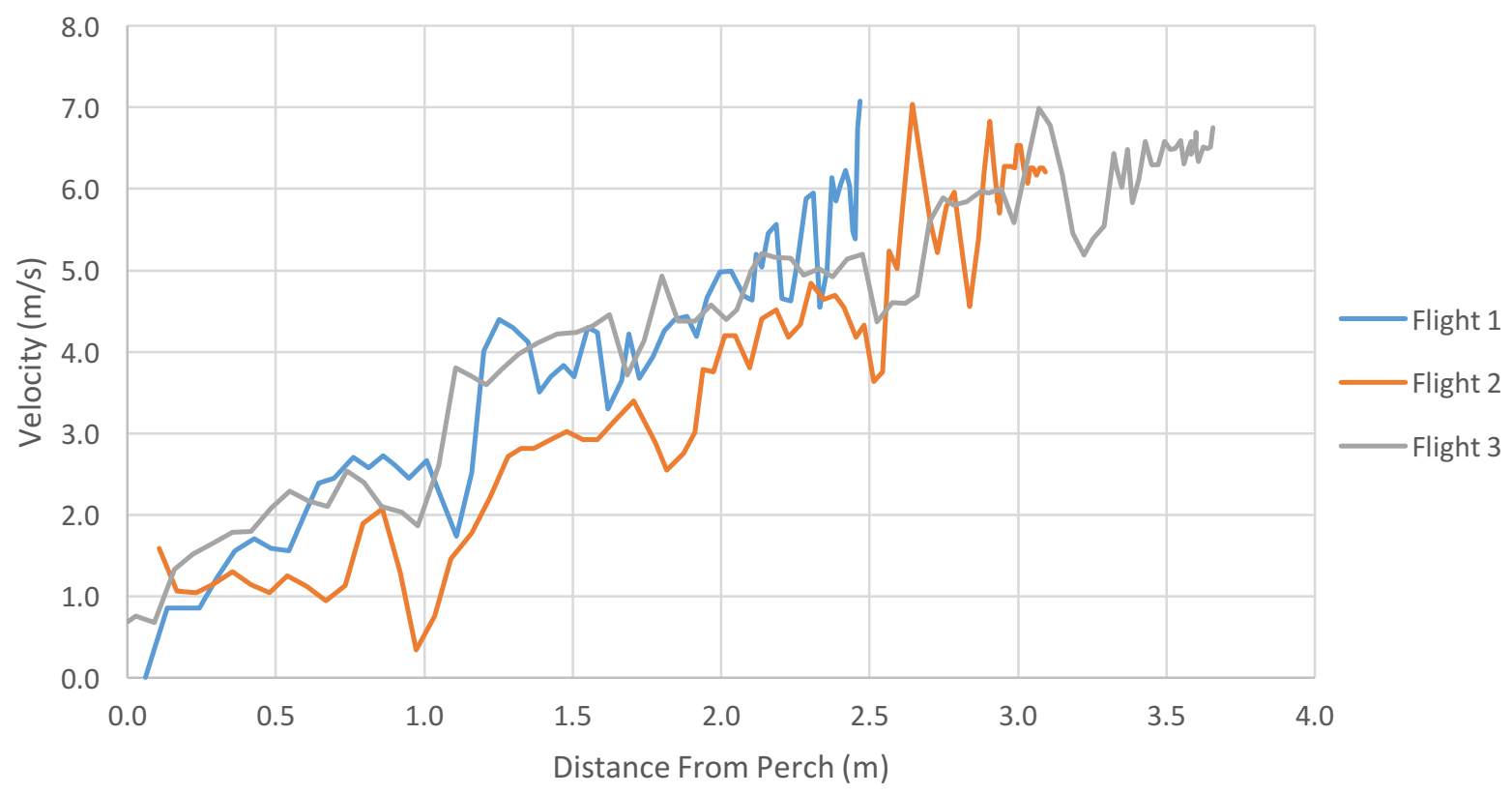

Figure 38. The magnitude of the velocity of bird approaching and landing on perch: session 2.

Figure 39 and Figure 40 display the landing profile as the bird approaches and lands on the perch for all flights recorded during session 1 and session 2, respectively. Both figures show that the landing profiles generally following the same trend. 


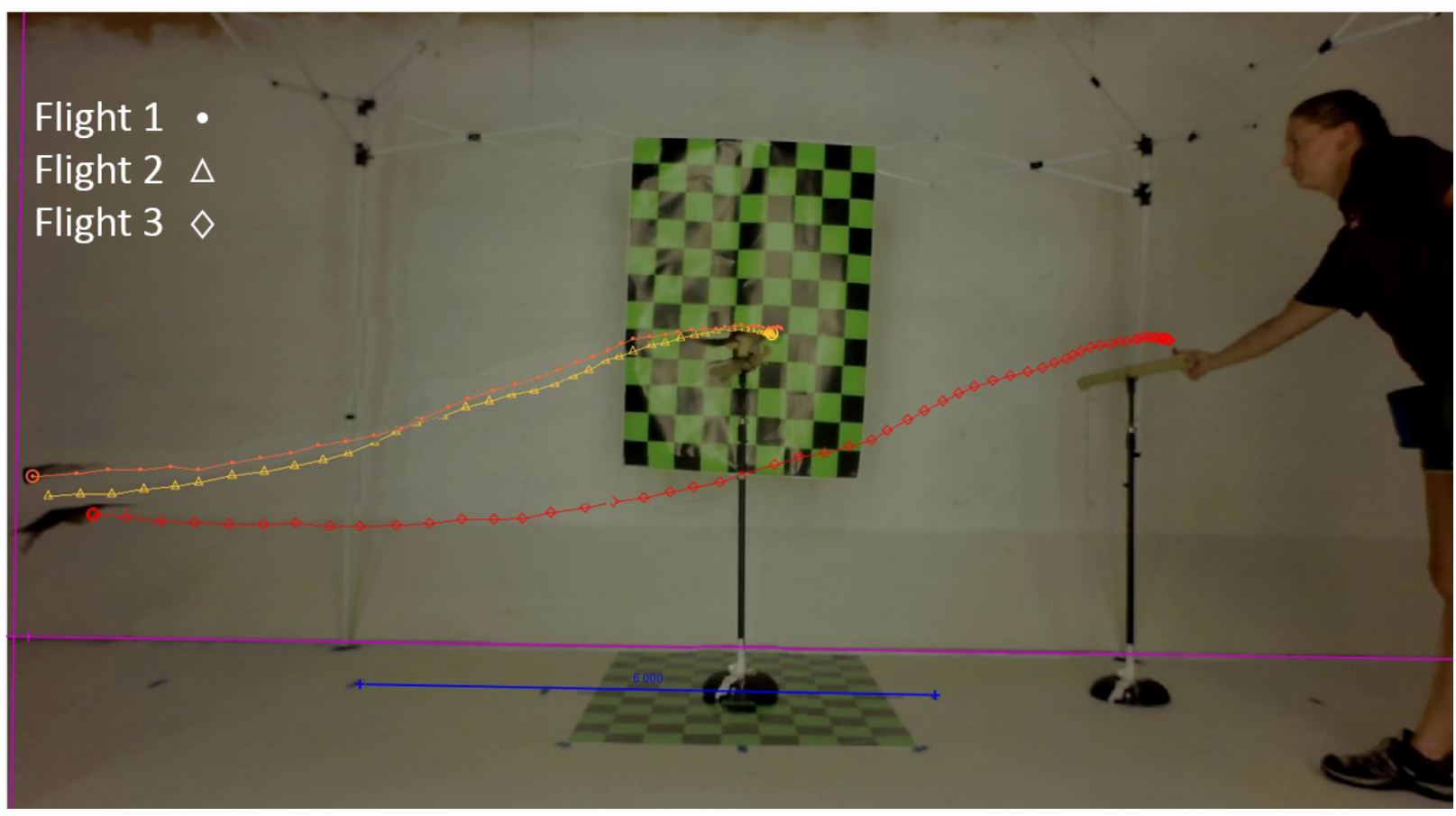

Figure 39. Overlay of landing profiles occurring during session 1.

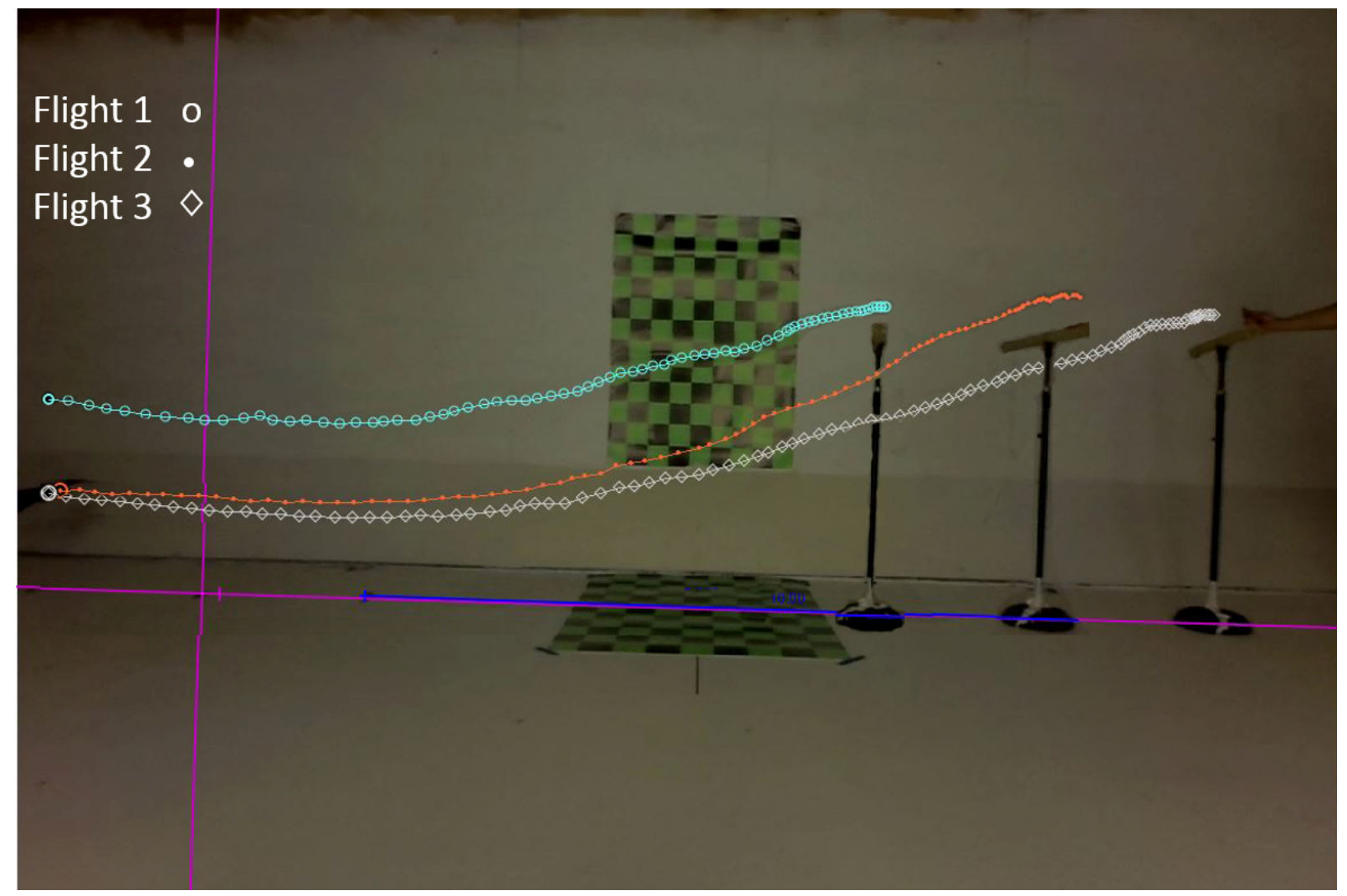

Figure 40. Overlay of landing profiles occurring during session 2. 
Flight 1 displays a path that is much higher than the others. This could be due to the perch distance.

\subsubsection{Feather Frequency}

For frequency analysis, a total of nine high-speed videos were used taken over three sessions. Four of the videos only captured the last wing flap before touch down, four of the videos captured the last two wing flaps before touch down, and only one captured the last three wing flaps before touch down. All frequency data tables can be referenced in Appendix B.

Note that the average velocities found using GoPro footage for flap A, flap B, flap C are $6.04 \mathrm{~m} / \mathrm{s}, 4.85 \mathrm{~m} / \mathrm{s}, 3.72 \mathrm{~m} / \mathrm{s}$ respectively. Of all the high-speed footage taken during session 4 , only one video captured three wings flaps leading up to the touch down. Table 8 shows this frequency data which can be referenced in Appendix B, wing region, wing flap, and the average velocity at the beginning of each wing flap previously obtained. Table 8 includes all frequency values recorded during this particular video. Based off of all frequency data, the minimum frequency recorded was $21.39 \mathrm{~Hz}$, the maximum frequency recorded was $81.63 \mathrm{~Hz}$, and the average was $42.69 \mathrm{~Hz}$. It is interesting to note that though the feathers are capable of achieving this average $42.69 \mathrm{~Hz}$, it was observed that the covert feathers only oscillated between 1 and 3 times per wing flap. Coverts in regions 1 and 4 move approximately 1 to 3 times per flap (during landing) while coverts in the 2, 3, and lower regions of the wing move between 2 and 3 times per flap (during landing).

Table 8. Frequency data: session 4.

\begin{tabular}{|c|c|c|c|}
\hline Wing Flap & Wing Region & Av. Velocity $(\mathrm{m} / \mathrm{s})$ & Frequency $(\mathrm{Hz})$ \\
\hline A & 1 & 6.04 & 21.39 \\
\hline A & 2 & 6.04 & 55.56 \\
\hline B & 1 & 4.85 & 21.26 \\
\hline B & 2 & 4.85 & 37.04 \\
\hline B & 3 & 4.85 & 26.32 \\
\hline B & 4 & 4.85 & 37.04 \\
\hline C & 1 & 3.72 & 38.46 \\
\hline C & 3 & 3.72 & 30.30 \\
\hline C & 4 & 3.72 & 45.45 \\
\hline
\end{tabular}


Figure 41 displays the frequency versus the average velocity. As the bird gets closer to the perch, its velocity decreases. It can be seen from the graph that, in general, as the bird approaches the perch, the feather frequency increases. The data points have a specific color to identify in what region the feather frequency occurred. Green represents region 1, yellow represents region 2, blue represents region 3, and red represents region 4. Wing regions can be referenced in Figure 31. Of the 48 feather frequencies recorded, 13 occurred in region 1, 13 occurred in region 2, 13 occurred in region 3, and 9 occurred in region 4.

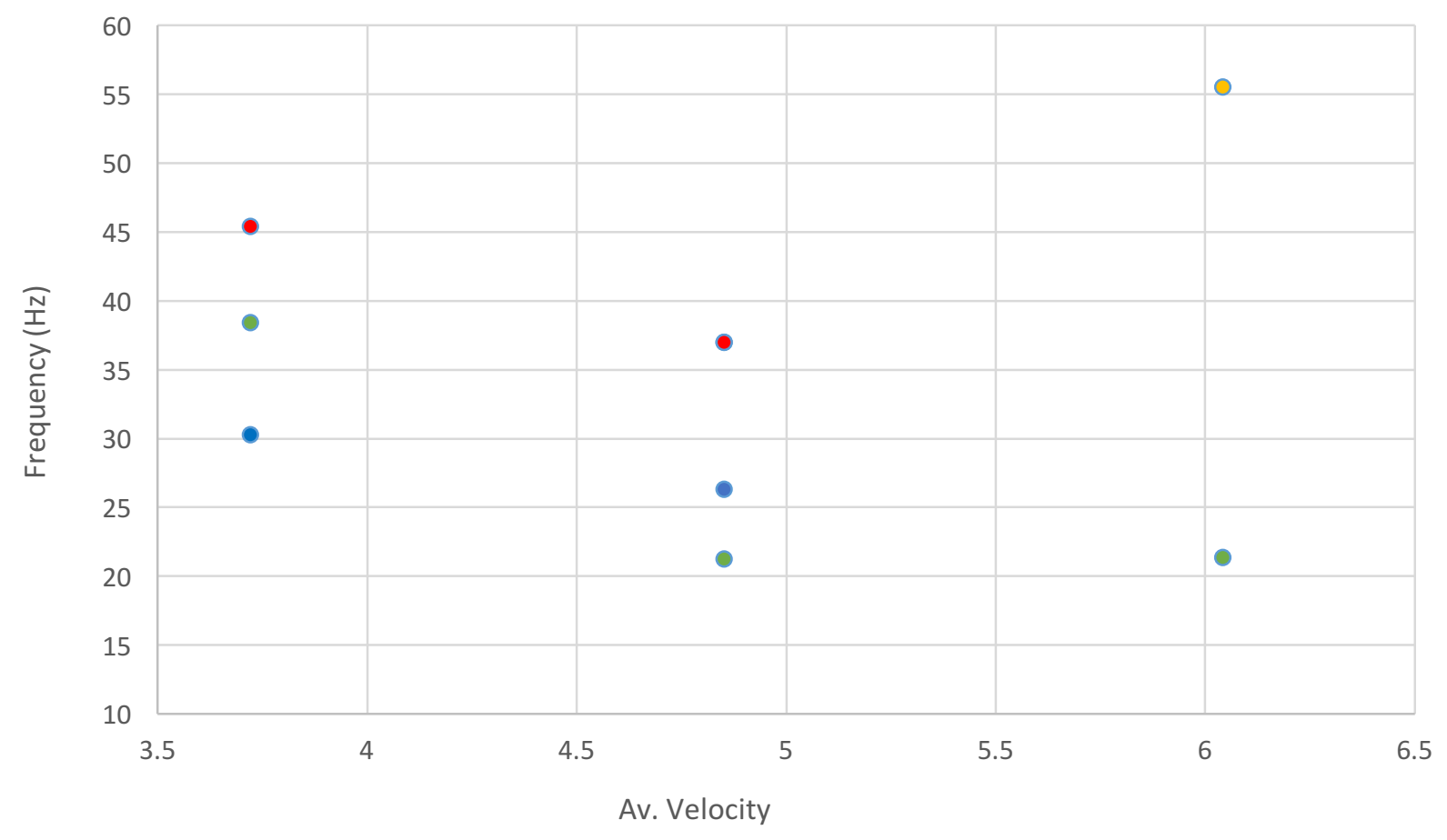

Figure 41. Frequency vs. Av. Velocity based off of Table 8.

\subsection{Wind Tunnel Experiment Using Cadaver Wing}

The wing was tested at static angles ranging between 0 to 55 degrees angle of attack at 5degree intervals and varying velocities in the test section ranging from $4.99 \mathrm{~m} / \mathrm{s}$ to $9.12 \mathrm{~m} / \mathrm{s}, \mathrm{Re}$ number between 56,801 and 103,768. The wing was also tested while oscillating at varying motor RPMs ranging between 62 RPM and 114 RPM which was within the pitching rate of the live bird wing (59 RPMs-131.1 RPMs). It is important to note that the preserved wing was first tested at static angles and while pitching the wing at each set RPM with the test section velocity at $0 \mathrm{~m} / \mathrm{s}$. All tests with velocity held at $0 \mathrm{~m} / \mathrm{s}$ yielded no feather movement which means that the rotational motion of the wing had no effect on the frequency. Upon completion of the static and dynamic 
angle testing in the wind tunnel, an ANOVA was performed by Patrick Browning, $\mathrm{PhD}$ at West Virginia University.

\subsubsection{Feather Frequency for Static Angles of Attack}

Frequencies were recorded at ten velocity intervals between $4.99 \mathrm{~m} / \mathrm{s}$ and $9.12 \mathrm{~m} / \mathrm{s}$, or Re number between 56,801 and 103,768. Velocity intervals were kept small in hopes that any change in flight could be traced to a critical point. At each velocity interval, the wing was pitched from 0 to 55 degrees angle of attack at 5-degree intervals. Feather motion was not observed in all wing regions for each set angle during any set test section velocity.

To conduct dimensional analysis of the feather frequencies, a dimensionless number had to be used. The Strouhal number $(\mathrm{St})$ is a dimensionless number that is used to evaluate oscillating unsteady fluid flow problems and can be expressed as

$$
S t=\frac{f D}{U}
$$

where $f$ is the oscillating frequency, $\mathrm{D}$ is the MAC, and $\mathrm{U}$ is the flow velocity. As shown in Figure 42, the Strouhal number mainly falls between 0.2 and 0.6 as Re number increases. Each point represents a feather frequency recorded during the static angle testing. All feather frequency data collected is shown. Of the 180 feather frequencies recorded, 35 occurred in region 1, 39 occurred in region 2, 82 occurred in region 3, and 24 occurred in region 4. It can be observed that as $R e$ number increases, the Strouhal number decreases. 


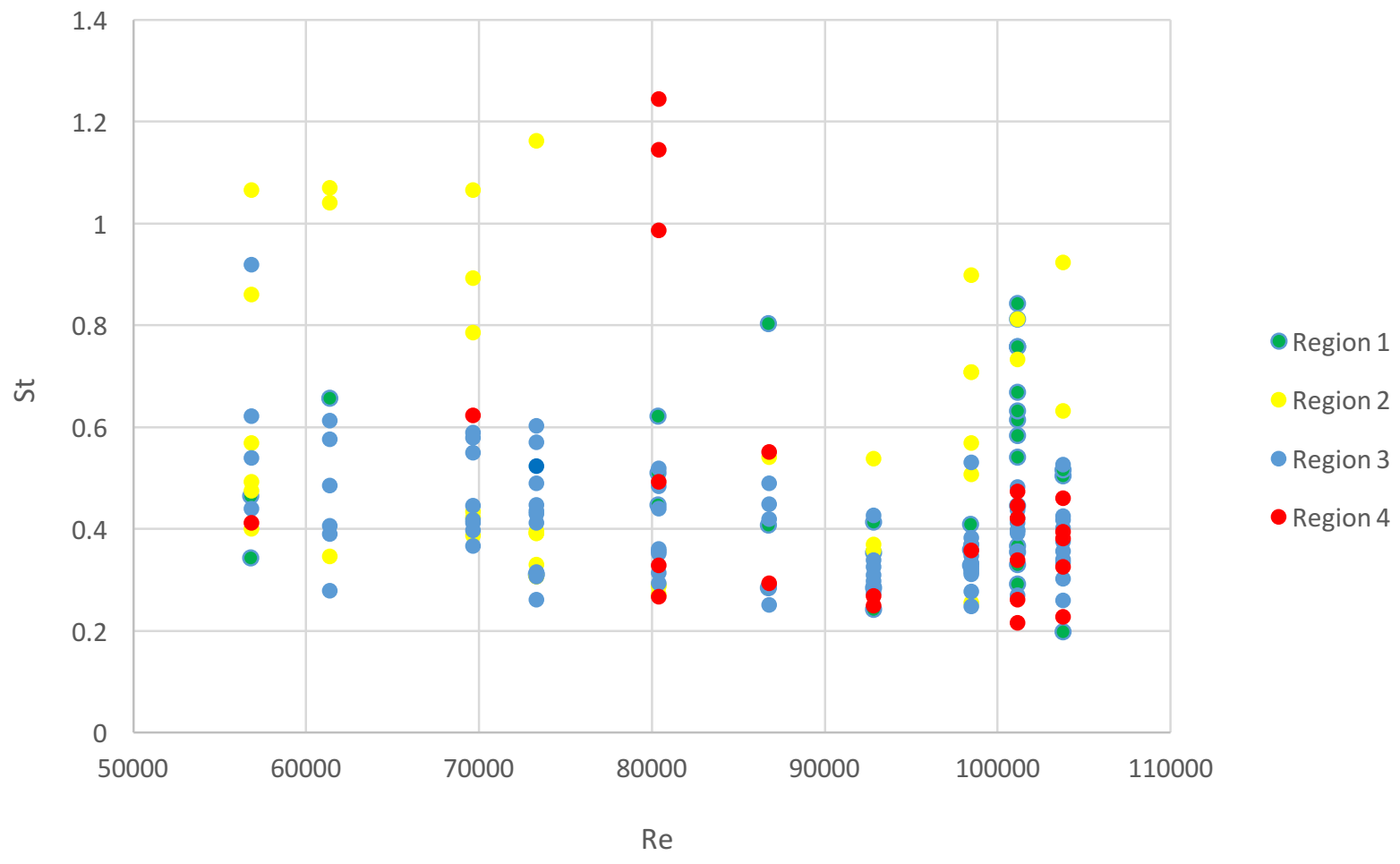

Figure 42. Static Testing: Measured Strouhal number as a function of Reynolds number for wing.

Figure 43 displays the wing region activity as the angle of attack increases. Each point represents a feather frequency data point. It can be seen that feather frequency begins in region 1 at 10 degrees angle of attack, in region 2 at 5 degrees angle of attack, in region 3 at 35 degrees angle of attack, in region 4 at 20 degrees angle of attack, and no activity in region 5 . Note that in region 2 data, only one feather frequency was collected at 5 degrees angle of attack while eight feather frequency occurrences were recorded at 15 degrees angle of attack. It can be concluded that there is a correlation between the angle of attack and location of feather frequency occurrences. 


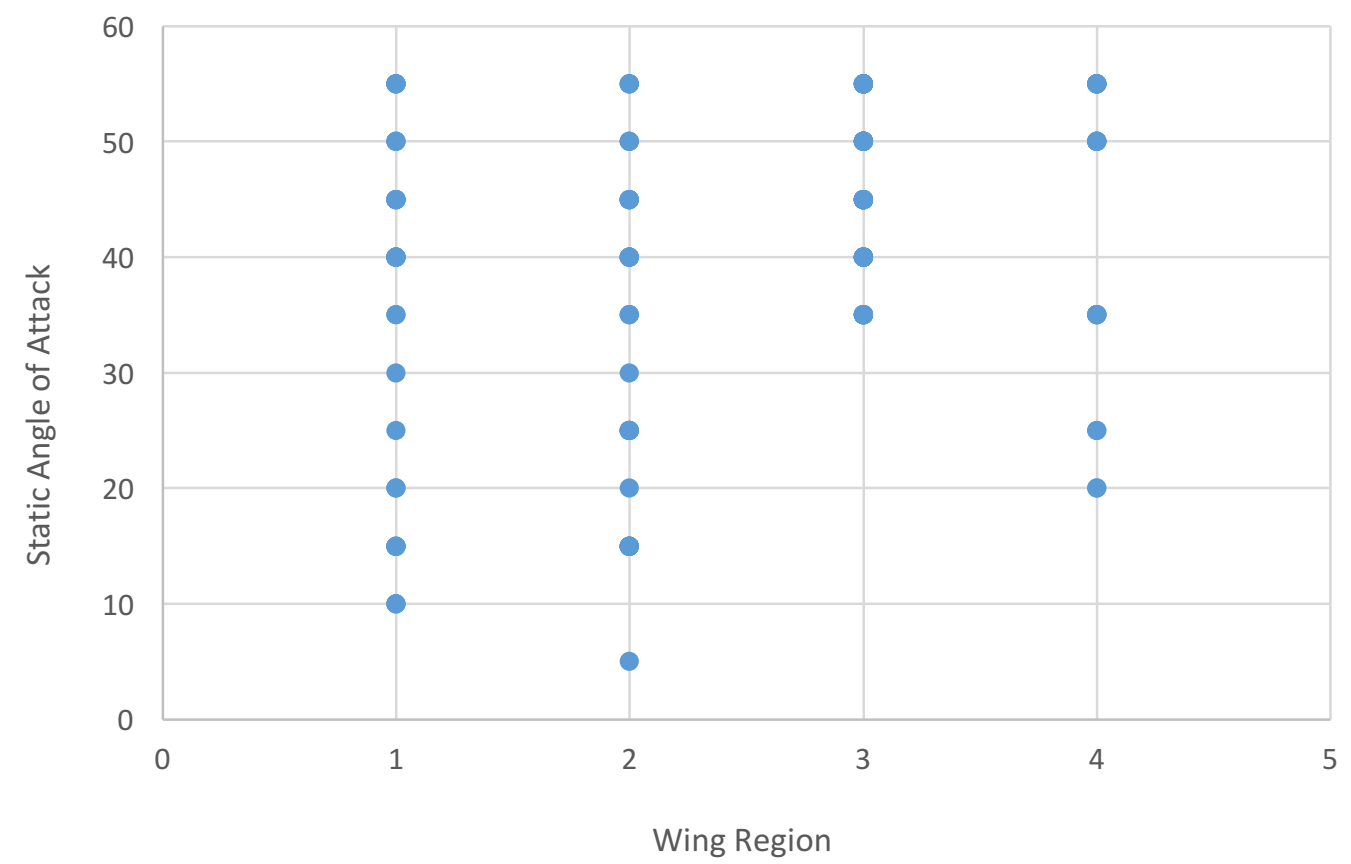

Figure 43. Static angle of attack vs. wing region showing region activity as angle of attack increases.

ANOVA stands for analysis of variance and is used to determine if results are significant by comparing the differences of means between 2 or more groups. For this analysis a null hypothesis, which states that the data sets or groups are not related, is used which depends on the $\mathrm{P}$ value located in the last column of the following ANOVA tables. If the P value is greater than 0.05 then the null hypothesis holds true but if the $\mathrm{P}$ value is less than 0.05 then the null hypothesis gets rejected. Table 9 displays the ANOVA results for feather frequency correlation to angle of attack and Reynolds numbers for the static test data and Table 10 displays the ANOVA results for the feather location correlation to the angle of attack and Reynolds number for the static test data. For the static tests, the system treatments were angle of attack and Reynolds number while the measured system responses were the feather frequency and the feather activity location. It can be concluded from these ANOVA results that static angle of attack has a significant influence on feather frequency and has a significant influence on feather activity location. Figure 44 reinforces this trend. Reynolds number had no significant influence on feather activity location. 
Table 9. Static Testing: ANOVA results for feather frequency correlation to angle of attack and Reynolds number.

\begin{tabular}{|l|c|c|c|c|c|}
\hline Source & Sum Sq. & d.f & Mean Sq. & F & P \\
\hline Angle of Attack & 5535.3 & 10 & 553.534 & 27.92 & 0 \\
\hline Reynolds Number & 479.1 & 9 & 53.232 & 2.68 & 0.0062 \\
\hline Error & 3172.2 & 160 & 19.826 & & \\
\hline Total & 10058.4 & 179 & & & \\
\hline
\end{tabular}

Table 10. Static Testing: ANOVA results for feather activity location correlation to the angle of attack and Reynolds number.

\begin{tabular}{|l|c|c|c|c|c|}
\hline Source & Sum Sq. & d.f. & Mean Sq. & F & P \\
\hline Angle of Attack & 29.127 & 10 & 2.91272 & 3.73 & 0.0002 \\
\hline Reynolds Number & 5.155 & 9 & 0.57279 & 0.73 & 0.6769 \\
\hline Error & 124.781 & 160 & 0.77988 & & \\
\hline Total & 162.861 & 179 & & & \\
\hline
\end{tabular}

Figure 44 shows the frequency occurrences at static angles of attack. As the angle increases, feathers are activated in different regions of the wing.

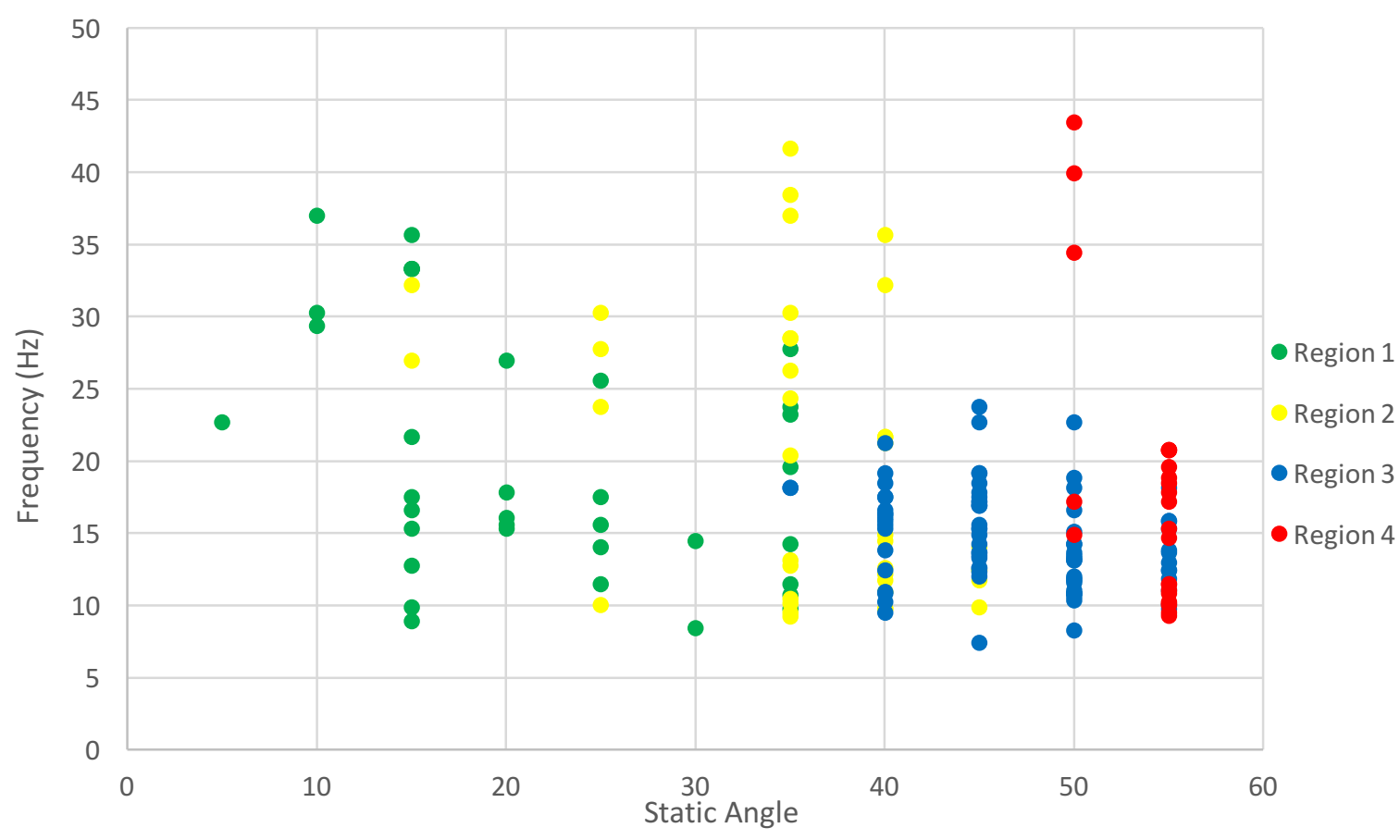

Figure 44. Frequency vs. static angle data including feather location. 


\subsubsection{Feather Frequency for Dynamic Angles}

For dynamic pitch up angles, frequencies were recorded at ten velocity intervals between $4.99 \mathrm{~m} / \mathrm{s}$ and $9.12 \mathrm{~m} / \mathrm{s}$, Re number between 56,801 and 103,768. At each velocity interval, the wing was pitched from 0 to 55 degrees angle of attack. Figure 45 shows that the St number mainly falls between 0.2 and 1.0 as Re number increases. Each point represents a feather frequency recorded during the dynamic angle testing. All feather frequency data collected is shown. Of the 299 feather frequencies recorded, 93 occurred in region 1, 10 occurred in region 2, 46 occurred in region 3, 127 occurred in region 4, and 23 occurred in region 5. It can be observed that as $\operatorname{Re}$ number increases, the St number decreases. The St range for dynamic data is much higher than that of the static data.

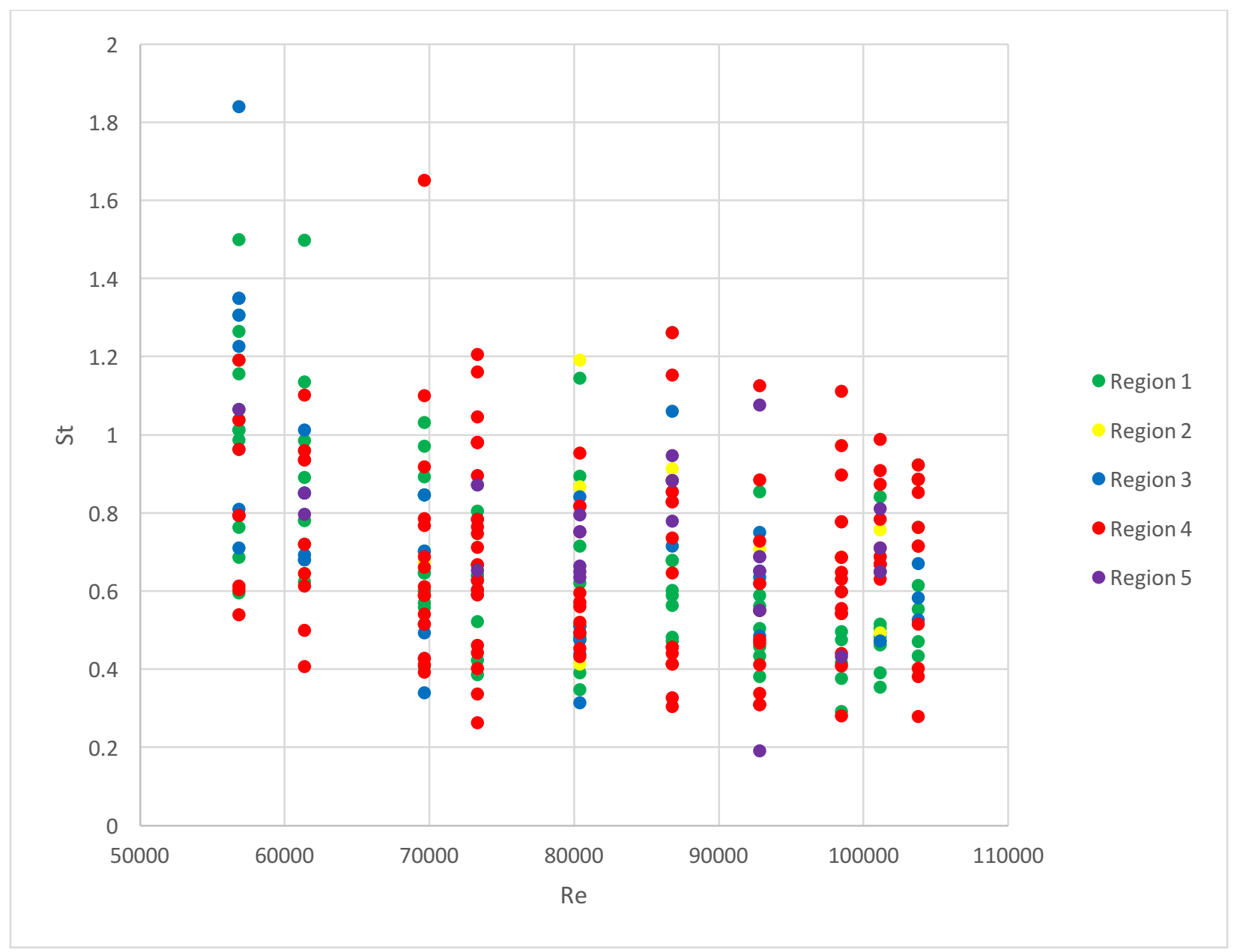

Figure 45. Dynamic Testing: Measured Strouhal number as a function of Reynolds number for wing.

Figure 46 displays the wing region activity as the angle of attack increases. Each point represents a feather frequency data point. From the data results, feather frequency begins in region 
1 at 23 degrees angle of attack, in region 2 at 22 degrees angle of attack, in region 3 at 36 degrees angle of attack, in region 4 at 25 degrees angle of attack, and in region 5 at 24.

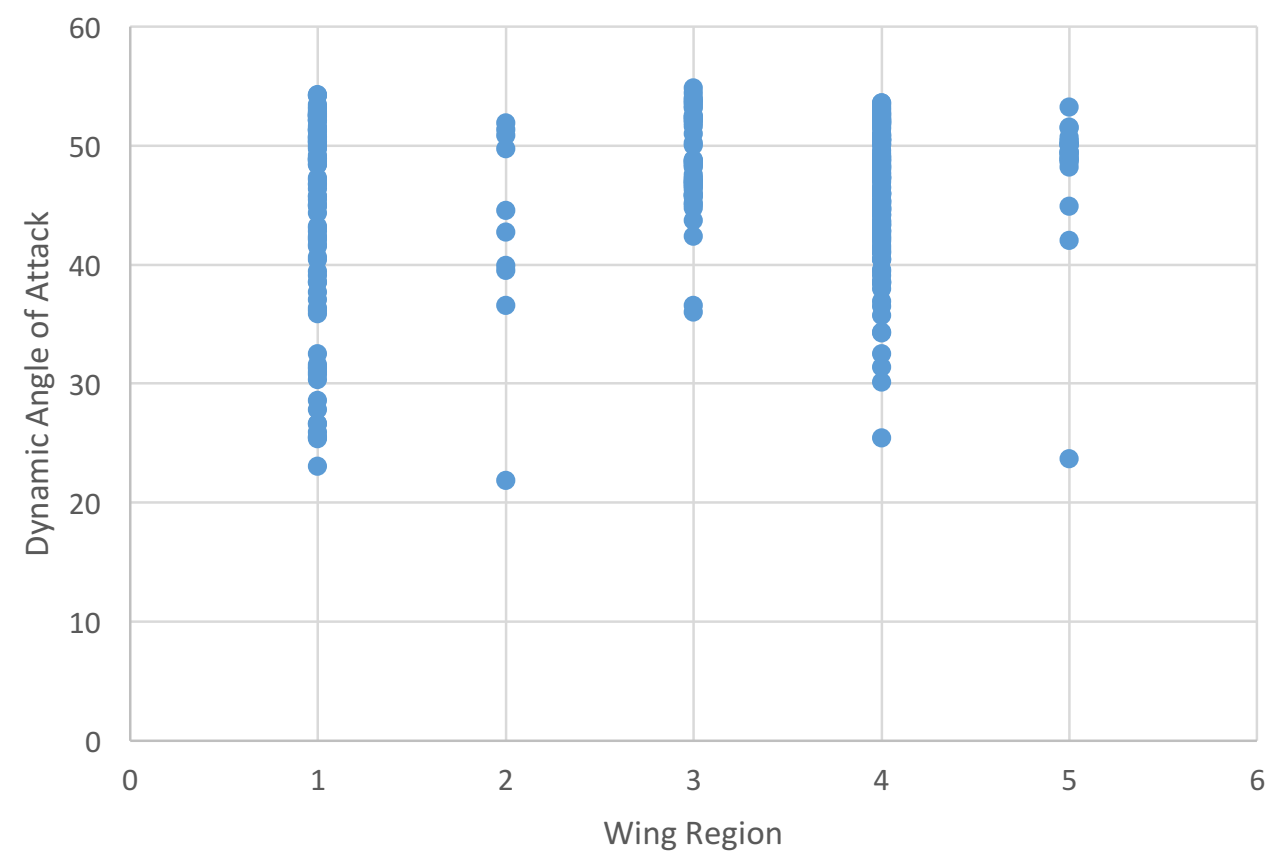

Figure 46. Dynamic angle of attack vs. wing region showing region activity as angle of attack increases.

Table 11 displays the ANOVA results for feather frequency correlation to the $10-\mathrm{Hz}$ binned pitching rate and Reynolds numbers for the dynamic test data. Data binning means to sort into smaller data sets. In doing so, the data will not have to be evaluated individually but in small "bins". Increasing the ranges within the smaller data sets allows for trends to emerge. For the dynamic tests the system treatments were pitching rate and Reynolds number. The measured system response was feather frequency. Binning was used to set treatment levels since the system treatments were non-recursive. Binning for the pitching rates was set in $10 \mathrm{~Hz}$ bins. A second run was completed with bins set at $25 \mathrm{~Hz}$. Binning gives more accurate results. Table 12 displays the ANOVA results for the feather frequency correlation to the $25-\mathrm{Hz}$ binned pitching rate and Reynolds number for the dynamic test data. Table 13 displays the ANOVA results for feather location to $10 \mathrm{~Hz}$ binned pitching rate and 10k-binned Reynolds number. Table 14 displays the ANOVA results for active feather frequency to $10 \mathrm{~Hz}$-binned pitching rate and 10k-binned Reynolds number. It can be concluded from this data that the pitching motion had no significant influence on feather frequency but did have a significant influence on feather activity location. It 
can also be concluded that Reynolds number has some influence on feather frequency but has no influence on feather activity location.

Table 11. Dynamic Testing: ANOVA results for feather frequency correlation to 10-Hz binned pitching rate and Reynolds number.

\begin{tabular}{|l|c|c|c|c|c|}
\hline Source & Sum Sq. & d.f & Mean Sq. & F & P \\
\hline Pitching Rate & 2858.5 & 38 & 75.223 & 1.23 & 0.1761 \\
\hline Reynolds Number & 1717.3 & 9 & 190.813 & 3.13 & 0.0014 \\
\hline Error & 15315.5 & 251 & 61.018 & & \\
\hline Total & 20502.3 & 298 & & & \\
\hline
\end{tabular}

Table 12. Dynamic Testing: ANOVA results for feather frequency correlation to 25-Hz binned pitching rate and Reynolds number.

\begin{tabular}{|l|c|c|c|c|c|}
\hline Source & Sum Sq. & d.f. & Mean Sq. & F & P \\
\hline Pitching Rate & 1637.2 & 18 & 90.956 & 1.49 & 0.0925 \\
\hline Reynolds Number & 2369.6 & 9 & 263.287 & 4.31 & 0 \\
\hline Error & 16536.8 & 271 & 61.021 & & \\
\hline Total & 20502.3 & 298 & & & \\
\hline
\end{tabular}

Table 13. Dynamic Testing: ANOVA results for feather location to 10-Hz binned pitching rate and 10k-binned Reynolds number.

\begin{tabular}{|c|c|c|c|c|c|}
\hline Source & Sum Sq. & d.f. & Mean Sq. & F & P \\
\hline Reynolds Number & 18.251 & 5 & 3.65018 & 1.95 & 0.0856 \\
\hline Pitching Rate & 41.822 & 6 & 6.97029 & 3.73 & 0.0014 \\
\hline Error & 536.186 & 287 & 1.86824 & & \\
\hline Total & 599.231 & 298 & & & \\
\hline
\end{tabular}

Table 14. Dynamic Testing: ANOVA results for active feather frequency to $10-\mathrm{Hz}$ binned pitching rate and 10k-binned Reynolds number.

\begin{tabular}{|c|c|c|c|c|c|}
\hline Source & Sum Sq. & d.f. & Mean Sq. & F & P \\
\hline Reynolds Number & 2293.6 & 5 & 458.717 & 6.24 & 0 \\
\hline Pitching Rate & 1192.1 & 6 & 198.679 & 2.7 & 0.0144 \\
\hline Error & 21108.3 & 287 & 73.548 & & \\
\hline Total & 24459.5 & 298 & & & \\
\hline
\end{tabular}

\subsection{Static, Dynamic, and Free Flight Data Comparison}

The 180 frequencies collected during all tests at static angles using the preserved wing ranged between $7.46 \mathrm{~Hz}$ and $43.48 \mathrm{~Hz}$ with the average being $17.30 \mathrm{~Hz}$. The most feather activity occurred 
in wing region 3. Figure 47 shows that the majority of the frequencies occurred between $12.00 \mathrm{~Hz}$ and $34.00 \mathrm{~Hz}$. The frequencies collected during all tests at dynamic angles using the preserved wing ranged between $8.00 \mathrm{~Hz}$ and $50.00 \mathrm{~Hz}$ with the average being $24.4 \mathrm{~Hz}$. The most feather activity occurred in wing region 4 . Figure 48 shows that the majority of the frequencies occurred between $10 \mathrm{~Hz}$ and $25 \mathrm{~Hz}$.

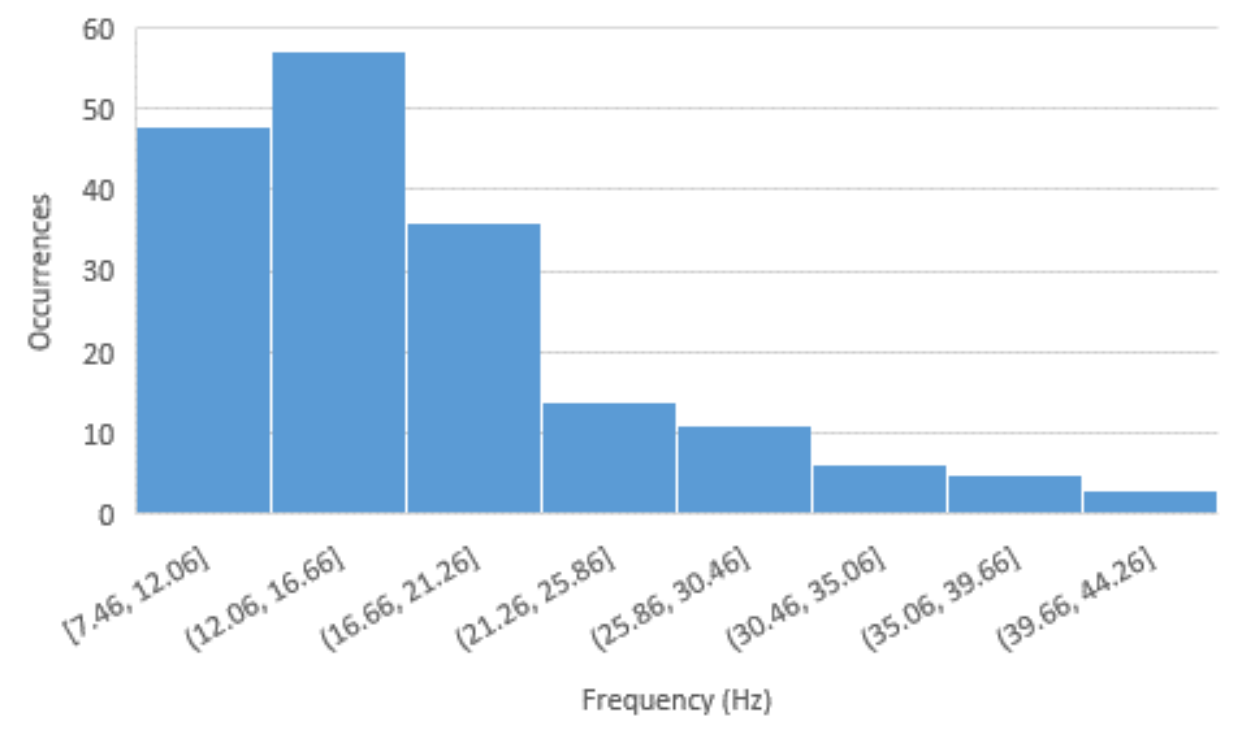

Figure 47. Distribution of 180 frequencies recorded during static angle testing.

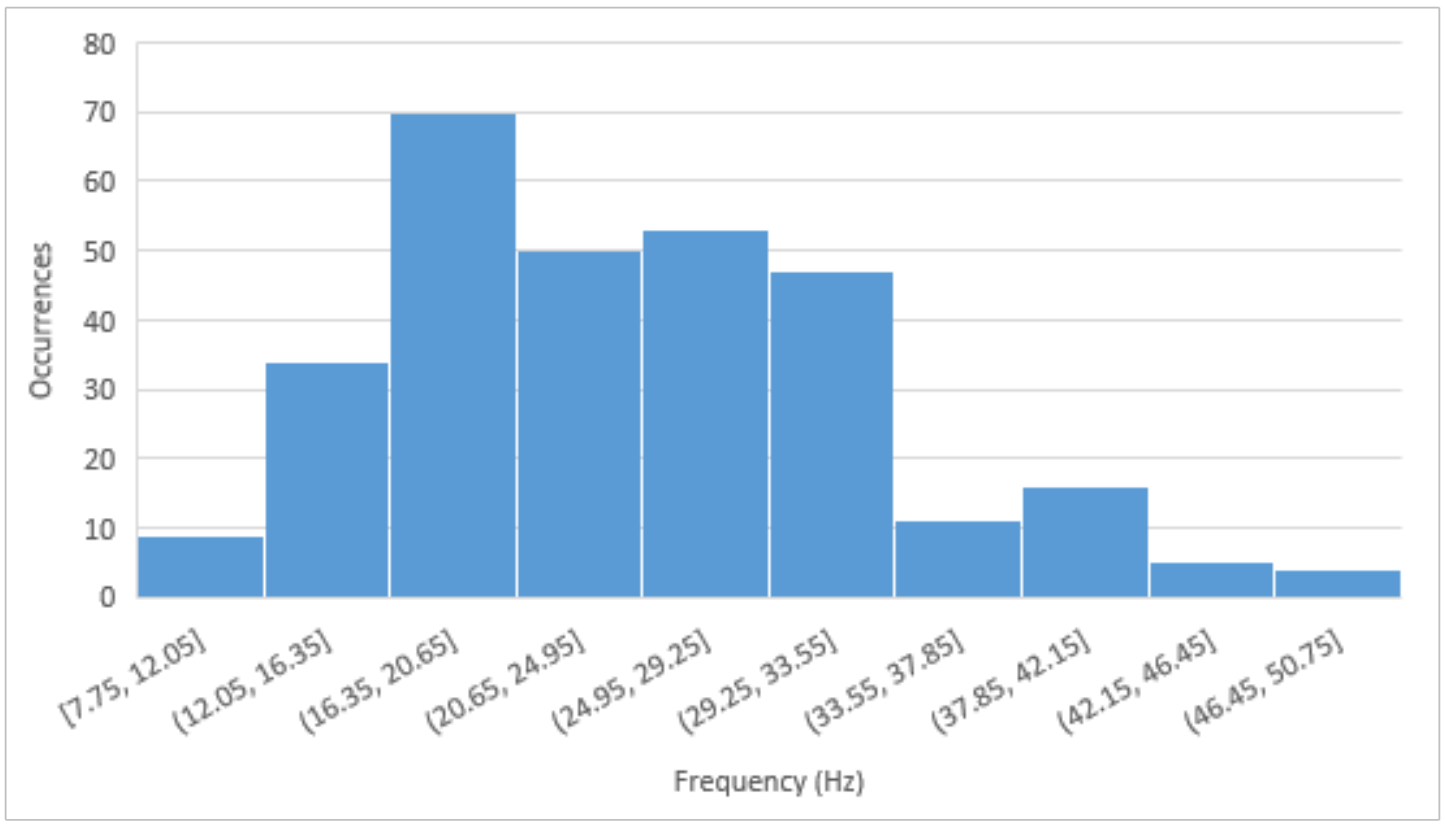

Figure 48. Distribution of 299 frequencies recorded during dynamic pitch testing. 
Based off of the number of feather frequencies recorded, more feather movement was observed during dynamic pitch testing than during static angle testing. Feather motion began at much higher angles of attack during dynamic pitch testing than static angle testing. Minimum, maximum, and average frequencies were slightly higher during the dynamic pitch testing than the static angle.

The frequencies collected during all free flight experiments ranged between $21.39 \mathrm{~Hz}$ and $81.63 \mathrm{~Hz}$ with the average being $42.69 \mathrm{~Hz}$. Figure 49 shows that the majority of the frequencies occurred between $21.26 \mathrm{~Hz}$ and $60.26 \mathrm{~Hz}$. Compared to the max, min, and average frequencies obtained during static and dynamic testing, the minimum and maximum values are much higher with the average falling in the middle between the static and dynamic values.

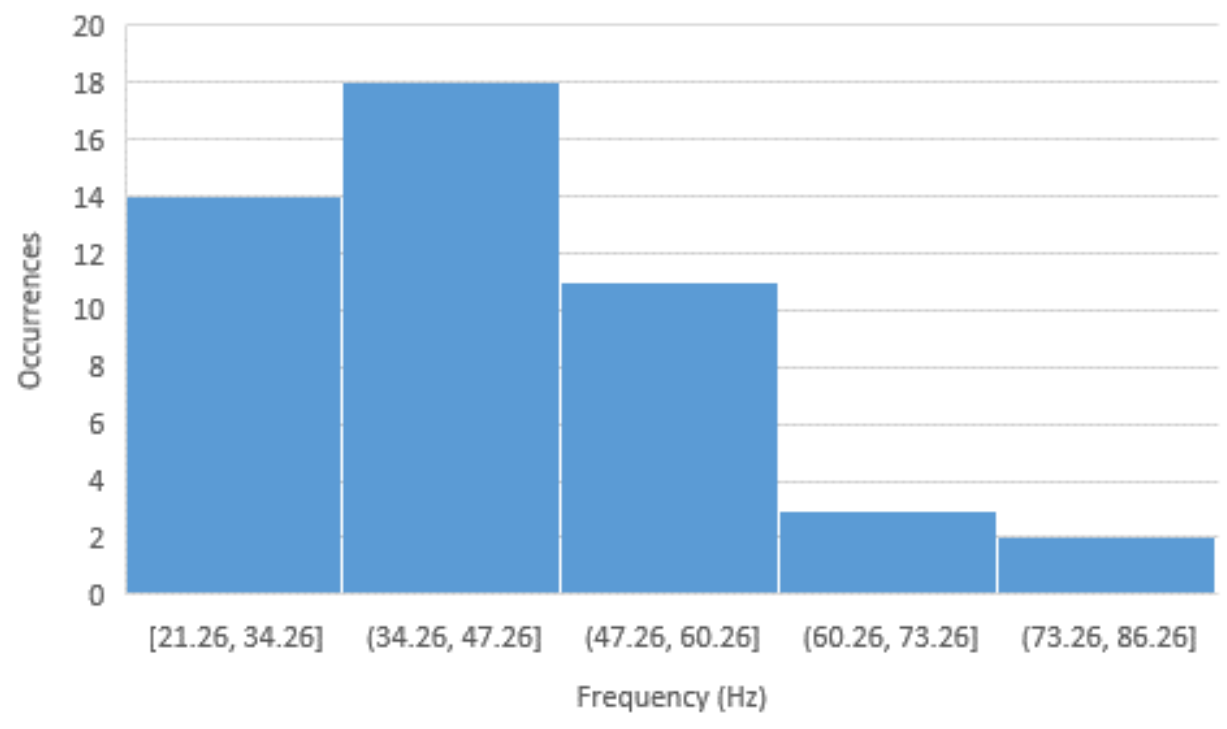

Figure 49. Distribution of 48 frequencies recorded during free flight testing.

\section{Chapter 6: Summary and Conclusions}

Footage captured of a live bird using a high-speed and GoPro cameras was analyzed. Landing velocity and feather frequency data was recorded. Feather frequencies ranged between $21.39 \mathrm{~Hz}$ and $81.63 \mathrm{~Hz}$. A preserved Red-tailed hawk wing was mounted in a wind tunnel and tested at varying static angles and pitching rates while the velocity of the air passing through the test section was varied. A high-speed camera was used to capture feather activity. Data from the live bird experiment and from the wind tunnel experiment were then compared. It was found that more feather activity was observed during dynamic pitch testing than during static angle testing. Feather motion began at much higher angles of attack during dynamic pitch testing than static angle testing. Minimum, maximum, and average frequencies were slightly higher during the 
dynamic pitch testing than the static angle. Compared to the max, min, and average frequencies obtained during the wind tunnel experiment, the minimum and maximum values obtained during the free flight experiment are much higher with the average falling in the middle between the static and dynamic values.

ANOVA was conducted on the data collated during the wind tunnel experiment, it was found that the pitching motion had no significant influence on the feather frequency while the static angle of attack did have a significant influence on the feather frequency. The pitching motion had a significant influence on the feather activity location. The static angle of attack also had a significant influence on the location of the feather frequency. The Re number of the air passing through the wind tunnel test section had some influence on the feather frequency during both dynamic and static testing but had no significant influence on the location of the feather frequency. The Re number had significant influence on the feather activity location.

Future research in this area may include:

- Development of a stronger support for cadaver wings. Tests could have included higher velocities but the wing began to bend under the stress of the flow.

- Study a wider range of raptors having different wing shapes. These studies would first observe the live bird and then replicate the same conditions using a cadaver wing from that specific type of bird.

- Study the same bird but at different times in the molting season. This would allow a better look into how the preexisting feather performance compares to post molting performance.

- Development of a pitching mechanism that would allow for high RPMs. The tests could have included higher RPMs but the mechanism would whip causing the wing to shake. 


\section{References}

[1] A. Fotouhi, M. Ding and M. Hassan, "Understanding autonomous drone maneuverability for Internet of Things applications", A World of Wireless, Mobile and Multimedia Networks (WoWMoM), 2017 IEEE 18th International Symposium on, pp. 1-6, 2017.

[2] M. Schatz, T. Knacke, F. Thiele, R. Meyer, W. Hage and D. W. Bechert, "Separation Control by Self-Activated Moveable Flaps", AIAA Journal, vol. 45, no.1, pp.191-199, 2007.

[3] I. J. Lovette and J. W. Fitzpatrick, "Handbook of Bird Biology," in The Cornell Lab of Ornithology, Wiley-Blackwell, 2016, p. 730.

[4] J. A. Smallwood and D. M. Bird, American Kestrel (Falco sparverius), The Birds of North America Online, Ithica: Cornell Lab of Ornithology, 2002.

[5] C. D. Griffin, P. H. Browning, S. D. Hamburg, J. Cox, E. Katzner, T. Katzner and W. W. Huebsch, "Free Flight Observations and Aerodynamic Analysis for Biologically- Inspired Optimization," $55^{\text {th }}$ AIAA Aerospace Sciences Meeting, AIAA SciTech Forum, (AIAA 20170501)

[6] D. Brown, "Tracker," 2017. [Online]. Available: https://physlets.org/tracker/. [Accessed 8 October 2017].

[7] W. W. Orville Wright, "Flying - Machine". Patent 821, 393, 1906.

[8] J. F. Keane and S. S. Carr, "A Brief History of Early Unmanned Aircraft," Johns Hopkins APL Technical Digest, vol. 32, no. 3, 2013.

[9] A. Smith, Pawlicki, JM, L. Pease, T. Startz, C. Pierce and Y. Zhang, "The Effect of Molluscan Glue Protein on Gel Mechanics," The Journal of Experimental Biology, vol. 207, pp. 1127-1135, 2004.

[10] H. Y. S. H. Li, "Fabrication of Cuo Hierarchical Flower Like Structures with Biomimetic Superamphiphobic, Self Cleaning and Corrosion Resistance Properties," Chemical Engineering Journal, vol. 283, p. 11, 2016.

[11] T. B. Institute, "The Biomimcry Institute," 2017. [Online]. Available: https://biomimicry.org/. [Accessed 23 June 2017].

[12] W. Liebe, "Der auftrieb am tragflügel: Entstehung und zusammenbruch," Aerokurier, pp. 1520-1523, 1979. 
[13] J. Wang and J. Schluter, "Stall control with feathers: Self-activated flaps on finite wings," Mecanique, vol. 340, no. 1-2, pp. 57-66, 30 December 2011.

[14] A. A. Biewener, "Muscle Function in Avian Flight: Achieving Power and Control," Philisophical Trasnactions of the Royal Society B, vol. 366, no. 1570, pp. 1496-1506, 2011.

[15] M. Gamez, "Digital Photography Forums," 28 April 2009. [Online]. [Accessed 24 November 2017].

[16] R. Grasfield, "AVES (birds)," 2010. [Online]. Available: https://sharon-taxonomy2010p6.wikispaces.com/Chordata-Aves. [Accessed 23 November 2017].

[17] C. M. Perrins, C. J. Oliver and C. Ad, Birds: Their Life, Their Ways, Their World, Pleasantville, NY: Reader's Digest, 1979.

[18] J. M. Rayner, "A New Approach to Animal Flight Mechanics," Journal of Experimental Biology, vol. 80, no. 1, pp. 17-54, 1979.

[19] C. Carey, Avian Energetics Nutritional Ecology, New York: Chapman and Hall, 1996.

[20] C. D. Griffin, W. W. Huebsch, "Numerical and Experimental Study on the Ability of Dynamic Roughness to Alter the Development of a Leading Edge Vorte,", 32nd AIAA Applied Aerodynamics Conference, AIAA AVIATION forum, (AIAA 2014-2047)

[21] M. R. Visbal and J. S. Shang, "Investigation of the Flow Structure Around a Rapidly Pitching Airfoil," AIAA, vol. 27, no. 8, p. 8, 1989.

[22] C. Lab, Birds and their Wing Shapes, Ithaca, NY: The Cornell Lab of Ornithology.

[23] M. W. Group, "What Birds - American Kestrels," 2013. [Online]. Available: https://identify.whatbird.com/obj/58/_American_Kestrel.aspx. [Accessed 7 May 2017].

[24] M. W. Group, "What Birds - Red Tailed Hawk," 2013. [Online]. Available: http://identify.whatbird.com/obj/41/_target.aspx. [Accessed 7 May 2017].

[25] U. F. a. W. Service, "The Feather Atlas: Feather Identification and Scans-US Fish and Wild life Forensic Lab," 28 October 2015. [Online]. [Accessed 12 October 2016].

[26] G. Ruppell, Bird Flight, New York: Van Nostrand Reinhold, 1977. 
[27] Dr. Foster and Dr. Smith, "Bird Feather Types, Anatomy, Growth, Color, and Molting," Pet Education, 2017. [Online]. Available:

http://www. peteducation.com/article. $. \mathrm{fm} ? \mathrm{c}=15+1829 \&$ aid=2776. [Accessed 11 November 2016].

[28] S. Rohwer, R. E. Ricklefs, V. G. Rohwer and M. M. Copple, "Allometry of tyhe Duration of Flight Feather Molt in Birds," PLOSBiology, 16 June 2009. [Online]. Available: http://journals. plos.org/plosbiology/article?id=10.1371/journal.pbio.1000132. [Accessed 22 August 2017].

[29] ACCA, "Avian Conservation Center of Appalachia - Welcome," Wordpress, [Online]. Available: http://www.accawv.org/. [Accessed 17 July 2017].

[30] T. Pridle, E. Hepach and L. Tate, "Preserving Bird Wings, Tails, or Talons," 15 September 1998. [Online]. Available: http://www.nativetech.org/feather/featherpres.html. [Accessed 3 September 2017].

[31] J. A. Cox, "Comparitive Analysis of Unhibited and Contrained Avian Wing Aerodynamics", M.S. thesis, Dept. Mechanical and Aerospace Eng., West Virginia University, Morgantown, WV, 2016.

[32] Photron, "Photron Software," Photron, [Online]. Available: https://photron.com/softwaredownloads/. [Accessed 12 November 2017].

[33] R. Chambers and W. Chambers, Chambers's Encyclopedia: A Dictionary of Universal Knowledge, Pennsylvania: J.B. Lippincott Co., 1901.

[34] M. Zagrobelna, "Taking Flight: A Beginner's Guide Into Drawing Wings," 18 September 2013. [Online]. Available: https://design.tutsplus.com/articles/taking-flight-a-beginnersguide-into-drawing-wings--vector-15996. [Accessed 2811 2017].

[35] K. McCollough, "Americna Kestrel Falco sparverius," Animal Diversity Web. University of Michigan Musuem of Geology, 2001. [Online]. Available:

http://animaldiversity.org/site/accounts/information/Falco_sparverius.html. [Accessed 17 April 2018].

[36] R. H. Wauer, Naturally...South Texas, Austin, Texas: University of Texas Press, 2001.

[37] Phys.com, "Shape of Bird Wings Depends on Ancestors more than Flight Style," 5 November 2015. [Online]. [Accessed December 2016]. 


\section{Appendix A: Free Flight Velocity Tables}

The following tables list the time and velocity data generated using Tracker. Four flight tests occurred during session 1 and three flight tests occurred during session 2 .

Table 1: Session 1, GoPro Flight Test 1

\begin{tabular}{|c|c|c|c|c|}
\hline Description of Flight Phenomena & $t(s)$ & $\mathbf{v}_{x}(\mathbf{f t} / \mathbf{s})$ & $v_{\mathbf{y}}(\mathbf{f t} / \mathbf{s})$ & Magnitude v (m/s) \\
\hline \multirow[t]{4}{*}{ Gliding } & 0.02 & 23.19 & 2.38 & 7.12 \\
\hline & 0.03 & 19.71 & 1.73 & 6.03 \\
\hline & 0.05 & 19.36 & 1.12 & 5.91 \\
\hline & 0.07 & 18.05 & 0.14 & 5.50 \\
\hline \multirow[t]{2}{*}{ Bottom out } & 0.08 & 18.99 & 1.48 & 5.80 \\
\hline & 0.10 & 19.32 & 3.89 & 6.00 \\
\hline \multirow[t]{6}{*}{ Beginning of flap 1: wings at lowest points } & 0.12 & 18.24 & 3.51 & 5.66 \\
\hline & 0.13 & 17.63 & 4.23 & 5.52 \\
\hline & 0.15 & 16.92 & 3.73 & 5.28 \\
\hline & 0.17 & 17.16 & 3.38 & 5.33 \\
\hline & 0.18 & 17.27 & 4.34 & 5.42 \\
\hline & 0.20 & 14.97 & 5.39 & 4.84 \\
\hline \multirow[t]{10}{*}{ End of flap 1: Beginning of flap 2} & 0.22 & 14.23 & 6.70 & 4.79 \\
\hline & 0.23 & 13.99 & 6.46 & 4.69 \\
\hline & 0.25 & 13.88 & 5.38 & 4.53 \\
\hline & 0.27 & 14.50 & 4.42 & 4.62 \\
\hline & 0.28 & 13.78 & 4.17 & 4.38 \\
\hline & 0.30 & 13.29 & 4.77 & 4.30 \\
\hline & 0.32 & 11.85 & 4.87 & 3.90 \\
\hline & 0.33 & 10.77 & 4.49 & 3.55 \\
\hline & 0.35 & 9.69 & 3.87 & 3.18 \\
\hline & 0.37 & 8.73 & 3.86 & 2.90 \\
\hline \multirow[t]{8}{*}{ End of flap 2: beginning of flap 3} & 0.38 & 7.89 & 3.60 & 2.64 \\
\hline & 0.40 & 8.75 & 2.29 & 2.75 \\
\hline & 0.42 & 9.73 & 1.59 & 3.00 \\
\hline & 0.43 & 8.76 & 1.69 & 2.71 \\
\hline & 0.45 & 8.16 & 1.44 & 2.52 \\
\hline & 0.47 & 8.05 & 0.96 & 2.47 \\
\hline & 0.48 & 7.57 & 0.59 & 2.31 \\
\hline & 0.50 & 6.49 & 0.70 & 1.98 \\
\hline \multirow[t]{4}{*}{ Feet touched the perch } & 0.52 & 5.77 & 0.81 & 1.77 \\
\hline & 0.53 & 5.17 & 0.68 & 1.58 \\
\hline & 0.55 & 4.45 & -0.06 & 1.35 \\
\hline & 0.57 & 3.61 & -0.07 & 1.10 \\
\hline \multirow[t]{9}{*}{ End of flap 3: Beginning of stabilization } & 0.58 & 3.13 & 0.17 & 0.95 \\
\hline & 0.60 & 3.02 & -0.56 & 0.93 \\
\hline & 0.62 & 3.13 & -0.32 & 0.96 \\
\hline & 0.63 & 2.89 & -0.08 & 0.88 \\
\hline & 0.65 & 1.57 & -0.10 & 0.47 \\
\hline & 0.67 & 1.21 & -0.10 & 0.36 \\
\hline & 0.68 & 1.08 & 0.26 & 0.33 \\
\hline & 0.70 & 1.32 & 0.26 & 0.41 \\
\hline & 0.72 & 1.33 & -0.46 & 0.42 \\
\hline
\end{tabular}

**For future use using the same videos: reference 09/04/2014 - Side (5) 
Table 2: Session 1, GoPro Flight Test 2

\begin{tabular}{|c|c|c|c|c|}
\hline Description of Flight Phenomena & $t(s)$ & $\mathbf{v}_{x}(\mathbf{f t} / \mathbf{s})$ & $v_{y}(\mathbf{f t} / \mathbf{s})$ & Magnitude v (m/s) \\
\hline & 0.02 & 19.93 & 0.89 & 6.07 \\
\hline Bottom out & 0.03 & 19.79 & 1.73 & 19.87 \\
\hline \multirow[t]{2}{*}{ Wing rotates and reaches lowest point } & 0.05 & 20.02 & 2.58 & 20.19 \\
\hline & 0.07 & 17.26 & 2.66 & 17.46 \\
\hline \multirow[t]{7}{*}{ Beginning of flap 1} & 0.08 & 17.84 & 3.75 & 18.23 \\
\hline & 0.10 & 20.61 & 3.55 & 20.91 \\
\hline & 0.12 & 19.53 & 3.41 & 19.82 \\
\hline & 0.13 & 18.56 & 4.12 & 19.00 \\
\hline & 0.15 & 16.99 & 4.09 & 17.48 \\
\hline & 0.17 & 16.13 & 5.64 & 17.09 \\
\hline & 0.18 & 14.91 & 7.19 & 16.55 \\
\hline \multirow[t]{11}{*}{ End of flap 1: beginning of flap 2} & 0.20 & 13.12 & 6.20 & 14.51 \\
\hline & 0.21 & 14.58 & 5.10 & 15.42 \\
\hline & 0.23 & 15.42 & 5.15 & 16.25 \\
\hline & 0.25 & 14.46 & 4.78 & 15.23 \\
\hline & 0.27 & 14.35 & 4.30 & 14.97 \\
\hline & 0.28 & 14.12 & 3.69 & 14.59 \\
\hline & 0.30 & 13.40 & 3.68 & 13.89 \\
\hline & 0.32 & 12.06 & 4.74 & 12.96 \\
\hline & 0.33 & 10.63 & 4.36 & 11.48 \\
\hline & 0.35 & 10.14 & 4.95 & 11.28 \\
\hline & 0.37 & 9.54 & 4.47 & 10.53 \\
\hline \multirow[t]{8}{*}{ End of flap 2: beginning of flap 3} & 0.38 & 8.60 & 3.01 & 9.11 \\
\hline & 0.40 & 10.15 & 3.87 & 10.86 \\
\hline & 0.42 & 10.17 & 3.03 & 10.60 \\
\hline & 0.43 & 9.10 & 2.18 & 9.35 \\
\hline & 0.45 & 9.09 & 2.54 & 9.43 \\
\hline & 0.47 & 7.90 & 1.80 & 8.10 \\
\hline & 0.48 & 6.94 & 1.66 & 7.13 \\
\hline & 0.50 & 6.10 & 2.01 & 6.41 \\
\hline \multirow[t]{2}{*}{ End of flap 3: beginning of stabilization } & 0.52 & 4.92 & 0.67 & 4.96 \\
\hline & 0.53 & 4.33 & -0.06 & 4.32 \\
\hline \multirow[t]{10}{*}{ Feet touch the perch } & 0.55 & 4.20 & 0.06 & 4.20 \\
\hline & 0.57 & 3.97 & -0.42 & 3.99 \\
\hline & 0.58 & 3.61 & -0.31 & 3.62 \\
\hline & 0.60 & 3.02 & -0.80 & 3.11 \\
\hline & 0.62 & 2.53 & -0.44 & 2.56 \\
\hline & 0.63 & 1.93 & -0.33 & 1.95 \\
\hline & 0.65 & 1.33 & -0.58 & 1.45 \\
\hline & 0.67 & 1.21 & -0.34 & 1.25 \\
\hline & 0.68 & 0.72 & 0.01 & 0.72 \\
\hline & 0.70 & 0.24 & 0.00 & 0.24 \\
\hline
\end{tabular}

**For future use using the same videos: reference 09/04/2014 - Side (9) 
Table 3: Session 1, GoPro Flight Test 3

\begin{tabular}{|c|c|c|c|c|}
\hline Description of Flight Phenomena & $\mathbf{t}(\mathbf{s})$ & $v_{x}(f t / s)$ & $v_{y}(f t / s)$ & Magnitude v (m/s) \\
\hline \multirow[t]{7}{*}{ Gliding } & 0.02 & 20.94 & -1.85 & 6.40 \\
\hline & 0.03 & 21.42 & -1.35 & 21.40 \\
\hline & 0.05 & 21.41 & -0.63 & 21.42 \\
\hline & 0.07 & 21.40 & -0.38 & 21.41 \\
\hline & 0.08 & 20.90 & 0.57 & 20.91 \\
\hline & 0.10 & 20.67 & -0.15 & 20.67 \\
\hline & 0.12 & 20.07 & -0.53 & 20.07 \\
\hline End Glide & 0.13 & 20.66 & 0.57 & 20.67 \\
\hline \multirow[t]{6}{*}{ Bottoms Out } & 0.15 & 21.74 & 1.20 & 21.78 \\
\hline & 0.17 & 20.64 & 2.03 & 20.73 \\
\hline & 0.18 & 20.16 & 1.53 & 20.21 \\
\hline & 0.20 & 18.96 & 0.54 & 18.96 \\
\hline & 0.22 & 17.71 & 2.35 & 17.87 \\
\hline & 0.23 & 19.39 & 3.71 & 19.74 \\
\hline \multirow[t]{6}{*}{ Beginning of Flap 1} & 0.25 & 19.63 & 3.84 & 20.01 \\
\hline & 0.27 & 18.18 & 3.45 & 18.50 \\
\hline & 0.28 & 17.46 & 3.19 & 17.75 \\
\hline & 0.30 & 15.75 & 3.53 & 16.14 \\
\hline & 0.32 & 15.75 & 3.41 & 16.11 \\
\hline & 0.33 & 15.97 & 4.99 & 16.73 \\
\hline \multirow[t]{7}{*}{ End of Flap 1: Beginning of Flap 2} & 0.35 & 16.93 & 5.86 & 17.91 \\
\hline & 0.37 & 16.94 & 5.01 & 17.67 \\
\hline & 0.38 & 15.50 & 3.89 & 15.98 \\
\hline & 0.40 & 15.50 & 3.53 & 15.90 \\
\hline & 0.42 & 14.52 & 4.12 & 15.10 \\
\hline & 0.43 & 11.58 & 5.29 & 12.74 \\
\hline & 0.45 & 11.32 & 6.74 & 13.18 \\
\hline \multirow[t]{10}{*}{ End of Flap 2: Beginning of Flap 3} & 0.47 & 11.81 & 6.27 & 13.37 \\
\hline & 0.48 & 10.85 & 5.88 & 12.34 \\
\hline & 0.50 & 10.36 & 5.63 & 11.80 \\
\hline & 0.52 & 9.89 & 4.78 & 10.98 \\
\hline & 0.53 & 10.87 & 4.06 & 11.61 \\
\hline & 0.55 & 11.13 & 3.34 & 11.62 \\
\hline & 0.57 & 10.89 & 2.97 & 11.29 \\
\hline & 0.58 & 9.92 & 2.83 & 10.32 \\
\hline & 0.60 & 8.22 & 2.92 & 8.72 \\
\hline & 0.62 & 7.37 & 2.91 & 7.92 \\
\hline \multirow[t]{8}{*}{ End of Flap 3: Beginning of Flap 4} & 0.63 & 5.79 & 2.52 & 6.32 \\
\hline & 0.65 & 4.70 & 2.38 & 5.27 \\
\hline & 0.66 & 5.31 & 2.51 & 5.87 \\
\hline & 0.68 & 5.92 & 2.04 & 6.26 \\
\hline & 0.70 & 6.30 & 1.07 & 6.39 \\
\hline & 0.71 & 6.06 & 1.07 & 6.15 \\
\hline & 0.73 & 4.96 & 1.05 & 5.07 \\
\hline & 0.75 & 4.97 & 0.93 & 5.05 \\
\hline \multirow[t]{10}{*}{ Feet touch perch } & 0.76 & 3.75 & 0.91 & 3.86 \\
\hline & 0.78 & 2.42 & 0.64 & 2.50 \\
\hline & 0.80 & 2.91 & 0.16 & 2.92 \\
\hline & 0.81 & 2.31 & -0.05 & 2.31 \\
\hline & 0.83 & 2.18 & 0.15 & 2.19 \\
\hline & 0.85 & 2.07 & -0.32 & 2.09 \\
\hline & 0.86 & 1.82 & -0.35 & 1.85 \\
\hline & 0.88 & 1.70 & -0.26 & 1.71 \\
\hline & 0.90 & 1.08 & 0.38 & 1.15 \\
\hline & 0.91 & 0.48 & 0.37 & 0.60 \\
\hline
\end{tabular}




\begin{tabular}{|c|c|c|c|c|}
\hline & 0.93 & 0.73 & -0.59 & 0.94 \\
\hline & 0.95 & 1.46 & -0.46 & 1.53 \\
\hline End of flap 4: beginning of stabilization & 0.96 & 0.60 & 0.13 & 0.61 \\
\hline & 0.98 & 0.12 & -0.24 & 0.27 \\
\hline & 1.00 & 0.49 & -0.47 & 0.68 \\
\hline
\end{tabular}

**For future use using the same videos: reference $09 / 04 / 2014$ - Side (11)

Table 4: Session 1, GoPro Flight Test 4

\begin{tabular}{|c|c|c|c|c|}
\hline Description of Flight Phenomena & t (s) & $v_{x}(\mathbf{f t} / \mathbf{s})$ & $v_{v}(\mathbf{f t} / \mathbf{s})$ & Magnitude v (m/s) \\
\hline \multirow[t]{2}{*}{ Gliding } & 0.25 & 21.69 & 1.05 & 21.72 \\
\hline & 0.26 & 20.59 & 1.89 & 20.67 \\
\hline End Glide & 0.28 & 20.61 & 0.67 & 20.62 \\
\hline Bottoms Out & 0.30 & 21.09 & 0.56 & 21.10 \\
\hline Wing Rotation: Landing Begins & 0.31 & 20.60 & 0.92 & 20.62 \\
\hline \multirow[t]{6}{*}{ Flap 1 begins } & 0.33 & 19.26 & 1.74 & 19.33 \\
\hline & 0.35 & 19.13 & 1.99 & 19.23 \\
\hline & 0.36 & 20.59 & 1.52 & 20.65 \\
\hline & 0.38 & 20.48 & 1.28 & 20.52 \\
\hline & 0.40 & 19.74 & 1.99 & 19.84 \\
\hline & 0.41 & 19.48 & 3.20 & 19.74 \\
\hline \multirow[t]{8}{*}{ End of Flap 1. Beginning of Flap 2} & 0.43 & 19.71 & 3.57 & 20.03 \\
\hline & 0.45 & 19.09 & 4.53 & 19.62 \\
\hline & 0.46 & 17.04 & 3.65 & 17.43 \\
\hline & 0.48 & 17.07 & 1.83 & 17.17 \\
\hline & 0.50 & 17.55 & 2.20 & 17.69 \\
\hline & 0.51 & 16.55 & 3.89 & 17.01 \\
\hline & 0.53 & 16.04 & 5.70 & 17.02 \\
\hline & 0.55 & 13.86 & 5.79 & 15.02 \\
\hline \multirow[t]{7}{*}{ End of Flap 2: Beginning of Flap 3} & 0.56 & 12.05 & 4.67 & 12.93 \\
\hline & 0.58 & 13.15 & 4.44 & 13.88 \\
\hline & 0.60 & 14.60 & 4.83 & 15.38 \\
\hline & 0.61 & 14.37 & 4.10 & 14.94 \\
\hline & 0.63 & 13.0 & 3.83 & 13.59 \\
\hline & 0.65 & 11.89 & 5.15 & 12.88 \\
\hline & 0.66 & 11.00 & 5.87 & 12.53 \\
\hline \multirow[t]{8}{*}{ End of Flap 3: Beginning of flap 4} & 0.68 & 10.46 & 5.73 & 11.93 \\
\hline & 0.70 & 9.61 & 5.84 & 11.25 \\
\hline & 0.71 & 9.13 & 5.59 & 10.71 \\
\hline & 0.73 & 9.75 & 4.39 & 10.70 \\
\hline & 0.75 & 9.76 & 3.66 & 10.43 \\
\hline & 0.76 & 9.16 & 3.41 & 9.78 \\
\hline & 0.78 & 8.92 & 3.16 & 9.47 \\
\hline & 0.80 & 8.20 & 3.03 & 8.74 \\
\hline End of Flap 4 & 0.81 & 6.98 & 3.38 & 7.75 \\
\hline
\end{tabular}

**For future use using the same videos: reference 09/04/2014 - Side (13) 
Table 5: Session 2, GoPro Flight Test 1

\begin{tabular}{|c|c|c|c|c|}
\hline Description of Flight Phenomena & $\mathbf{t}(\mathbf{s})$ & $\mathbf{v}_{\mathbf{x}}(\mathbf{f t} / \mathbf{s})$ & $\mathbf{v}_{\mathbf{y}}(\mathbf{f t} / \mathbf{s})$ & Magnitude v (m/s) \\
\hline & 0.01 & 24.23 & -2.99 & 7.44 \\
\hline & 0.02 & 22.72 & -4.27 & 7.04 \\
\hline & 0.03 & 21.75 & -2.75 & 6.68 \\
\hline & 0.04 & 23.92 & -2.69 & 7.33 \\
\hline & 0.05 & 24.53 & -2.67 & 7.52 \\
\hline & 0.06 & 25.12 & -1.41 & 7.66 \\
\hline & 0.07 & 23.56 & -1.15 & 7.19 \\
\hline Bottoms out & 0.08 & 21.39 & -0.91 & 6.52 \\
\hline \multirow{13}{*}{ Beginning of flap 1} & 0.09 & 23.17 & 1.62 & 7.08 \\
\hline & 0.10 & 21.87 & 3.43 & 6.75 \\
\hline & 0.11 & 17.66 & -0.71 & 5.39 \\
\hline & 0.12 & 17.73 & -2.87 & 5.47 \\
\hline & 0.13 & 19.80 & 0.28 & 6.03 \\
\hline & 0.14 & 20.42 & 0.29 & 6.22 \\
\hline & 0.15 & 19.84 & -0.95 & 6.05 \\
\hline & 0.16 & 19.18 & 0.26 & 5.84 \\
\hline & 0.17 & 20.08 & 1.21 & 6.13 \\
\hline & 0.18 & 16.37 & 1.10 & 5.00 \\
\hline & 0.19 & 14.81 & 1.68 & 4.54 \\
\hline & 0.20 & 19.46 & 1.50 & 5.94 \\
\hline & 0.21 & 19.11 & 2.73 & 5.88 \\
\hline \multirow[t]{15}{*}{ End of flap 1: Beginning of flap 2} & 0.22 & 16.30 & 3.58 & 5.08 \\
\hline & 0.23 & 14.75 & 3.53 & 4.62 \\
\hline & 0.24 & 14.40 & 5.07 & 4.65 \\
\hline & 0.25 & 17.49 & 5.16 & 5.56 \\
\hline & 0.26 & 17.54 & 3.61 & 5.45 \\
\hline & 0.27 & 16.33 & 2.65 & 5.04 \\
\hline & 0.28 & 16.97 & 1.74 & 5.20 \\
\hline & 0.29 & 15.12 & 1.38 & 4.63 \\
\hline & 0.30 & 15.08 & 2.92 & 4.68 \\
\hline & 0.31 & 15.99 & 3.57 & 4.99 \\
\hline & 0.32 & 16.00 & 3.26 & 4.97 \\
\hline & 0.33 & 14.73 & 4.15 & 4.66 \\
\hline & 0.34 & 12.52 & 5.63 & 4.18 \\
\hline & 0.35 & 13.12 & 6.27 & 4.43 \\
\hline & 0.36 & 13.13 & 5.96 & 4.39 \\
\hline \multirow[t]{15}{*}{ End of flap 2: Beginning of flap 3} & 0.37 & 13.51 & 3.4 & 4.25 \\
\hline & 0.38 & 12.60 & 2.83 & 3.94 \\
\hline & 0.39 & 11.33 & 4.05 & 3.66 \\
\hline & 0.40 & 13.53 & 2.88 & 4.21 \\
\hline & 0.41 & 11.34 & 3.74 & 3.64 \\
\hline & 0.42 & 9.76 & 4.62 & 3.29 \\
\hline & 0.43 & 13.57 & 3.19 & 4.23 \\
\hline & 0.44 & 13.85 & 2.58 & 4.29 \\
\hline & 0.45 & 12.07 & 1.59 & 3.69 \\
\hline & 0.46 & 12.39 & 2.53 & 3.83 \\
\hline & 0.47 & 12.06 & 1.28 & 3.69 \\
\hline & 0.48 & 11.40 & 1.57 & 3.51 \\
\hline & 0.49 & 12.88 & 4.09 & 4.12 \\
\hline & 0.50 & 13.16 & 5.03 & 4.29 \\
\hline & 0.51 & 13.13 & 5.96 & 4.39 \\
\hline \multirow[t]{5}{*}{ End flap 3: Beginning Stabilization } & 0.52 & 11.57 & 6.22 & 4.00 \\
\hline & 0.53 & 6.66 & 4.84 & 2.51 \\
\hline & 0.54 & 5.19 & 2.32 & 1.73 \\
\hline & 0.55 & 6.73 & 2.67 & 2.20 \\
\hline & 0.56 & 7.94 & 3.64 & 2.66 \\
\hline
\end{tabular}




\begin{tabular}{|c|c|c|c|c|}
\hline & 0.57 & 7.66 & 2.39 & 2.44 \\
\hline & 0.58 & 8.29 & 2.10 & 2.60 \\
\hline & 0.59 & 8.59 & 2.42 & 2.72 \\
\hline & 0.60 & 8.31 & 1.48 & 2.57 \\
\hline & 0.61 & 8.60 & 2.11 & 2.70 \\
\hline & 0.62 & 7.66 & 2.39 & 2.44 \\
\hline Feet make contact with perch & 0.63 & 7.69 & 1.46 & 2.38 \\
\hline & 0.64 & 6.78 & 0.82 & 2.08 \\
\hline & 0.65 & 4.91 & 1.38 & 1.55 \\
\hline & 0.66 & 4.90 & 1.69 & 1.58 \\
\hline & 0.67 & 5.20 & 2.01 & 1.70 \\
\hline & 0.68 & 4.91 & 1.38 & 1.55 \\
\hline & 0.69 & 4.03 & -0.18 & 1.23 \\
\hline & 0.70 & 2.79 & -0.22 & 0.85 \\
\hline & 0.71 & 2.78 & 0.08 & 0.84 \\
\hline & 0.72 & 2.78 & 0.08 & 0.84 \\
\hline
\end{tabular}

$* *$ For future use using the same videos: reference 09/04/2015 - Side (5)

Table 6: Session 2, GoPro Flight Test 2

\begin{tabular}{|c|c|c|c|c|}
\hline Description of Flight Phenomena & t (s) & $\mathbf{v}_{\mathbf{x}}$ & $\mathbf{v}_{\mathbf{y}}$ & $\mathbf{v}(\mathbf{m} / \mathbf{s})$ \\
\hline \multirow[t]{15}{*}{ Gliding } & 0.01 & 20.22 & 0.01 & 6.16 \\
\hline & 0.02 & 19.05 & -1.56 & 5.82 \\
\hline & 0.03 & 20.53 & 0.02 & 6.25 \\
\hline & 0.04 & 21.43 & 0.66 & 6.53 \\
\hline & 0.05 & 19.63 & -0.62 & 5.98 \\
\hline & 0.06 & 19.63 & -0.62 & 5.98 \\
\hline & 0.07 & 21.45 & 0.05 & 6.53 \\
\hline & 0.08 & 20.83 & 0.03 & 6.35 \\
\hline & 0.09 & 20.87 & -1.19 & 6.37 \\
\hline & 0.10 & 20.28 & -1.82 & 6.20 \\
\hline & 0.11 & 20.54 & -0.28 & 6.26 \\
\hline & 0.12 & 20.53 & 0.02 & 6.25 \\
\hline & 0.13 & 20.22 & 0.01 & 6.16 \\
\hline & 0.14 & 20.51 & 0.63 & 6.25 \\
\hline & 0.15 & 20.53 & 0.02 & 6.25 \\
\hline End of glide & 0.16 & 19.90 & 0.62 & 6.06 \\
\hline \multirow[t]{9}{*}{ Bottoms Out } & 0.17 & 20.48 & 1.55 & 6.26 \\
\hline & 0.18 & 21.41 & 1.27 & 6.53 \\
\hline & 0.19 & 21.43 & 0.66 & 6.53 \\
\hline & 0.20 & 20.49 & 1.25 & 6.25 \\
\hline & 0.21 & 20.45 & 2.47 & 6.27 \\
\hline & 0.22 & 20.45 & 2.47 & 6.27 \\
\hline & 0.23 & 18.64 & 1.50 & 5.70 \\
\hline & 0.24 & 19.53 & 2.44 & 6.00 \\
\hline & 0.25 & 18.90 & 3.04 & 5.83 \\
\hline \multirow[t]{11}{*}{ Beginning of flap 1} & 0.26 & 20.43 & 3.08 & 6.29 \\
\hline & 0.27 & 21.92 & 4.66 & 6.82 \\
\hline & 0.28 & 19.76 & 4.90 & 6.20 \\
\hline & 0.29 & 17.01 & 4.82 & 5.38 \\
\hline & 0.30 & 14.26 & 4.42 & 4.55 \\
\hline & 0.31 & 16.44 & 3.57 & 5.12 \\
\hline & 0.32 & 18.49 & 6.39 & 5.96 \\
\hline & 0.33 & 17.88 & 6.37 & 5.78 \\
\hline & 0.34 & 16.74 & 3.58 & 5.21 \\
\hline & 0.35 & 17.96 & 3.93 & 5.60 \\
\hline & 0.36 & 20.06 & 5.22 & 6.31 \\
\hline
\end{tabular}




\begin{tabular}{|c|c|c|c|c|}
\hline & 0.37 & 22.17 & 6.51 & 7.04 \\
\hline & 0.38 & 18.22 & 5.47 & 5.79 \\
\hline & 0.39 & 15.45 & 5.69 & 5.01 \\
\hline & 0.40 & 15.72 & 6.92 & 5.23 \\
\hline \multirow[t]{14}{*}{ End of flap 1: beginning of flap 2} & 0.41 & 10.85 & 5.85 & 3.75 \\
\hline & 0.42 & 10.23 & 6.14 & 3.63 \\
\hline & 0.43 & 11.70 & 8.02 & 4.32 \\
\hline & 0.44 & 12.06 & 6.50 & 4.17 \\
\hline & 0.45 & 13.93 & 5.33 & 4.54 \\
\hline & 0.46 & 14.55 & 5.05 & 4.69 \\
\hline & 0.47 & 14.57 & 4.43 & 4.64 \\
\hline & 0.48 & 14.84 & 5.67 & 4.84 \\
\hline & 0.49 & 13.33 & 5.01 & 4.33 \\
\hline & 0.50 & 12.38 & 5.90 & 4.17 \\
\hline & 0.51 & 13.28 & 6.54 & 4.51 \\
\hline & 0.52 & 13.31 & 5.62 & 4.40 \\
\hline & 0.53 & 10.84 & 6.16 & 3.79 \\
\hline & 0.54 & 11.41 & 7.71 & 4.19 \\
\hline \multirow[t]{19}{*}{ End of flap 2: beginning of flap 3} & 0.55 & 11.41 & 7.71 & 4.19 \\
\hline & 0.56 & 9.88 & 7.35 & 3.75 \\
\hline & 0.57 & 10.20 & 7.06 & 3.78 \\
\hline & 0.58 & 8.42 & 5.16 & 3.01 \\
\hline & 0.59 & 7.83 & 4.53 & 2.75 \\
\hline & 0.60 & 7.55 & 3.60 & 2.54 \\
\hline & 0.61 & 8.45 & 4.24 & 2.88 \\
\hline & 0.62 & 10.28 & 4.30 & 3.39 \\
\hline & 0.63 & 9.69 & 3.67 & 3.15 \\
\hline & 0.64 & 9.10 & 3.04 & 2.92 \\
\hline & 0.65 & 9.10 & 3.04 & 2.92 \\
\hline & 0.66 & 9.07 & 3.96 & 3.01 \\
\hline & 0.67 & 9.10 & 3.04 & 2.92 \\
\hline & 0.68 & 8.80 & 2.72 & 2.80 \\
\hline & 0.69 & 8.47 & 3.63 & 2.80 \\
\hline & 0.70 & 7.84 & 4.23 & 2.71 \\
\hline & 0.71 & 6.65 & 2.96 & 2.21 \\
\hline & 0.72 & 5.45 & 2.01 & 1.77 \\
\hline & 0.73 & 4.22 & 2.28 & 1.46 \\
\hline \multirow[t]{16}{*}{ End of flap 3} & 0.74 & 2.10 & 1.29 & 0.75 \\
\hline & 0.75 & 0.90 & 0.64 & 0.33 \\
\hline & 0.76 & 3.61 & 2.26 & 1.29 \\
\hline & 0.77 & 6.36 & 2.34 & 2.06 \\
\hline & 0.78 & 5.75 & 2.32 & 1.89 \\
\hline & 0.79 & 3.32 & 1.63 & 1.12 \\
\hline & 0.80 & 3.05 & 0.40 & 0.93 \\
\hline & 0.81 & 3.68 & -0.19 & 1.12 \\
\hline & 0.82 & 4.01 & -0.80 & 1.24 \\
\hline & 0.83 & 3.35 & 0.72 & 1.04 \\
\hline & 0.84 & 2.99 & 2.24 & 1.13 \\
\hline & 0.85 & 3.93 & 1.65 & 1.30 \\
\hline & 0.86 & 3.64 & 1.03 & 1.15 \\
\hline & 0.87 & 3.35 & 0.72 & 1.04 \\
\hline & 0.88 & 3.40 & -0.81 & 1.06 \\
\hline & 0.89 & 5.19 & 0.47 & 1.58 \\
\hline
\end{tabular}

**For future use using the same videos: reference 09/04/2015 - Side (7) 
Table 7: Session 2, GoPro Flight Test 3

\begin{tabular}{|c|c|c|c|c|}
\hline \multirow[t]{18}{*}{ Description of Flight Phenomena } & $t(s)$ & $v_{X}(f t / s)$ & $v_{v}(f t / s)$ & Magnitude v (m/s) \\
\hline & 0.01 & 21.99 & -2.70 & 6.75 \\
\hline & 0.02 & 21.33 & -1.49 & 6.51 \\
\hline & 0.03 & 21.31 & -0.57 & 6.49 \\
\hline & 0.04 & 21.33 & -1.49 & 6.51 \\
\hline & 0.05 & 20.72 & -1.51 & 6.33 \\
\hline & 0.06 & 21.32 & -1.18 & 6.50 \\
\hline & 0.07 & 21.93 & -0.80 & 6.68 \\
\hline & 0.08 & 21.64 & -1.48 & 6.61 \\
\hline & 0.09 & 21.03 & -1.50 & 6.42 \\
\hline & 0.10 & 21.60 & -0.25 & 6.58 \\
\hline & 0.11 & 21.32 & -1.18 & 6.50 \\
\hline & 0.12 & 20.69 & -0.50 & 6.30 \\
\hline & 0.13 & 21.61 & -0.56 & 6.58 \\
\hline & 0.14 & 21.31 & -0.57 & 6.49 \\
\hline & 0.15 & 21.28 & 0.35 & 6.48 \\
\hline & 0.16 & 21.59 & 5.54 & 6.58 \\
\hline & 0.17 & 20.65 & 0.64 & 6.29 \\
\hline \multirow[t]{8}{*}{ Bottom Out } & 0.18 & 20.65 & 0.64 & 6.29 \\
\hline & 0.19 & 21.56 & 1.28 & 6.58 \\
\hline & 0.20 & 20.01 & 1.54 & 6.11 \\
\hline & 0.21 & 19.11 & 0.59 & 5.82 \\
\hline & 0.22 & 21.26 & 0.97 & 6.48 \\
\hline & 0.23 & 19.7 & 1.53 & 6.02 \\
\hline & 0.24 & 20.28 & 2.48 & 6.22 \\
\hline & 0.25 & 20.88 & 3.11 & 6.43 \\
\hline \multirow[t]{15}{*}{ Beginning of flap 1} & 0.26 & 17.77 & 3.94 & 5.54 \\
\hline & 0.27 & 17.14 & 4.23 & 5.38 \\
\hline & 0.28 & 16.9 & 2.06 & 5.18 \\
\hline & 0.29 & 17.87 & 0.86 & 5.45 \\
\hline & 0.30 & 19.94 & 3.70 & 6.18 \\
\hline & 0.31 & 21.07 & 7.13 & 6.78 \\
\hline & 0.32 & 21.67 & 7.46 & 6.98 \\
\hline & 0.33 & 19.92 & 4.32 & 6.21 \\
\hline & 0.34 & 18.12 & 2.72 & 5.58 \\
\hline & 0.35 & 18.97 & 5.21 & 5.99 \\
\hline & 0.36 & 18.98 & 4.60 & 5.95 \\
\hline & 0.37 & 19.34 & 3.07 & 5.96 \\
\hline & 0.38 & 18.69 & 4.28 & 5.84 \\
\hline & 0.39 & 18.01 & 6.11 & 5.79 \\
\hline & 0.4 & 18.32 & 6.12 & 5.88 \\
\hline \multirow[t]{15}{*}{ end of flap 1:beginning of flap 2} & 0.41 & 17.41 & 5.78 & 5.59 \\
\hline & 0.42 & 14.32 & 5.69 & 4.69 \\
\hline & 0.43 & 13.69 & 6.28 & 4.59 \\
\hline & 0.44 & 14.01 & 5.68 & 4.60 \\
\hline & 0.45 & 13.42 & 5.04 & 4.37 \\
\hline & 0.46 & 15.84 & 6.35 & 5.20 \\
\hline & 0.47 & 15.86 & 5.73 & 5.14 \\
\hline & 0.48 & 15.60 & 4.18 & 4.92 \\
\hline & 0.49 & 15.91 & 4.19 & 5.01 \\
\hline & 0.5 & 15.59 & 4.49 & 4.94 \\
\hline & 0.51 & 16.56 & 3.29 & 5.14 \\
\hline & 0.52 & 16.55 & 3.60 & 5.16 \\
\hline & 0.53 & 16.18 & 5.44 & 5.20 \\
\hline & 0.54 & 15.58 & 5.11 & 4.99 \\
\hline & 0.55 & 14.04 & 4.75 & 4.51 \\
\hline
\end{tabular}




\begin{tabular}{|c|c|c|c|c|}
\hline & 0.56 & 13.41 & 5.35 & 4.40 \\
\hline & 0.57 & 14.02 & 5.37 & 4.57 \\
\hline & 0.58 & 13.08 & 5.96 & 4.38 \\
\hline \multirow[t]{16}{*}{ end of flap 2: beginning of flap 3} & 0.59 & 13.08 & 5.96 & 4.38 \\
\hline & 0.6 & 15.26 & 5.41 & 4.93 \\
\hline & 0.61 & 12.48 & 5.32 & 4.13 \\
\hline & 0.62 & 11.27 & 4.67 & 3.71 \\
\hline & 0.63 & 13.73 & 5.05 & 4.45 \\
\hline & 0.64 & 13.44 & 4.42 & 4.31 \\
\hline & 0.65 & 13.47 & 3.50 & 4.24 \\
\hline & 0.66 & 13.48 & 3.19 & 4.22 \\
\hline & 0.67 & 13.18 & 2.87 & 4.11 \\
\hline & 0.68 & 12.54 & 3.47 & 3.96 \\
\hline & 0.69 & 11.92 & 3.45 & 3.78 \\
\hline & 0.70 & 10.97 & 4.35 & 3.59 \\
\hline & 0.71 & 10.94 & 5.27 & 3.70 \\
\hline & 0.72 & 11.58 & 4.68 & 3.80 \\
\hline & 0.73 & 7.59 & 3.93 & 2.60 \\
\hline & 0.74 & 4.49 & 4.15 & 1.80 \\
\hline \multirow[t]{14}{*}{ end of flap 3: beginning of flap 4} & 0.75 & 5.43 & 3.87 & 2.03 \\
\hline & 0.76 & 6.06 & 3.27 & 2.10 \\
\hline & 0.77 & 6.65 & 4.21 & 2.40 \\
\hline & 0.78 & 6.95 & 4.53 & 2.53 \\
\hline & 0.79 & 6.74 & 1.44 & 2.10 \\
\hline & 0.80 & 7.07 & 0.83 & 2.16 \\
\hline & 0.81 & 7.35 & 1.46 & 2.28 \\
\hline & 0.82 & 6.76 & 0.82 & 2.07 \\
\hline & 0.83 & 5.83 & 0.79 & 1.79 \\
\hline & 0.84 & 5.85 & 0.18 & 1.78 \\
\hline & 0.85 & 4.86 & 2.31 & 1.64 \\
\hline & 0.86 & 4.23 & 2.60 & 1.51 \\
\hline & 0.87 & 4.29 & 0.75 & 1.32 \\
\hline & 0.88 & 1.81 & 1.29 & 0.67 \\
\hline End of flap 4: beginning of stabilization & 0.89 & 2.11 & 1.30 & 0.75 \\
\hline \multirow[t]{7}{*}{ Feet touch perch } & 0.90 & 2.17 & -0.54 & 0.68 \\
\hline & 0.91 & $9.60 \mathrm{E}-03$ & -0.30 & 0.09 \\
\hline & 0.92 & 1.80 & 1.59 & 0.73 \\
\hline & 0.93 & 4.27 & 1.36 & 1.36 \\
\hline & 0.94 & 4.61 & 0.45 & 1.41 \\
\hline & 0.95 & 3.70 & -0.19 & 1.13 \\
\hline & 0.96 & 3.4 & -0.203 & 1.03 \\
\hline
\end{tabular}

**For future use using the same videos: reference $09 / 04 / 2015$ - Side (11) 


\section{Appendix B: Free Flight Frequency Tables}

\section{Table 1: Session 2, High-Speed Flight Test 1}

\begin{tabular}{|c|c|c|c|}
\hline Wing Flap & Wing Region & Av. Velocity $(\mathrm{m} / \mathrm{s})$ & Feather Frequency $(\mathrm{Hz})$ \\
\hline C & 1 & 3.72 & 45.45 \\
\hline C & 2 & 3.72 & 48.78 \\
\hline C & 3 & 3.72 & 51.28 \\
\hline C & 4 & 3.72 & 62.50 \\
\hline
\end{tabular}

**For future use using the same videos: reference High-speed 20140905 - 160101

Table 2: Session 2, High-Speed Flight Test 2

\begin{tabular}{|c|c|c|c|}
\hline Wing Flap & Wing Region & Av. Velocity $(\mathrm{m} / \mathrm{s})$ & Feather Frequency $(\mathrm{Hz})$ \\
\hline C & 1 & 3.72 & 44.44 \\
\hline C & 2 & 3.72 & 52.63 \\
\hline C & 3 & 3.72 & 63.49 \\
\hline C & 4 & 3.72 & 47.62 \\
\hline
\end{tabular}

**For future use using the same videos: reference High-speed 20140905 - 155751

Table 3: Session 2, High Speed Flight Test 3

\begin{tabular}{|c|c|c|c|}
\hline Wing Flap & Wing Region & Av. Velocity $(\mathrm{m} / \mathrm{s})$ & Feather Frequency $(\mathrm{Hz})$ \\
\hline C & 1 & 3.72 & 41.67 \\
\hline C & 2 & 3.72 & 25.48 \\
\hline C & 3 & 3.72 & 49.38 \\
\hline C & 4 & 3.72 & 49.38 \\
\hline
\end{tabular}

**For future use using the same videos: reference High-speed 20140905 - 160430

Table 4: Session 2, High Speed Flight Test 4

\begin{tabular}{|c|c|c|c|}
\hline Wing Flap & Wing Region & Av. Velocity $(\mathrm{m} / \mathrm{s})$ & Feather Frequency $(\mathrm{Hz})$ \\
\hline B & 1 & 4.85 & 37.74 \\
\hline B & 2 & 4.85 & 45.45 \\
\hline C & 1 & 3.72 & 42.55 \\
\hline C & 2 & 3.72 & 56.34 \\
\hline C & 3 & 3.72 & 58.39 \\
\hline
\end{tabular}

**For future use using the same videos: reference High-speed 20140905 - 160749 
Table 5: Session 2, High Speed Flight Test 5

\begin{tabular}{|c|c|c|c|}
\hline Wing Flap & Wing Region & Av. Velocity $(\mathrm{m} / \mathrm{s})$ & Feather Frequency $(\mathrm{Hz})$ \\
\hline C & 2 & 3.72 & 36.7 \\
\hline C & 3 & 3.72 & 81.63 \\
\hline
\end{tabular}

**For future use using the same videos: reference High-speed 20140905 - 161114

Table 6: Session 3, High Speed Flight Test 1

\begin{tabular}{|c|c|c|c|}
\hline Wing Flap & Wing Region & Av. Velocity $(\mathrm{m} / \mathrm{s})$ & Feather Frequency $(\mathrm{Hz})$ \\
\hline B & 1 & 4.85 & 25.97 \\
\hline B & 2 & 4.85 & 39.60 \\
\hline B & 3 & 4.85 & 54.79 \\
\hline C & 1 & 3.72 & 28.57 \\
\hline C & 2 & 3.72 & 50.00 \\
\hline C & 3 & 3.72 & 40.00 \\
\hline
\end{tabular}

**For future use using the same videos: reference High-speed 20140908 - 153815

Table 7: Session 3, High Speed Flight Test 2

\begin{tabular}{|c|c|c|c|}
\hline Wing Flap & Wing Region & Av. Velocity $(\mathrm{m} / \mathrm{s})$ & Feather Frequency $(\mathrm{Hz})$ \\
\hline B & 1 & 4.85 & 43.48 \\
\hline B & 2 & 4.85 & 25.64 \\
\hline B & 3 & 4.85 & 31.25 \\
\hline B & 4 & 4.85 & 31.75 \\
\hline C & 1 & 3.72 & 65.57 \\
\hline C & 3 & 3.72 & 30.30 \\
\hline C & 4 & 3.72 & 40.00 \\
\hline
\end{tabular}

**For future use using the same videos: reference High-speed 20140908 - 154148

Table 8: Session 3, High Speed Flight Test 3

\begin{tabular}{|c|c|c|c|}
\hline Wing Flap & Wing Region & Av. Velocity $(\mathrm{m} / \mathrm{s})$ & Feather Frequency $(\mathrm{Hz})$ \\
\hline B & 1 & 4.85 & 40.00 \\
\hline B & 2 & 4.85 & 23.81 \\
\hline B & 3 & 4.85 & 28.57 \\
\hline B & 4 & 4.85 & 41.67 \\
\hline C & 2 & 3.72 & 81.63 \\
\hline C & 3 & 3.72 & 34.19 \\
\hline C & 4 & 3.72 & 38.83 \\
\hline
\end{tabular}

**For future use using the same videos: reference High-speed 20140908 - 154242 
Table 9: Session 4, High Speed Flight Test 1

\begin{tabular}{|c|c|c|c|}
\hline Wing Flap & Wing Region & Av. Velocity $(\mathrm{m} / \mathrm{s})$ & Feather Frequency $(\mathrm{Hz})$ \\
\hline A & 1 & 6.04 & 21.39 \\
\hline A & 2 & 6.04 & 55.56 \\
\hline B & 1 & 4.85 & 21.26 \\
\hline B & 2 & 4.85 & 37.04 \\
\hline B & 3 & 4.85 & 26.32 \\
\hline B & 4 & 4.85 & 37.04 \\
\hline C & 1 & 3.72 & 38.46 \\
\hline C & 3 & 3.72 & 30.3 \\
\hline C & 4 & 3.72 & 45.45 \\
\hline
\end{tabular}

**For future analysis using the same videos: reference High-speed 20140909 - 161456 


\section{Appendix C: Uncertainty Analysis}

To support and validate the measured and calculated values in these experiments, uncertainty analysis must be conducted [31]. The addition of quadrature method was used to conduct this analysis. Note that the measured quantities are independent of each other with random uncertainties.

\section{Table 1. Uncertainty Analysis of Measured Data}

\begin{tabular}{|c|c|c|c|c|c|}
\hline Value & $\begin{array}{c}\text { Smallest } \\
\text { Increment of } \\
\text { Measurement } \\
(\Delta)\end{array}$ & Unit & $\begin{array}{c}\text { Uncertainty } \\
\text { Formula }\end{array}$ & Calculation & $\begin{array}{l}\text { Calculated } \\
\text { Uncertainty }\end{array}$ \\
\hline Temperature (T) & \pm 1 & $\mathrm{~F}$ & $\frac{\Delta T}{T_{a v g}} * 100 \%$ & $\frac{0.5}{68} * 100 \%$ & $0.7 \%$ \\
\hline Pressure (P) & \pm 0.025 & $\begin{array}{c}\text { In. of } \\
\mathrm{Hg}\end{array}$ & $\frac{\Delta P}{P_{\text {avg. }}}(100 \%)$ & $\frac{0.0125}{28.91} * 100 \%$ & $0.04 \%$ \\
\hline $\begin{array}{l}\text { Test Section } \\
\text { Head Pressure } \\
\text { (q) }\end{array}$ & \pm 0.02 & $\begin{array}{l}\text { In. of } \\
\text { Water }\end{array}$ & $\frac{\Delta q}{q_{\min }} * 100 \%$ & $\frac{0.01}{0.06} * 100 \%$ & $16.67 \%$ \\
\hline $\begin{array}{l}\text { Angle of Attack } \\
\qquad(\alpha)\end{array}$ & \pm 0.01 & $\circ$ & $\frac{\Delta \alpha}{\alpha_{\max }} * 100 \%$ & $\frac{0.005}{55} * 100 \%$ & $0.009 \%$ \\
\hline \multirow[t]{2}{*}{$\begin{array}{l}\text { Wing Model } \\
\text { Dimensions }\end{array}$} & \multirow[t]{2}{*}{$\pm \frac{1}{16}$} & \multirow[t]{2}{*}{ In } & $\begin{array}{l}\frac{\Delta \text { width }}{\text { wing width }} \\
* 100 \%\end{array}$ & $\frac{\left(\frac{1}{32}\right)}{11.7} * 100 \%$ & $0.3 \%$ \\
\hline & & & $\begin{array}{l}\frac{\Delta \text { length }}{\text { wing length }} \\
* 100 \%\end{array}$ & $\frac{\left(\frac{1}{32}\right)}{17.1} * 100 \%$ & $0.2 \%$ \\
\hline
\end{tabular}




\section{Table 2. Uncertainty Analysis of Calculated Data}

\begin{tabular}{|c|c|c|c|c|c|}
\hline \begin{tabular}{|c|} 
Calculated \\
Data
\end{tabular} & Formula & $\begin{array}{c}\text { Required } \\
\text { Measured } \\
\text { Values }\end{array}$ & Uncertainty Formula & Calculation & $\begin{array}{l}\text { Calculated } \\
\text { Uncertainty }\end{array}$ \\
\hline MAC & $\begin{array}{c}\begin{array}{c}\text { Chord } \\
\text { Measurements }\end{array} \\
\text { Number of } \\
\text { Measurements }\end{array}$ & Width & $\frac{\frac{1}{32}}{\text { Width }_{\text {mean }}} * 100 \%$ & $\frac{\frac{1}{32}}{6.77} * 100 \%$ & $0.46 \%$ \\
\hline \begin{tabular}{|c|} 
Air \\
Velocity (v)
\end{tabular} & $\begin{array}{l}\sqrt{\frac{q * 5.2 * 2}{\frac{P}{R T}}} \\
\mathrm{R} \text { is the gas } \\
\text { constant for air }\end{array}$ & $\mathrm{P}, \mathrm{T}, \mathrm{q}$ & $\sqrt{u n c_{P}{ }^{2}+u n c_{T}{ }^{2}+u n c_{q}{ }^{2}}$ & $\begin{array}{l}\sqrt{0.04^{2}+0.7^{2}} \\
+16.67^{2}\end{array}$ & $16.68 \%$ \\
\hline $\begin{array}{c}\text { Reynolds } \\
\text { Number } \\
(\mathrm{Re})\end{array}$ & $R e=\frac{\rho V C}{\mu}$ & $\mathrm{V}, \mathrm{C}, \rho$ & $\sqrt{u n c_{V}{ }^{2}+u n c_{C}{ }^{2}+u n c_{\rho}^{2}}$ & $\begin{array}{l}\sqrt{16.67^{2}+0.46^{2}} \\
+1.47^{2}\end{array}$ & $16.74 \%$ \\
\hline \begin{tabular}{|c|} 
Density of \\
Air $(\rho)$
\end{tabular} & $\rho=\frac{P}{R T}$ & $\mathrm{P}, \mathrm{T}$ & $\sqrt{u n c_{P}^{2}+u n c_{T}^{2}}$ & $\sqrt{0.04^{2}+0.7^{2}}$ & $0.70 \%$ \\
\hline
\end{tabular}

